\title{
STAG2 promotes the myelination transcriptional program
}

\section{in oligodendrocytes}

Ningyan Cheng ${ }^{1}$, Mohammed Kanchwala ${ }^{2}$, Bret M. Evers ${ }^{3}$, Chao Xing ${ }^{2,4}$, Hongtao Yu ${ }^{1,5,6,7, *}$

${ }^{1}$ Department of Pharmacology, University of Texas Southwestern Medical Center, Dallas, TX 75390, USA.

${ }^{2}$ Eugene McDermott Center for Human Growth and Development, University of Texas Southwestern Medical Center, Dallas, TX 75390, USA.

${ }^{3}$ Division of Neuropathology, University of Texas Southwestern Medical Center, Dallas, TX, 75390, USA.

${ }^{4}$ Department of Bioinformatics, Department of Population and Data Sciences, University of Texas Southwestern Medical Center, Dallas, TX 75390, USA.

${ }^{5}$ Westlake Laboratory of Life Sciences and Biomedicine, Hangzhou, China. ${ }^{6}$ School of Life Sciences, Westlake University, Hangzhou, China.

${ }^{7}$ Institute of Biology, Westlake Institute for Advanced Study, Hangzhou, China.

*Correspondence: yuhongtao@westlake.edu.cn 


\section{SUMMARY}

Cohesin folds chromosomes via DNA loop extrusion. Cohesin-mediated chromosome loops regulate transcription by shaping long-range enhancer-promoter interactions, among other mechanisms. Mutations of cohesin subunits and regulators cause human developmental diseases termed cohesinopathy. Vertebrate cohesin consists of SMC1, SMC3, RAD21, and either STAG1 or STAG2. To probe the physiological functions of cohesin, we created conditional knockout (cKO) mice with Stag2 deleted in the nervous system. Stag2 cKO mice exhibit growth retardation, neurological defects, and premature death, in part due to insufficient myelination of nerve fibers. Stag2 cKO oligodendrocytes exhibit delayed maturation and downregulation of myelinationrelated genes. Stag2 loss reduces promoter-anchored loops at downregulated genes in oligodendrocytes. Thus, STAG2-cohesin generates promoter-anchored loops at myelinationpromoting genes to facilitate their transcription. Our study implicates defective myelination as a contributing factor to cohesinopathy and establishes oligodendrocytes as a relevant cell type to explore the mechanisms by which cohesin regulates transcription. 


\section{INTRODUCTION}

Chromosomes in a single human diploid cell, if linearly stitched together, span a length of more than two meters. They need to be properly folded to be housed in the cell nucleus with a diameter of $10 \mu \mathrm{m}$. Chromosome folding occurs in a dynamic, structured way that regulates gene expression, and DNA replication and repair. Initially discovered as the molecular glue that tethers sister chromatids for segregation during mitosis (Haarhuis et al., 2014; Uhlmann, 2016; Yatskevich et al., 2019; Zheng and $\mathrm{Yu}, 2015)$, the cohesin complex has later been shown to be critical for structured chromosome folding and gene expression (Haarhuis et al., 2017; Rao et al., 2017; Schwarzer et al., 2017; Wutz et al., 2017).

Cohesin is loaded on chromosomes by the cohesin loader NIPBL. The cohesin-NIPBL complex can extrude DNA loops bi-directionally in an ATP-dependent manner (Davidson et al., 2019; Kim et al., 2019; Vian et al., 2018). The chromatin insulator CTCF has been proposed to block loop extrusion by cohesin, establishing topologically associated domains (TADs) and marking TAD boundaries. Chromatin interactions within each TAD are favored whereas interTAD interactions are disfavored. Thus, chromosome loops and TADs shape long-range ciselement interactions, such as promoter-enhancer interactions, thereby regulating transcription.

The vertebrate cohesin complex contains four core subunits: the SMC1-SMC3 heterodimeric ATPase, the kleisin subunit RAD21 that links the ATPase heads, and the HEATrepeat protein STAG1 or STAG2. STAG1 and STAG2 bind to RAD21 in a mutually exclusive manner and create docking sites for several regulatory proteins, including CTCF (Hara et al., 2014; Li et al., 2020). STAG1 and STAG2 also interact with DNA and the SMC1-SMC3 hinge domains (Shi et al., 2020). STAG1 and STAG2 play redundant roles in sister-chromatid cohesion in 
cultured human cells, as both need to be simultaneously depleted to produce overt cohesion defects (Hara et al., 2014).

Mutations of NIPBL and cohesin subunits, including STAG2, result in human developmental diseases termed cohesinopathies, which affect multiple organs and systems (Remeseiro et al., 2013b; Soardi et al., 2017). In patients with cohesinopathies, mental retardation and neurological abnormalities caused by brain development defects are common (Piche et al., 2019). Dysregulation of gene transcription as a result of reduced cohesin functions has been suggested to underlie these developmental defects (De Koninck and Losada, 2016; Remeseiro et al., 2013a). In addition, several cohesin genes, including STAG2, are frequently mutated in a variety of human cancers (Martincorena and Campbell, 2015).

To better understand the physiological roles of cohesin, we deleted Stag2 specifically in the nervous system in the mouse. The Stag2 conditional knockout (cKO) mice exhibited deficient myelination. Loss of STAG2 delayed the maturation of oligodendrocytes and reduced chromosome loops in oligodendrocytes and impaired the transcription of myelination-related genes. Our findings establish the requirement for cohesin in proper gene expression in specific cell types and implicate defective myelination as a potential contributing factor to cohesinopathy. 


\section{RESULTS}

\section{Stag2 ablation in the nervous system causes growth retardation and neurological defects}

Stagl is required for mammalian embryonic development (Remeseiro et al., 2012), indicating that Stag2 cannot compensate for the loss of Stag1. To examine the roles of Stag2 during development in the mouse, we targeted a critical exon (exon 8) of Stag2, which is located on the X chromosome, using CRISPR-Cas9 (Figure S1A). The Stag2 $2^{\text {null }}$ embryos showed severe developmental defects and underwent necrosis by E11.5 days (Figure S1B). Thus, Stag2 is required for mouse embryonic development, consistent with a recent report (De Koninck et al., 2020). Stag1 and Stag2 have nonredundant developmental functions.

Because whole-body knockout of Stag2 caused embryonic lethality, we created a Stag2 "floxed" mouse line $\left(\operatorname{Stag} 2^{f f f}\right)$ by homologous recombination with a template that contained two LoxP sites flanking exon 8 (Figure S2A,B). To study the physiological function of STAG2 in adult mice, we crossed the Stag $2^{f / f}$ mice with mice bearing the Ert2-Cre genomic insertion and generated Stag $2^{f / y} ; E r t 2-C r e$ progenies. The Stag2 $2^{f / y} ; E r t 2-C r e$ adult mice were injected with tamoxifen to induce Stag2 deletion in the whole body (Figure S2C). Genotyping analysis of blood extracts showed that tamoxifen induced efficient disruption of the Stag2 gene locus in Stag $2^{f / y} ;$ Ert2-Cre mice (Figure S2D,E). These Stag2-deficient adult mice did not show early onset of spontaneous tumor formation, indicating that Stag2 mutation alone in somatic cells of mice is insufficient to induce tumorigenesis. The Stag2-deficient mice also did not have other obvious adverse phenotypes (Figure S2F), except that they had slightly lower body weight (Figure S2G,H), probably due to tissue homeostasis alterations recently reported by others (De Koninck et al., 2020). 
STAG2 mutations are found in human cohesinopathy patients with mental retardation and neuropsychiatric behaviors (Soardi et al., 2017). To study the function of STAG2 in the nervous system, we generated Stag2 conditional knockout mice (Stag2 cKO) by crossing Stag $2^{\text {fff }}$ mice with Nestin-Cre mice (Giusti et al., 2014) (Figure 1A,B). The progenies were born in the Mendelian ratio, but $S t a g 2^{f / y}$;Cre pups presented growth retardation and premature death (Figure 1C-E). More than $50 \% \operatorname{Stag} 2^{f / y}$;Cre mice died aged about 3 weeks while the rest died at about 4 months. Stag $2^{f / y}$ mice did not show differences discernible from WT littermates. Although $S t a g 2^{f / y}$;Cre mice did not present microcephaly, they exhibited frequent hydrocephaly that might contribute to their premature death. The $\operatorname{Stag} 2^{f / y}$;Cre mice displayed normal drinking and feeding behaviors (Figure $1 \mathrm{~F}, \mathrm{G})$, but showed reduced plasma IGF-1 levels compared to the control mice (Figure 1H). Stag $2^{f / y}$; Cre mice showed forepaw and hindlimb clasping (Figure 1I) and limb tremors (Movie 1), which were not seen in Stag $2^{f / y}$ mice. These data indicate that Stag2 deficiency in the nervous system causes growth retardation and neurological defects.

\section{Stag2 ablation causes hypomyelination}

Hematoxylin and eosin staining of brain sections of $S t a g 2^{f / y}$;Cre mice did not reveal overt anatomical defects (Figure S3A). To understand the origins of neurological defects caused by Stag2 deletion, we analyzed the gene expression changes in $S \operatorname{tag} 2^{f / y}$;Cre mouse brains by RNAsequencing (RNA-seq) (Figure 2A). Compared with the control groups, 105 and 62 genes were significantly downregulated or upregulated by more than two folds, respectively, in the Stag2deficient brains. The decreased expression of top differentially expressed genes (DEGs) was confirmed by reverse transcription quantitative PCR (RT-qPCR) (Figure 2B). Among the 105 downregulated DEGs in the brains of Stag2 cKO mice, 44 were enriched in myelin (Figure 2C) 
(Thakurela et al., 2016). The Ingenuity Pathway Analysis (IPA) pinpoints cholesterol biosynthesis pathways as the most affected canonical pathways (Figure 2D). We further confirmed that the cholesterol biosynthesis precursors were reduced in Stag $2^{f / y}$;Cre brains (Figure S3B).

Myelin is the membrane sheath that wraps around axons to facilitate rapid nerve conduction and maintain metabolic supply (Williamson and Lyons, 2018). Dynamic myelination in the central nervous system (CNS) is critical for proper neurodevelopment, and defective myelination is associated with autoimmune and neurodegenerative diseases (Mathys et al., 2019; Wolf et al., 2021). As cholesterol biosynthesis is essential for normal myelination (Hubler et al., 2018; Saher et al., 2005), we hypothesized that depletion of STAG2 caused myelination defects in the nervous system.

Indeed, brain sections of Stag $2^{f / y}$; Cre mice showed greatly reduced luxol fast blue (LFB) staining compared to those of Stag $2^{f / y}$ and Nestin-Cre heterozygous mice (Figure 3A and S4A). Immunohistochemistry using antibodies against myelin proteins, MBP and PLP1, confirmed that Stag2 cKO mice had significant defects in myelin fiber formation (Figure 3B-F). In both cerebral cortex and cerebellum, there were fewer and sparser myelin fibers in $\operatorname{Stag} 2^{f / y}$;Cre mice, as compared to the Stag2 $2^{f / y}$ controls. Axon myelin ensheathment was further examined using transmission electron microscopy (Figure 3G). Stag $2^{f / y}$; Cre mice had significantly fewer myelinwrapped axons at optic nerves. Collectively, these data indicate insufficient myelination in the Stag2 cKO mice. Myelination predominantly occurs at 3 weeks after birth in the mouse. The timing of premature death of Stag2 cKO mice is thus consistent with defective myelination as a contributing factor to the lethality.

\section{STAG2 regulates transcription in OLs}


We examined Stag1 and Stag2 expression patterns in wild-type mouse brains by in situ hybridization using isotope-labeled RNA probes (Figure S4B). Both Stag1 and Stag2 were expressed at high levels in hippocampus, medial habenula, neocortex, and cerebellum granular layer. Aside from these regions, the Stag2 transcripts were detected at relatively high levels in subventricular zone, thalamus, fiber tracts, midbrain, and hindbrain regions. Stag2 is thus ubiquitously expressed in the brain.

Oligodendrocytes (OLs) are responsible for myelination in the CNS. To examine whether the OL lineage was affected by Stag2 deletion, we performed single-cell RNA sequencing (scRNA-seq) analysis of $S t a g 2^{f / y}$;Cre and $S t a g 2^{f / y}$ forebrains. As revealed by clusters in the t-SNE plot, the two genotype groups had similar cellular compositions (Figure 4A,B). All cell clusters were present in $\operatorname{Stag} 2^{f / y}$;Cre brains, indicating generally normal neural cell differentiation. Celltype identities were discovered with feature gene expression (Figure S5A). The OL lineage consisted of five clusters: cycling OL progenitors (OPCcycs), OL progenitors (OPCs), newly formed OLs (NFOLs), myelin-forming OLs (mFOLs), and fully matured OLs (MOLs). Quantification of the distributions of these five cell types within the OL lineage revealed a mild reduction in the number of MOLs in $S t a g 2^{f / y}$ forebrains (Figure 4C). We noticed that a higher percentage of neurons was recovered in the $\operatorname{Stag} 2^{f / y}$;Cre group. Since the bulk RNA-seq results did not show global upregulation of neuron-specific genes, we suspect that neurons in Stag ${ }^{f / y}$; Cre had fewer myelin-wrapped axons and were easier to be dissociated and kept alive during our library preparation for scRNA-seq. Thus, from the transcriptome analysis, we did not observe overt defects in most neural cell differentiation in the Stag2-deficient forebrain regions.

We then performed trajectory inference and pseudotime analysis of the OL lineage (Figure S5B,C). Consistent with our cell-type assignment, pseudotime variables indicated continuous 
differentiation from OPCs to NFOLs, mFOLs, and MOLs (Figure S5D,E). The re-clustering of single cells in the OL lineage along the pseudotime path revealed that more cells were present in the terminal maturation stages in the Stag $2^{f / y}$ brains (Figure S5F,G). Conversely, more cells were retained at the undifferentiated stages in the $\operatorname{Stag} 2^{f / y}$;Cre brains. Strikingly, some myelination genes, including Mal, were specifically repressed in Stag $2^{f / y}$;Cre MOLs, with their expression in non-neural cells unaltered (Figures 4D and S6A). These observations suggest that STAG2 deficiency delays the maturation of OLs and compromises myelination-specific gene expression in mature OLs. Interestingly, compared to Stag2 and genes encoding other cohesin core subunits, Stagl transcripts are less abundant in the OL lineage, except for cycling OPCs (Figure S6B,C). The low expression of Stag1 in mature OLs might make these cells more dependent on Stag2 for function.

To confirm the transcriptional defects in the OL lineage caused by Stag2 deletion, we isolated primary OLs at intermediate differentiation stages from Stag $2^{f / y} ; C r e$ and Stag $2^{f / y}$ forebrains with antibody-conjugated magnetic beads and conducted bulk RNA-seq analysis (Figure 4E). For both genotypes, the marker genes for NFOL and mFOLs were highly expressed in the isolated primary OLs (Figure S7A), suggesting that they mainly contained these two cell types. In Stag2-deleted OLs, 271 and 292 genes were downregulated or upregulated by more than two folds, respectively (Figure 4F). The top canonical pathway enriched in these DEGs was the cholesterol biosynthesis pathway (Figure 4G). Intriguingly, the downregulated genes were generally highly expressed in WT cells, whereas the upregulated genes had low expression levels in WT cells (Figure S7B-D). Among the 105 downregulated DEGs identified by RNA-seq analysis of the whole brain of Stag2-deficient mice, 42 were also differentially expressed in primary oligodendrocytes (Figure $4 \mathrm{H}$ ). The cholesterol biosynthesis pathways were recognized as 
the major altered pathways (Figure S7E). Thus, defective cholesterol biosynthesis likely underlies hypomyelination and neurological defects in Stag2 cKO mice.

We performed chromatin immunoprecipitation sequencing (ChIP-seq) experiments to examine the enrichment of the active transcription mark H3K27ac in $S t a g 2^{f / y}$ and Stag $2^{f / y}$;Cre OLs and found that Stag2 loss did not appreciably affect H3K27Ac enrichment at transcription start sites (TSS) (Figure S8A,B). Consistent with our RNA-seq results, the upregulated genes had much lower H3K27ac enrichment near their TSS, indicating that they were less active. We then checked the genomic distribution of STAG2 by ChIP-seq. Among other genomic loci, STAG2 was enriched at TSS of stable and downregulated genes, including genes in the cholesterol biosynthesis pathways (Figure S8C,D). It was enriched at the TSS of upregulated genes to a lesser extent, suggesting that Stag2 loss might have indirectly affected the expression of these less active genes.

\section{Stag2 deletion does not alter compartments or TADs in OLs}

To investigate whether chromosome conformation was altered by Stag2 deletion and whether that caused transcription dysregulation, we performed high-dimensional chromosome conformational capture (Hi-C) analysis of primary OLs isolated from Stag2 ${ }^{f / y}$ and Stag2 $2^{f / y} ; C r e$ mice. We observed few compartment switching events in Stag2-deleted cells (Figure 5A-C and S9A-C). Virtually all genomic regions in Stag2-deleted cells were kept in their original compartment categories (AA or BB) (Figure 5C). Only a very small number of genomic regions switched compartments (AB or BA). Consistent with the RNA-seq data, analysis of average gene expression changes of DEGs in these genomic regions revealed that more genes located in the transcriptionally active A compartment (AA) were repressed in Stag2-deleted cells and more genes in the transcriptionally silent B compartment (BB) were upregulated (Figure 5D and S9D). Genes that switched from the 
A compartment to the B compartment were not more repressed compared to those that remained in the A compartment. Likewise, compared to genes that stayed in the B compartment, genes located in chromatin regions that switched from compartment B to A were not significantly activated. Acute depletion of all forms of cohesin eliminates TAD formation (Wutz et al., 2017). In contrast, deletion of Stag2 had minimal impact on TAD formation in oligodendrocytes (Figure 5E-H, S9E,F), suggesting that STAG1-cohesin compensates for the loss of STAG2-cohesin in spatial organization of chromatin at larger than megabase scales. Therefore, our findings are inconsistent with compartment switching and TAD alterations being the underlying cause for the observed gene expression changes in STAG2-deficient OLs.

\section{Promoter-anchored loops were reduced in Stag2-deleted OLs}

While TAD boundaries are largely conserved among species and cell types, chromatin interactions within each TAD are more flexible and variable in cells undergoing differentiation, tumorigenesis, and reprogramming (Dixon et al., 2015; Dixon et al., 2012). Among the intra-TAD chromatin interactions, the enhancer-promoter loops are particularly important for transcription and are often cell-type specific. We examined whether chromatin loops in OLs were affected by Stag2 loss. Compared to Stag2 ${ }^{f / y}$ OLs, Stag $2^{f / y}$; Cre OLs had significantly fewer loops across almost all genomic distances (Figure 6A,B and S10). Loops specific to Stag $2^{f / y}$;Cre OLs, which were likely mediated by STAG1-cohesin, were longer than STAG2-dependent Stag2 f/y-specific loops. When genomic distances exceeded $0.25 \mathrm{Mb}$, the loops from Stag $2^{f / y}$;Cre cells gradually gained higher scores over loops from Stag2 ffy cells (Figure 6C). Therefore, STAG1-cohesin cannot completely compensate for STAG2-cohesin during loop formation. STAG1-cohesin-mediated loops are 
relatively longer than STAG2-cohesin-mediated loops, consistent with published findings in HeLa cells (Wutz et al., 2020).

We then tested whether the loop number decrease in Stag2-deficient cells could be a cause for transcriptional changes. When examining the local Hi-C maps, we noticed that loops anchored at gene promoters, including those of downregulated genes, were reduced in Stag ${ }^{f / y}$; Cre oligodendrocytes (Figure 6D and S11). Promoter-anchored loops (P-loops) can potentially be promoter-promoter links, promoter-enhancer links, and gene loops. The total number of P-loops was proportionally decreased in $\operatorname{Stag} 2^{f / y} ;$ Cre cells (Figure S12A). Moreover, the loops anchored at the downregulated genes were stronger than those at upregulated and stable genes (Figure S12B). We then compared P-loops associated with DEGs using pileup analysis of local contact maps. Loop enrichment at promoters of downregulated genes was reduced in Stag $2^{f / y}$;Cre cells to a greater extent than that at promoters of upregulated and stable genes (Figure 6E). Taken together, our results suggest that Stag2 loss diminishes short chromosome loops, including promoteranchored loops. Highly expressed genes might be more reliant on these loops for transcription and are preferentially downregulated by Stag2 loss.

We also performed pileup analysis of local chromatin regions flanking transcription start sites (TSS) (Figure 6F). Strikingly, we observed a clear stripe that extended from the TSS of downregulated gene only in the direction of transcription. The formation of promoter-anchored stripes (P-stripes) on aggregated plots is consistent with one-sided loop extrusion from the promoter to the gene body. The P-stripe was still present in $S t a g 2^{f / y}$;Cre cells, suggesting that STAG1 could compensate for the loss of STAG2 and mediate its formation (Figure 6F and S12C). 


\section{DISCUSSION}

Cohesin is critical for the three-dimensional (3D) organization of the genome by extruding chromosome loops. Acute depletion of cohesin abolishes chromosome loops and TADs, but has moderate effects on transcription. The two forms of cohesin in vertebrate somatic cells, namely STAG1-cohesin and STAG2-cohesin, have largely redundant functions in supporting sisterchromatid cohesion and cell viability, but they have non-redundant functions during development. In this study, we have established a myelination-promoting function of STAG2 in the central nervous system (CNS) in the mouse. We further provide evidence linking hypomyelination caused by STAG2 loss to reduced promoter-anchored loops at myelination genes in oligodendrocytes.

\section{Myelination functions of STAG2 and implications for cohesinopathy}

Selective ablation of Stag2 in the nervous system in the mouse causes growth retardation, neurological defects, and premature death. STAG2 loss delays the maturation of oligodendrocytes and reduces the expression of highly active myelin and cholesterol biosynthesis genes in oligodendrocytes, resulting in hypomyelination in the CNS. Hypomyelination disorders in humans and mice are known to produce abnormal neurological behaviors similar to those seen in our Stag2 cKO mice, suggesting that hypomyelination is a major underlying cause for the phenotypes in Stag2 cKO mice. The growth retardation in these mice can be explained by insufficient secretion of growth hormones, which may be a consequence of defective neuronal signaling.

Mutations of cohesin subunits and regulators, including STAG2, cause the Cornelia de Lange syndrome (CdLS) and other similar developmental diseases, collectively termed cohesinopathy. CdLS patients exhibit short stature and developmental defects in multiple tissues 
and organs, including the brain. Although STAG2 mutations are implicated in human cohesinopathy, these mutations are rare and hypomorphic (Soardi et al., 2017). The cohesin loader NIPBL is the most frequently mutated cohesin regulator in cohesinopathy (Mannini et al., 2013). NIPBL deficiency is expected to affect the functions of both STAG1- and STAG2-cohesin. It is possible that the partial loss of STAG2-cohesin function leads to subtle myelination defects in patients with cohesinopathy. Indeed, lack of myelination in certain brain regions of CdLS patients has been reported (Avagliano et al., 2017; Vuilleumier et al., 2002). As myelination of the CNS mostly occurs after birth and during childhood, strategies aimed at enhancing myelination might help to alleviate certain disease phenotypes and symptoms.

\section{Mechanisms by which STAG2 promotes myelination}

STAG2 promotes oligodendrocyte maturation and the expression of myelination genes in mature oligodendrocytes. Because STAG2 does not have an established cohesin-independent function, it most likely activates the myelination-promoting transcriptional program as a core component of cohesin. Consistent with previous reports (Rao et al., 2017), loss of STAG2-cohesin in oligodendrocytes does not affect genome compartmentalization, but reduces the number of relatively short chromosome loops, including promoter-anchored loops. Promoter-anchored loops at downregulated genes are reduced to a greater extent than those at stable and upregulated genes. These findings suggest that STAG2-cohesin promotes the myelination transcriptional program by forming promoter-anchored loops.

Pileup analysis of Hi-C maps reveals the formation of asymmetric promoter-anchored stripes in the direction of transcription at downregulated genes, indicative of active loading of cohesin at transcription start sites followed by one-sided loop extrusion from the promoter to the 
gene body. The stripes are, however, not reduced in STAG2-deficient cells. Because both forms of cohesin are capable of loop extrusion, it is possible that STAG1-cohesin can compensate for the loss of STAG2-cohesin in loop extrusion. It remains to be tested whether the intrinsic kinetics and processivity of loop extrusion mediated by the two forms of cohesin are differentially regulated by cellular factors or posttranslational modifications and whether these differences contribute to their non-redundant roles in transcription regulation.

We envision three possibilities that may account for why oligodendrocytes, but not other cell types, are more severely affected by Stag2 loss in the CNS. First, STAG2-cohesin may be more abundant than STAG1-cohesin in post-mitotic OLs, making them more dependent on STAG2 for proper functions. Second, STAG1-cohesin preferentially localizes to CTCF-enriched TAD boundaries whereas STAG2-cohesin is more enriched at enhancers lacking CTCF (Kojic et al., 2018). Enhancers are critical for cell-type-specific gene transcriptional programs. To cooperate with the axonal growth during postnatal neurodevelopment, enhancer-enriched transcription factors induce timely and robust gene expression in oligodendrocytes for proper myelination (Mitew et al., 2014). The high-demand for enhancer function may render the transcription of myelination genes more reliant on STAG2-cohesin. Finally, the C-terminal regions of STAG1 and STAG2 are divergent in sequence and may bind to different interacting proteins and be subjected to differential regulation. STAG2 may interact with oligodendrocytespecific transcription factors and be preferentially recruited to myelination genes. It will be interesting to investigate the interactomes of STAG1 and STAG2 in oligodendrocytes using mass spectrometry.

\section{STAG2-mediated chromosome looping and transcription}


The mechanisms by which STAG2-dependent chromosome looping facilitates transcription are unclear at present. We propose several models that are not mutually exclusive (Figure 7). First, by forming promoter-enhancer loops, STAG2-cohesin brings the mediator complex and other enhancer-binding factors to the spatial proximity of the general transcriptional machinery at the promoter, thereby enhancing RNA polymerase II recruitment and transcription initiation. The existence of P stripes at STAG2-dependent genes in the Hi-C maps suggests that STAG2-mediated promoter-enhancer loops may involve enhancers located in the gene body. Second, loop extrusion by STAG2-cohesin may promote transcription elongation by regulating transcription-coupled premRNA processing. For example, STAG2 has been shown to interact with RNA-DNA hybrid structures termed R-loops in vitro and in cells (Pan et al., 2020; Porter et al., 2021). R-loops formed between the nascent pre-mRNA and the DNA template impede transcription elongation and need to be suppressed (Moore and Proudfoot, 2009). When traveling with the transcription machinery on DNA, STAG2-cohesin might directly suppress R-loop formation or recruit other factors, such as the spliceosome, for co-transcriptional pre-mRNA processing and R-loop resolution. Third, STAG2-cohesin may establish promoter-terminator gene loops to recycle the RNA polymerase II that has finished one cycle of transcription back to the transcription start site for another round of transcription. Future experiments using high-resolution Hi-C methods in oligodendrocytes will allow us to better define the nature of STAG2-dependent promoter-anchored loops and stripes. It will also be interesting to examine whether Stag2 deletion causes the accumulation of R-loops in downregulated genes and the incomplete splicing of their pre-mRNAs. 


\section{CONCLUSION}

We have discovered a requirement for the cohesin subunit STAG2 in the myelination of the central nervous system in mammals. Our findings implicate hypomyelination as a contributing factor to certain phenotypes of cohesinopathy, including growth retardation and neurological disorders. We provide evidence to suggest that STAG2 promotes the myelination transcriptional program in oligodendrocytes through the formation of promoter-anchored loops. Our study establishes oligodendrocytes as a physiologically relevant cell system for dissecting the cellular functions and regulatory mechanisms of cohesin-mediated chromosome folding and genome organization. 


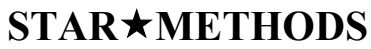

Detailed methods are provided in the online version of this paper and include the following:

- KEY RESOURCES TABLE

- RESOURCE AVAILABILITY

$\circ$ Lead contact

○ Materials availability

- Data and code availability

- EXPERIMENTAL MODEL AND SUBJECT DETAILS

- Generation of Stag2 ${ }^{f f f}$ and $\operatorname{Stag} 2^{f / y}$ mice and mouse husbandry

- METHOD DETAILS

○ Immunoblotting

- Tissue histology and immunohistochemistry

- Isolation of primary oligodendrocytes

- TSE Metabolic cage analysis

○ Growth hormone and IGF-1 detection

- Sterol and oxysterol composition analysis

- Electron microscopy

- Generation of RNA-seq libraries and sequencing

○ Differential expression and pathway analysis

- RT-qPCR analysis

- Transcriptional profiling of brain cells

- Chromatin immunoprecipitation followed by sequencing (ChIP-seq)

- Hi-C library generation, sequencing, and analysis 
- Chromosome loop analysis and integration with RNA-seq

- QUANTIFICATION AND STAITSTICAL ANALYSIS

\section{SUPPLEMENTAL INFORMATION}

Supplemental Information including Supplemental Figures 1-12 can be found online.

\section{ACKNOWLEDGMENTS}

We thank Sung Jun Bae for taking the mouse photos and John Shelton for help with histology and in situ hybridization. We are grateful to Jeffrey McDonald for the sterol composition analysis, Richard $\mathrm{Lu}$ and $\mathrm{Lu}$ Sun for providing reagents and advice for oligodendrocytes isolation, and Applied Bioinformatics Laboratories at NYU Langone Health for the Hi-C analysis. We also thank the Yu lab members for helpful discussions and for reading the manuscript critically. This study was supported by the Cancer Prevention and Research Institute of Texas (CPRIT) (RP160667-P2) and the Welch foundation (I-1441).

\section{AUTHOR CONTRIBUTIONS}

N.C. and H.Y. conceived and designed the study. N.C. performed all the experiments. M.K., N.C., and C. X. performed the analysis and interpretation of NGS data. N.C. and B.M.E. performed histology and EM image analysis. N.C. and H.Y. wrote the manuscript with input from all authors. H.Y. supervised the project. All authors approved the manuscript.

\section{DECLARATION OF INTERESTS}

The authors declare no competing interests. 


\section{REFERENCES}

Andrews, S. (2010). FastQC: a quality control tool for high throughput sequence data.

Avagliano, L., Grazioli, P., Mariani, M., Bulfamante, G.P., Selicorni, A., and Massa, V. (2017).

Integrating molecular and structural findings: Wnt as a possible actor in shaping cognitive impairment in Cornelia de Lange syndrome. Orphanet J. Rare Dis. 12, 174.

Ay, F., Bailey, T.L., and Noble, W.S. (2014). Statistical confidence estimation for Hi-C data reveals regulatory chromatin contacts. Genome Res 24, 999-1011.

Butler, A., Hoffman, P., Smibert, P., Papalexi, E., and Satija, R. (2018). Integrating single-cell transcriptomic data across different conditions, technologies, and species. Nat Biotechnol 36, 411-420.

Cahoy, J.D., Emery, B., Kaushal, A., Foo, L.C., Zamanian, J.L., Christopherson, K.S., Xing, Y., Lubischer, J.L., Krieg, P.A., Krupenko, S.A., et al. (2008). A transcriptome database for astrocytes, neurons, and oligodendrocytes: a new resource for understanding brain development and function. J Neurosci 28, 264-278.

Cao, J., Spielmann, M., Qiu, X., Huang, X., Ibrahim, D.M., Hill, A.J., Zhang, F., Mundlos, S., Christiansen, L., Steemers, F.J., et al. (2019). The single-cell transcriptional landscape of mammalian organogenesis. Nature 566, 496-502.

Choi, E., Zhang, X., Xing, C., and Yu, H. (2016). Mitotic Checkpoint Regulators Control Insulin Signaling and Metabolic Homeostasis. Cell 166, 567-581.

Davidson, I.F., Bauer, B., Goetz, D., Tang, W., Wutz, G., and Peters, J.M. (2019). DNA loop extrusion by human cohesin. Science 366, 1338-1345.

De Koninck, M., Lapi, E., Badia-Careaga, C., Cossio, I., Gimenez-Llorente, D., RodriguezCorsino, M., Andrada, E., Hidalgo, A., Manzanares, M., Real, F.X., et al. (2020). Essential Roles 
of Cohesin STAG2 in Mouse Embryonic Development and Adult Tissue Homeostasis. Cell Rep. 32, 108014.

De Koninck, M., and Losada, A. (2016). Cohesin Mutations in Cancer. Cold Spring Harb Perspect Med 6.

Dixon, J.R., Jung, I., Selvaraj, S., Shen, Y., Antosiewicz-Bourget, J.E., Lee, A.Y., Ye, Z., Kim, A., Rajagopal, N., Xie, W., et al. (2015). Chromatin architecture reorganization during stem cell differentiation. Nature 518, 331-336.

Dixon, J.R., Selvaraj, S., Yue, F., Kim, A., Li, Y., Shen, Y., Hu, M., Liu, J.S., and Ren, B. (2012). Topological domains in mammalian genomes identified by analysis of chromatin interactions. Nature 485, 376-380.

Dobin, A., Davis, C.A., Schlesinger, F., Drenkow, J., Zaleski, C., Jha, S., Batut, P., Chaisson, M., and Gingeras, T.R. (2013). STAR: ultrafast universal RNA-seq aligner. Bioinformatics 29, 15-21.

Dulken, B.W., Buckley, M.T., Navarro Negredo, P., Saligrama, N., Cayrol, R., Leeman, D.S., George, B.M., Boutet, S.C., Hebestreit, K., Pluvinage, J.V., et al. (2019). Single-cell analysis reveals T cell infiltration in old neurogenic niches. Nature 571, 205-210.

Durand, N.C., Shamim, M.S., Machol, I., Rao, S.S., Huntley, M.H., Lander, E.S., and Aiden, E.L. (2016). Juicer Provides a One-Click System for Analyzing Loop-Resolution Hi-C Experiments. Cell Syst. 3, 95-98.

Flores-Obando, R.E., Freidin, M.M., and Abrams, C.K. (2018). Rapid and Specific Immunomagnetic Isolation of Mouse Primary Oligodendrocytes. J. Vis. Exp.

Flyamer, I.M., Illingworth, R.S., and Bickmore, W.A. (2020). Coolpup.py: versatile pile-up analysis of Hi-C data. Bioinformatics 36, 2980-2985. 
Giusti, S.A., Vercelli, C.A., Vogl, A.M., Kolarz, A.W., Pino, N.S., Deussing, J.M., and Refojo, D. (2014). Behavioral phenotyping of Nestin-Cre mice: implications for genetic mouse models of psychiatric disorders. J. Psychiatr. Res. 55, 87-95.

Haarhuis, J.H., Elbatsh, A.M., and Rowland, B.D. (2014). Cohesin and its regulation: on the logic of X-shaped chromosomes. Dev. Cell 31, 7-18.

Haarhuis, J.H.I., van der Weide, R.H., Blomen, V.A., Yanez-Cuna, J.O., Amendola, M., van Ruiten, M.S., Krijger, P.H.L., Teunissen, H., Medema, R.H., van Steensel, B., et al. (2017). The Cohesin Release Factor WAPL Restricts Chromatin Loop Extension. Cell 169, 693-707 e614. Hara, K., Zheng, G., Qu, Q., Liu, H., Ouyang, Z., Chen, Z., Tomchick, D.R., and Yu, H. (2014). Structure of cohesin subcomplex pinpoints direct shugoshin-Wapl antagonism in centromeric cohesion. Nat. Struct. Mol. Biol. 21, 864-870.

Heinz, S., Benner, C., Spann, N., Bertolino, E., Lin, Y.C., Laslo, P., Cheng, J.X., Murre, C., Singh, H., and Glass, C.K. (2010). Simple combinations of lineage-determining transcription factors prime cis-regulatory elements required for macrophage and B cell identities. Mol. Cell $38,576-589$.

Hubler, Z., Allimuthu, D., Bederman, I., Elitt, M.S., Madhavan, M., Allan, K.C., Shick, H.E., Garrison, E., M, T.K., Factor, D.C., et al. (2018). Accumulation of 8,9-unsaturated sterols drives oligodendrocyte formation and remyelination. Nature 560, 372-376.

Kim, Y., Shi, Z., Zhang, H., Finkelstein, I.J., and Yu, H. (2019). Human cohesin compacts DNA by loop extrusion. Science $366,1345-1349$.

Kojic, A., Cuadrado, A., De Koninck, M., Gimenez-Llorente, D., Rodriguez-Corsino, M., Gomez-Lopez, G., Le Dily, F., Marti-Renom, M.A., and Losada, A. (2018). Distinct roles of 
cohesin-SA1 and cohesin-SA2 in 3D chromosome organization. Nat. Struct. Mol. Biol. 25, 496504.

Langmead, B., and Salzberg, S.L. (2012). Fast gapped-read alignment with Bowtie 2. Nat. Methods 9, 357-359.

Lazaris, C., Kelly, S., Ntziachristos, P., Aifantis, I., and Tsirigos, A. (2017). HiC-bench: comprehensive and reproducible $\mathrm{Hi}-\mathrm{C}$ data analysis designed for parameter exploration and benchmarking. BMC Genomics 18, 22.

Li, Y., Haarhuis, J.H.I., Sedeno Cacciatore, A., Oldenkamp, R., van Ruiten, M.S., Willems, L., Teunissen, H., Muir, K.W., de Wit, E., Rowland, B.D., et al. (2020). The structural basis for cohesin-CTCF-anchored loops. Nature 578, 472-476.

Liao, Y., Smyth, G.K., and Shi, W. (2014). featureCounts: an efficient general purpose program for assigning sequence reads to genomic features. Bioinformatics 30, 923-930.

Liu, X., Zhang, Y., Chen, Y., Li, M., Zhou, F., Li, K., Cao, H., Ni, M., Liu, Y., Gu, Z., et al. (2017). In Situ Capture of Chromatin Interactions by Biotinylated dCas9. Cell 170, 1028-1043 e1019.

Lopez-Delisle, L., Rabbani, L., Wolff, J., Bhardwaj, V., Backofen, R., Gruning, B., Ramirez, F., and Manke, T. (2020). pyGenomeTracks: reproducible plots for multivariate genomic data sets. Bioinformatics.

Luecken, M.D., and Theis, F.J. (2019). Current best practices in single-cell RNA-seq analysis: a tutorial. Mol Syst Biol 15, e8746.

Mannini, L., Cucco, F., Quarantotti, V., Krantz, I.D., and Musio, A. (2013). Mutation spectrum and genotype-phenotype correlation in Cornelia de Lange syndrome. Hum. Mutat. 34, 15891596. 
Marques, S., van Bruggen, D., Vanichkina, D.P., Floriddia, E.M., Munguba, H., Varemo, L., Giacomello, S., Falcao, A.M., Meijer, M., Bjorklund, A.K., et al. (2018). Transcriptional Convergence of Oligodendrocyte Lineage Progenitors during Development. Dev. Cell 46, 504517 e507.

Marques, S., Zeisel, A., Codeluppi, S., van Bruggen, D., Mendanha Falcao, A., Xiao, L., Li, H., Haring, M., Hochgerner, H., Romanov, R.A., et al. (2016). Oligodendrocyte heterogeneity in the mouse juvenile and adult central nervous system. Science 352, 1326-1329.

Martincorena, I., and Campbell, P.J. (2015). Somatic mutation in cancer and normal cells.

Science 349, 1483-1489.

Marton, R.M., Miura, Y., Sloan, S.A., Li, Q., Revah, O., Levy, R.J., Huguenard, J.R., and Pasca, S.P. (2019). Differentiation and maturation of oligodendrocytes in human three-dimensional neural cultures. Nat. Neurosci. 22, 484-491.

Mathys, H., Davila-Velderrain, J., Peng, Z., Gao, F., Mohammadi, S., Young, J.Z., Menon, M., He, L., Abdurrob, F., Jiang, X., et al. (2019). Single-cell transcriptomic analysis of Alzheimer's disease. Nature 570, 332-337.

McDonald, J.G., Smith, D.D., Stiles, A.R., and Russell, D.W. (2012). A comprehensive method for extraction and quantitative analysis of sterols and secosteroids from human plasma. J. Lipid Res. 53, 1399-1409.

Mitew, S., Hay, C.M., Peckham, H., Xiao, J., Koenning, M., and Emery, B. (2014). Mechanisms regulating the development of oligodendrocytes and central nervous system myelin.

Neuroscience 276, 29-47.

Moore, M.J., and Proudfoot, N.J. (2009). Pre-mRNA processing reaches back to transcription and ahead to translation. Cell 136, 688-700. 
Pan, H., Jin, M., Ghadiyaram, A., Kaur, P., Miller, H.E., Ta, H.M., Liu, M., Fan, Y., Mahn, C.,

Gorthi, A., et al. (2020). Cohesin SA1 and SA2 are RNA binding proteins that localize to RNA containing regions on DNA. Nucleic Acids Res. 48, 5639-5655.

Piche, J., Van Vliet, P.P., Puceat, M., and Andelfinger, G. (2019). The expanding phenotypes of cohesinopathies: one ring to rule them all! Cell Cycle 18, 2828-2848.

Porter, H., Li, Y., Varsally, W., Neguembor, M.V., Beltran, M., Pezic, D., Martin, L., Cornejo, M.T., Bhamra, A., Surinova, S., et al. (2021). STAG proteins promote cohesin ring loading at Rloops. bioRxiv, 2021.2002.2020.432055.

Rao, S.S.P., Huang, S.C., Glenn St Hilaire, B., Engreitz, J.M., Perez, E.M., Kieffer-Kwon, K.R., Sanborn, A.L., Johnstone, S.E., Bascom, G.D., Bochkov, I.D., et al. (2017). Cohesin Loss Eliminates All Loop Domains. Cell 171, 305-320 e324.

Remeseiro, S., Cuadrado, A., Carretero, M., Martinez, P., Drosopoulos, W.C., Canamero, M., Schildkraut, C.L., Blasco, M.A., and Losada, A. (2012). Cohesin-SA1 deficiency drives aneuploidy and tumourigenesis in mice due to impaired replication of telomeres. EMBO J. 31, 2076-2089.

Remeseiro, S., Cuadrado, A., Kawauchi, S., Calof, A.L., Lander, A.D., and Losada, A. (2013a). Reduction of Nipbl impairs cohesin loading locally and affects transcription but not cohesiondependent functions in a mouse model of Cornelia de Lange Syndrome. Biochim. Biophys. Acta $1832,2097-2102$.

Remeseiro, S., Cuadrado, A., and Losada, A. (2013b). Cohesin in development and disease. Development 140, 3715-3718.

Robinson, M.D., McCarthy, D.J., and Smyth, G.K. (2010). edgeR: a Bioconductor package for differential expression analysis of digital gene expression data. Bioinformatics 26, 139-140. 
Ross-Innes, C.S., Stark, R., Teschendorff, A.E., Holmes, K.A., Ali, H.R., Dunning, M.J., Brown, G.D., Gojis, O., Ellis, I.O., Green, A.R., et al. (2012). Differential oestrogen receptor binding is associated with clinical outcome in breast cancer. Nature 481, 389-393.

Saher, G., Brugger, B., Lappe-Siefke, C., Mobius, W., Tozawa, R., Wehr, M.C., Wieland, F., Ishibashi, S., and Nave, K.A. (2005). High cholesterol level is essential for myelin membrane growth. Nat. Neurosci. 8, 468-475.

Saunders, A., Macosko, E.Z., Wysoker, A., Goldman, M., Krienen, F.M., de Rivera, H., Bien, E., Baum, M., Bortolin, L., Wang, S., et al. (2018). Molecular Diversity and Specializations among the Cells of the Adult Mouse Brain. Cell 174, 1015-1030 e1016.

Schwarzer, W., Abdennur, N., Goloborodko, A., Pekowska, A., Fudenberg, G., Loe-Mie, Y., Fonseca, N.A., Huber, W., Haering, C.H., Mirny, L., et al. (2017). Two independent modes of chromatin organization revealed by cohesin removal. Nature 551, 51-56.

Shi, Z., Gao, H., Bai, X.C., and Yu, H. (2020). Cryo-EM structure of the human cohesin-NIPBLDNA complex. Science 368, 1454-1459.

Soardi, F.C., Machado-Silva, A., Linhares, N.D., Zheng, G., Qu, Q., Pena, H.B., Martins, T.M.M., Vieira, H.G.S., Pereira, N.B., Melo-Minardi, R.C., et al. (2017). Familial STAG2 germline mutation defines a new human cohesinopathy. NPJ Genom. Med. 2, 7.

Stuart, T., Butler, A., Hoffman, P., Hafemeister, C., Papalexi, E., Mauck, W.M., 3rd, Hao, Y., Stoeckius, M., Smibert, P., and Satija, R. (2019). Comprehensive Integration of Single-Cell Data. Cell 177, 1888-1902 e1821.

Thakurela, S., Garding, A., Jung, R.B., Muller, C., Goebbels, S., White, R., Werner, H.B., and Tiwari, V.K. (2016). The transcriptome of mouse central nervous system myelin. Sci. Rep. 6, 25828. 
Tronche, F., Kellendonk, C., Kretz, O., Gass, P., Anlag, K., Orban, P.C., Bock, R., Klein, R., and Schutz, G. (1999). Disruption of the glucocorticoid receptor gene in the nervous system results in reduced anxiety. Nat. Genet. 23, 99-103.

Tsirigos, A., Haiminen, N., Bilal, E., and Utro, F. (2012). GenomicTools: a computational platform for developing high-throughput analytics in genomics. Bioinformatics 28, 282-283. Uhlmann, F. (2016). SMC complexes: from DNA to chromosomes. Nat. Rev. Mol. Cell Biol. 17, $399-412$.

van Tilborg, E., van Kammen, C.M., de Theije, C.G.M., van Meer, M.P.A., Dijkhuizen, R.M., and Nijboer, C.H. (2017). A quantitative method for microstructural analysis of myelinated axons in the injured rodent brain. Sci. Rep. 7, 16492.

Vian, L., Pekowska, A., Rao, S.S.P., Kieffer-Kwon, K.R., Jung, S., Baranello, L., Huang, S.C., El Khattabi, L., Dose, M., Pruett, N., et al. (2018). The Energetics and Physiological Impact of Cohesin Extrusion. Cell 175, 292-294.

Vuilleumier, N., Kovari, E., Michon, A., Hof, P.R., Mentenopoulos, G., Giannakopoulos, P., and Bouras, C. (2002). Neuropathological analysis of an adult case of the Cornelia de Lange syndrome. Acta Neuropathol. 104, 327-332.

Williamson, J.M., and Lyons, D.A. (2018). Myelin Dynamics Throughout Life: An EverChanging Landscape? Front. Cell Neurosci. 12, 424.

Wingett, S. (2011). FastQ Screen: quality control tool to screen a library of sequences in FastQ format against a set of sequence databases. .

Wolf, N.I., Ffrench-Constant, C., and van der Knaap, M.S. (2021). Hypomyelinating leukodystrophies - unravelling myelin biology. Nat. Rev. Neurol. 17, 88-103. 
Wutz, G., Ladurner, R., St Hilaire, B.G., Stocsits, R.R., Nagasaka, K., Pignard, B., Sanborn, A., Tang, W., Varnai, C., Ivanov, M.P., et al. (2020). ESCO1 and CTCF enable formation of long chromatin loops by protecting cohesin(STAG1) from WAPL. eLife 9.

Wutz, G., Varnai, C., Nagasaka, K., Cisneros, D.A., Stocsits, R.R., Tang, W., Schoenfelder, S., Jessberger, G., Muhar, M., Hossain, M.J., et al. (2017). Topologically associating domains and chromatin loops depend on cohesin and are regulated by CTCF, WAPL, and PDS5 proteins.

EMBO J. 36, 3573-3599.

Yatskevich, S., Rhodes, J., and Nasmyth, K. (2019). Organization of Chromosomal DNA by SMC Complexes. Annu. Rev. Genet. 53, 445-482.

Zeisel, A., Hochgerner, H., Lonnerberg, P., Johnsson, A., Memic, F., van der Zwan, J., Haring, M., Braun, E., Borm, L.E., La Manno, G., et al. (2018). Molecular Architecture of the Mouse Nervous System. Cell 174, 999-1014 e1022.

Zhang, Y., Liu, T., Meyer, C.A., Eeckhoute, J., Johnson, D.S., Bernstein, B.E., Nusbaum, C., Myers, R.M., Brown, M., Li, W., et al. (2008). Model-based analysis of ChIP-Seq (MACS). Genome Biol. 9, R137.

Zheng, G., and Yu, H. (2015). Regulation of sister chromatid cohesion during the mitotic cell cycle. Sci. China Life Sci. 58, 1089-1098.

Zywitza, V., Misios, A., Bunatyan, L., Willnow, T.E., and Rajewsky, N. (2018). Single-Cell Transcriptomics Characterizes Cell Types in the Subventricular Zone and Uncovers Molecular Defects Impairing Adult Neurogenesis. Cell Rep. 25, 2457-2469 e2458. 


\section{METHODS}

\section{KEY RESOURCES TABLE}

\section{RESOURCE AVAILABILITY}

\section{Lead contact}

Further information and requests for resources and reagents should be directed to and will be fulfilled by the Lead Contact, Hongtao Yu (yuhongtao@westlake.edu.cn).

\section{Material availability}

Unique materials generated in this study will be available upon request.

\section{Data and code availability}

The RNA-seq, scRNA-seq, ChIP-seq, and Hi-C datasets generated and analyzed during the current study are available in the GEO repository, with the accession number xxx. Relevant code is available from the corresponding author upon request.

\section{EXPERIMENTAL MODEL AND SUBJECT DETAILS}

Generation of $\operatorname{Stag} 2^{f / f}$ and $S t a g 2^{f / y}$ mice and mouse husbandry. The STAG2 locus was targeted by inserting one neo cassette and two loxP sites flanking exon 8 via homologous recombination in the mouse embryonic stem (ES) cells. G418-selected positive ES clones were screened for successful targeting by nested PCR tests on both 5' and 3' integration sites of loxP. Four confirmed ES clones were then microinjected into mouse blastocysts. The chimeras were bred to the R26FLP mouse line for the removal of the neo cassette. Stag $2^{f /+}$ mice with the 129/B6 background were were crossed with $S t a g 2^{f / y}$ or wildtype C57BL/6J mice and maintained on this background. For 
the generation of the central nervous system-specific Stag2 $2^{f / y}$;Cre mice, the Stag $2^{f / f}$ mice were crossed with the transgenic mice carrying one allele of Cre driven by the rat nestin promoter and enhancer (Tg(Nes-cre)1Kln, JAX stock \#003771) (Giusti et al., 2014; Tronche et al., 1999).

All animals were handled in accordance with institutional guidelines of the Institutional Animal Care and Use Committee of University of Texas (UT) Southwestern Medical Center. All mice were housed in the antigen-free barrier facility with $12 \mathrm{hr}$ light/dark cycles (6 AM on and 6 PM off). Mice were fed a standard rodent chow (2016 Teklad Global 16\% protein rodent diet, Harlan Laboratories).

\section{METHOD DETAILS}

Immunoblotting. The C-terminal fragment of human STAG2 protein was expressed and purified from Escherichia coli and used as the antigen to generate rabbit polyclonal antibodies against STAG2 at YenZym. Other antibodies were purchased from the following commercial sources: anti-SMC1 (Bethyl Laboratories, A300-055A), anti-SMC3 (Bethyl Laboratories, A300-060A), anti-RAD21 (Bethyl Laboratories, A300-080A), anti-SA1 (Bethyl Laboratories, A302-579A), anti-SA2 (Bethyl Laboratories, A302-581A), anti- $\alpha$-TUBULIN (Sigma-Aldrich, DM1A), antiMBP (Abcam, ab7349), anti-PLP1 (Abcam, ab28486), and anti-H3K27ac (Abcam, ab4729).

For immunoblotting, brain hemispheres were homogenized in a Precellys tissue homogenizer (Bertin Instruments) with the lysis buffer $[20 \mathrm{mM}$ Tris- $\mathrm{HCl}$ (pH 7.7), $137 \mathrm{mM} \mathrm{NaCl}$, $2 \mathrm{mM}$ EDTA, 10\% (v/v) glycerol, 1\% (v/v) TritonX-100, $0.5 \mathrm{mM}$ dithiothreitol, $1 \mathrm{mM}$ PMSF, 1 $\mathrm{mM} \mathrm{Na} \mathrm{VO}_{3}$, $10 \mathrm{mM} \beta$-glycerophosphate, $5 \mathrm{mM} \mathrm{NaF}$ and protease inhibitors (Roche)]. Homogenized brain tissues were lysed on ice for $1 \mathrm{hr}$. The lysate was then subjected to centrifugation at $20,817 \mathrm{~g}$ at $4^{\circ} \mathrm{C}$ for $20 \mathrm{~min}$ and further cleared by filtering through a $0.45 \mu \mathrm{m}$ 
filter. The cleared lysate was analyzed by SDS-PAGE and transferred to membranes, which was then incubated with the appropriate primary and secondary antibodies. The blots were imaged with the Odyssey Infrared Imaging System (LI-COR).

Tissue histology and immunohistochemistry. Mouse brains were fixed in 10\% neutral buffered formalin solution for $48 \mathrm{hr}$ followed by paraffin embedding and coronal or sagittal sectioning at 5 $\mu \mathrm{m}$. Hematoxylin and eosin (H\&E) staining and Luxol fast blue staining were performed by the Molecular Pathology Core at UT Southwestern Medical Center. Investigators were blinded to the genotype. Images were acquired with the DM2000 microscope (Leica) at 1.25X resolution.

Immunohistochemistry was performed as previously described (Choi et al., 2016). Briefly, deparaffinized sections were fixed with $4 \%$ paraformaldehyde, subjected to antigen retrieval by boiling with $10 \mathrm{mM}$ sodium citrate ( $\mathrm{pH}$ 6.0), and then incubated with the indicated antibodies at 1:100 dilution. The slides were scanned with an Axioscan.Z1 microscope (Zeiss) at 40X resolution at the Whole Brain Microscopy Facility at UT Southwestern Medical Center. Images were processed and quantified with Image J. For the myelinated fiber length measurement and coherency analysis, coronal sections of the brain cortex stained with the anti-MBP antibody were processed as previously described (van Tilborg et al., 2017). The myelinated axial thinning and fiber length measurement were performed by the plugin DiameterJ. The coherency analysis of myelinated axons was performed with the plugin OrientationJ.

Isolation of primary oligodendrocytes. The immunomagnetic isolation of oligodendrocytes from Stag $2^{f / y}$ and Stag2 $2^{f / y}$;Cre P12-P14 pups was conducted using anti-O4 microbeads (Miltenyi Biotec) according to a published protocol (Flores-Obando et al., 2018). Briefly, dissected brain 
cortex was triturated in the papain dissociation solution with B-27 supplement. The single-cell suspension was incubated with anti-O4 magnetic beads and passed through a magnetic column to enrich oligodendrocytes. Freshly prepared oligodendrocytes were directly used or fixed for subsequent analysis.

Metabolic cage analysis. Mice were singly housed in shoebox-sized cages with a five-day acclimation period followed with a four-day recording period. Recorded parameters were analyzed by the TSE system and normalized to body weight. The experiments were conducted by the core personnel under the core protocol at the Metabolic Phenotyping Core at UT Southwestern Medical Center. Investigators were blinded to the genotype.

Growth hormone and IGF-1 detection. Blood samples were collected from facial bleeding without fasting. Plasma growth hormone levels were determined with the rat/mouse growth hormone ELISA kit (EMD Milipore, EZRMGH-45K). Plasma IGF-1 concentrations were measured using the mouse/rat IGF1 Quantikine ELISA kit (R\&D Systems).

Sterol and oxysterol composition analysis. Brain hemispheres were pre-weighed and snapfrozen for extraction and measurement by mass spectrometry. The sterol extraction and quantitative analysis were conducted at the Center of Human Nutrition at UT Southwestern Medical Center as described previously (McDonald et al., 2012).

Electron microscopy. Stag $2^{f y}$ and $S t a g 2^{f / y} ;$ Cre P18 pups were transcardially perfused with $4 \%$ paraformaldehyde, $1 \%$ glutaraldehyde in $0.1 \mathrm{M}$ sodium cacodylate buffer $(\mathrm{pH} 7.4)$. Tissues were 
dissected and fixed with $2.5 \%(\mathrm{v} / \mathrm{v})$ glutaraldehyde in $0.1 \mathrm{M}$ sodium cacodylate buffer ( $\mathrm{pH} 7.4)$ for at least two hours. After three rinses with the $0.1 \mathrm{M}$ sodium cacodylate buffer, optic nerve samples were embedded in 3\% agarose and sliced into small blocks. All samples were again rinsed with the $0.1 \mathrm{M}$ sodium cacodylate buffer three times and post-fixed with $1 \%$ osmium tetroxide and $0.8 \%$ potassium ferricyanide in the $0.1 \mathrm{M}$ sodium cacodylate buffer for three hours at room temperature. Blocks were rinsed with water and en bloc stained with $4 \%$ uranyl acetate in 50\% ethanol for two hours. Samples were dehydrated with increasing concentrations of ethanol, transitioned into propylene oxide, infiltrated with Embed-812 resin, and polymerized in a $60^{\circ} \mathrm{C}$ oven overnight. Blocks were sectioned with a diamond knife (Diatome) on a Leica Ultracut 7 ultramicrotome (Leica Microsystems) and collected onto copper grids, post-stained with 2\% aqueous uranyl acetate and lead citrate. Images were acquired on a Tecnai G2 Spirit transmission electron microscope (Thermo Fischer) equipped with a LaB6 source using a voltage of $120 \mathrm{kV}$. Tissue processing, sectioning, and staining were completed by the Electron Microscopy Core at UT Southwestern Medical Center.

RNA-seq library preparation and sequencing. Total RNA was extracted from brain hemispheres or isolated oligodendrocytes with Trizol. RNA integrity was determined by the Agilent BioAnalyzer 2100. TruSeq Stranded mRNA library prep kit (Illumina) was used to generate the mRNA libraries. The libraries were analyzed by the Bioanalyzer and multiplexed and sequenced using the NextSeq 500 high output kit (400M reads) for the brain libraries or NextSeq 500 mid output kit (130M reads) for the isolated oligodendrocytes libraries at the Next Generation Sequencing Core at UT Southwestern Medical Center. 
Differential expression and pathway analysis. Raw data from the sequencer were demultiplexed and converted to fastq files using bcl2fastq (v2.17, Illumina). The fastq files were checked for quality using fastqc (v0.11.2) (Andrews, 2010) and fastq_screen (v0.4.4) (Wingett, 2011). Fastq files were mapped to the mm10 mouse reference genome (from iGenomes) using STAR (Dobin et al., 2013). Read counts were then generated using featureCounts (Liao et al., 2014). TMM normalization and differential expression analysis were performed using edgeR (Robinson et al., 2010). Pathway analysis was performed with the Ingenuity pathway analysis (IPA) software. Genes with more than 1.5 -fold change and FDR $<0.01$ were included in the brain RNA-seq pathway analysis. Genes with more than 2 -fold change and FDR $<0.05$ were used for the pathway analysis of the RNA-seq data from oligodendrocytes.

RT-qPCR analysis. Single-stranded cDNAs were converted from $2 \mu \mathrm{g}$ of total RNA extracted from mouse brains with the high-capacity cDNA reverse transcription kit (Applied Biosystems). Quantitative-PCR was conducted to determine transcript levels using gene-specific TaqMan probes (Applied Biosystems).

Single-cell RNA-seq. Single-cell suspension was prepared from forebrains of P13 Stag2f/y or Stag $2^{f / y}$; Cre pups using the Papain Dissociation System (Worthington Biochemical, LK003150) according to the manufacturer's instructions. Biological duplicates were made for each genotype. Single-cell RNA-seq libraries were generated with the Chromium Single Cell 3' GEM, Library \& Gel Bead Kit v3 (10x Genomics) according to the manufacturer's guidelines. Cell density and viability were checked by the TC-20 Cell Counter (Bio-Rad). Cells were then loaded onto Chip B in the Chromium Controller (10x Genomics). 10,000 cells were targeted for each sample. The 
libraries were analyzed by the Bioanalyzer (Agilent) and pair-end sequenced in two flowcells of the NextSeq 500 High Output (400M) run. The sequencing was performed at the Next Generation Sequencing Core at UT Southwestern Medical Center.

Data de-multiplexing and alignment was performed using the Cell Ranger pipeline (https://support.10xgenomics.com/single-cell-gene-expression/software/pipelines/latest/using/ mkfastq) (10x Genomics). The raw features, barcodes, and matrixes were used as input for further analysis using the $\mathrm{R}$ package Seurat3 (Butler et al., 2018; Stuart et al., 2019) (https://satijalab.org/seurat/). Cells were filtered by the following criteria: nFeature_RNA (2009500) and percent.mt $<10$. After filtering, a total of 5,834 cells in Stag $2^{f / y} \# 1,4,699$ cells in Stag $2^{f / y} \# 2,9,050$ cells in Stag $2^{f / y} ; C r e \# 1$, and 3,073 cells in Stag2 $2^{f / y} ; C r e \# 2$ were used for downstream analysis. 2,000 variable features were found from each normalized dataset. All datasets were then integrated using identified anchors (dims $=1: 30$ ). Standard scaling and principal component analysis $(\mathrm{PCA})$, clustering $($ resolution $=0.5)$, and $\mathrm{tSNE}$ reduction $(\operatorname{dims}=$ 1:30) were performed on the integrated dataset. Cluster biomarkers were identified, and top features were examined. Clusters were then manually assigned to distinct cell type identities with knowledge from previous studies (Cahoy et al., 2008; Dulken et al., 2019; Marques et al., 2018; Marques et al., 2016; Marton et al., 2019; Saunders et al., 2018; Zeisel et al., 2018; Zywitza et al., 2018) (http://www.brainrnaseq.org/) (http://dropviz.org/). Clusters with the same cell type identities were merged. 5 clusters of oligodendrocyte lineage [cycling oligodendrocyte progenitors (OPCcycs), oligodendrocyte progenitors (OPCs), newly formed oligodendrocytes (NFOLs), myelin-forming oligodendrocytes (mFOLs) and fully matured oligodendrocytes (MFOLs)] were identified and selected for indicated gene expression comparison and plotting using Vlnplot or FeaturePlot functions. The trajectory analysis was performed using Monocle3 
(Cao et al., 2019) in the oligodendrocyte cell population. Gene density plot over pseudotime was generated as previously described (Luecken and Theis, 2019).

ChIP-seq. Chromatin immunoprecipitation (ChIP) was performed as previously described (Liu et al., 2017). Briefly, isolated oligodendrocytes were fixed with $1 \%$ formaldehyde and fragmented with a sonicator (Branson 450). The fragmented chromatin was incubated with antibodies overnight at $4^{\circ} \mathrm{C}$. Dynabeads Protein A (Thermo Fisher Scientific) was used for the immunoprecipitation. Libraries were generated by the Next Gen DNA Library Kit (Active Motif) with the Next Gen Indexing Kit (Active Motif) for STAG2 ChIP-seq or the KAPA HyperPrep Kits (KAPA Systems) for histone ChIP-seq. The libraries were analyzed by the Bioanalyzer and poolsequenced with the NextSeq 500 mid output (130M) kit. After mapping reads to the mouse genome (mm10) by bowtie2 (v2.2.3) (Langmead and Salzberg, 2012) with the parameter "sensitive", we performed filtering by removing alignments with mapping quality less than 10 and then removing duplicate reads identified by Picard MarkDuplicates (v1.127). For STAG2 ChIPseq, Picard MarkDuplicate was used to remove duplicates together with options to use molecular identifiers (MIDs) information in the reads. Enriched regions (peaks) were identified using MACS2 (v2.0.10) (Zhang et al., 2008), with a q-value cut-off of 0.05 for peaks. Peak regions were annotated by HOMER(Ross-Innes et al., 2012).

Hi-C library generation, sequencing, and analysis. $\mathrm{Hi}-\mathrm{C}$ was performed at the Genome Technology Center at NYU Langone Health from 3.5-4.0 $\mu \mathrm{g}$ of DNA isolated from cells crosslinked with $2 \%$ formaldehyde at room temperature for 10 minutes. Experiments were performed in duplicates following the instructions from the Arima Hi-C kit (Arima Genomics, San Diego, 
CA). Subsequently, Illumina-compatible sequencing libraries were prepared by using a modified version of the KAPA HyperPrep library kit (KAPA BioSystems, Willmington, MA). Quality check steps were performed to assess the fraction of proximally ligated DNA labeled with biotin, and the optimal number of PCR reactions needed to make libraries. The libraries were loaded into an Illumina flowcell (Illumina, San Diego, CA) on a NovaSeq 6000 instrument for paired-end 50 reads.

Hi-C analysis was performed using the HiC-Bench pipeline (Lazaris et al., 2017; Tsirigos et al., 2012) (https://github.com/NYU-BFX/hic-bench). The read pairs were aligned and filtered with the following parameters: Genome-build=mm10; -very-sensitive-local -local; mapq=20; min-dist 25000 -max-offset 500. The Juicer "pre" tool (Durand et al., 2016) (https://github.com/aidenlab/juicer) was used to generate the .hic file with default parameters. Sample duplicates were combined. The compartment analysis was done using the HOMER tool (Heinz et al., 2010) (http://homer.ucsd.edu/homer/index.html) with $100 \mathrm{~kb}$ bins. H3K27ac ChIP-seq data was used to assign A/B compartments. Eigenvector-1 bins were considered shifted (AB and BA) when the bin sign changed and the delta value was greater than 1.5. Topologically associated domains (TAD) and boundaries were identified with the HiCRatio method with the follow parameters: - min-lambda $=0.0-$ max-lambda $=1.0-$ n-lambda $=6-$ gamma $=0 \quad-$ distance $=500 \mathrm{~kb}-$ $\mathrm{fdr}=0.1$. The .hic files were converted to .cool format for visualization and plotting with pyGenomeTracks (Lopez-Delisle et al., 2020) at $5 \mathrm{~kb}$ resolution.

Loop analysis and RNA-seq integration. The loops were classified into group-specific loops and common loops by using the significance cutoffs provided by Fit-HiC (Ay et al., 2014). A qvalue cutoff of 0.01 was used to identify significant loops in both groups. A loop is considered 
"group-specific" if it is only present in one group with a qval $<0.01$ and not present in the other group with cutoff of qval $<0.1$. Loop anchors were annotated with the gene promoter information (promoter defined as $+/-2 \mathrm{~kb}$ from the transcription start site). The genes were classified into “down" and "up" regulated genes using an FDR cutoff of $0.05, \log$ FC cutoff of $+/-0.58$ and $\log \mathrm{CPM}>0$. "stable" or less changed genes are defined as $\log \mathrm{FC}<0.38$, and $\log \mathrm{CPM}>0$. Random 1,000 genes were chosen for analysis and plotting. The genes were also grouped in "high", "mid" and "low" expression groups by separating the genes in three quantiles according to the $\log \mathrm{CPM}$ values. For the loop enrichment scores, normalized contact scores were computed using Fit-HiC at $10 \mathrm{~kb}$ resolution and bias corrected. Pileup analysis was performed with coolpup.py (Flyamer et al., 2020) with the KR method to balance the weight and random shift controls for distance normalization at $5 \mathrm{~kb}$.

\section{QUANTIFICATION AND STATISTICAL ANALYSIS}

Statistical analysis was conducted in GraphPad Prism or R-studio. Specific statistical methods and approaches are indicated for each figure in the figure legend. 


\section{Figure legends}

Figure 1. Stag2 ablation in the mouse nervous system causes growth retardation and neurological defects.

(A) PCR analysis of genomic DNA extracted from brains (BR) or livers (LV) of indicated mice.

(B) Immunoblots of brain lysates of Stag2 $2^{f / y}$ and $\operatorname{Stag} 2^{f / y} ;$ Cre mice.

(C) Representative images of Stag $2^{f / y}$ and $\operatorname{Stag} 2^{f / y} ;$ Cre mice. Scale bar $=2 \mathrm{~cm}$.

(D) Body weight of $\operatorname{Stag} 2^{f / y}$ and $S \operatorname{Stag} 2^{f / y}$; Cre mice at different age. Mean $\pm \mathrm{SD}$ of at least three mice of the same age.

(E) Survival curves of $\operatorname{Stag} 2^{f / y}(\mathrm{n}=12)$ and $\operatorname{Stag} 2^{f / y} ; \operatorname{Cre}(\mathrm{n}=21)$ mice.

$(\mathrm{F}, \mathrm{G})$ Food $(\mathrm{F})$ and water $(\mathrm{G})$ consumption of 7- to 8-week-old Stag2 ${ }^{f / y}(\mathrm{n}=6)$ and Stag $2^{f / y} ; \mathrm{Cre}(\mathrm{n}$ =4) mice. Mean $\pm \mathrm{SD}$; ns, not significant.

(H) Plasma IGF-1 levels of two-month-old Stag2 $2^{f / y}(\mathrm{n}=5)$ and $\operatorname{Stag} 2^{f / y} ; C r e(\mathrm{n}=6)$ mice. Mean \pm $\mathrm{SD} ; * * * * \mathrm{p}<0.0001$

(I) Representative images of limb-clasping responses of $\operatorname{Stag} 2^{f / y}$ and $\operatorname{Stag} 2^{f / y}$;Cre mice.

Figure 2. Stag2 ablation in mouse brains downregulates the expression of myelin genes.

(A) Volcano plot of bulk RNA sequencing results of Stag2 $2^{f / y}$ and Stag2 $2^{f / y}$;Cre brain extracts. Top differentially expressed genes (DEGs) are colored blue and labeled. n $=4$ pairs of P21 Stag2f/y and $\operatorname{Stag} 2^{f / y}$;Cre brain hemispheres were used for the comparison.

(B) RT-qPCR analysis of the top downregulated genes in the brain extracts. $\mathrm{n}=4$ pairs of Stag2f/y and $\operatorname{Stag} 2^{f / y} ;$ Cre littermates were used. Mean \pm SD.

(C) Heatmap of the expression of myelin-enriched genes that were down-regulated by more than two folds in $S t a g 2^{f / y}$;Cre brains. $L 1$ and $R 1$, left and right brain hemispheres of the Stag $2^{f / y} \# 1$ 
mouse. L2 and R2, left and right brain hemispheres of the Stag $2^{f / y} \# 2$ mouse. L1' and $R 1$ ', left and right brain hemispheres of the Stag $2^{f / y}$; Cre \#1 mouse. L2' and $R 2^{\prime}$, left and right brain hemispheres of the $\operatorname{Stag} 2^{f / y} ;$ Cre\#2 mouse. The biological pathways of these genes are labeled on the right.

(D) Top canonical pathways identified by ingenuity pathway analysis (IPA) of the DEGs.

Figure 3. Stag2 ablation in the nervous system compromises myelination during early postnatal development.

(A) Luxol fast blue staining of the sagittal sections of Stag $2^{f / y}$ and Stag $2^{f / y}$;Cre brains. $\mathrm{n}=3$ animals per genotype. Scale bar $=1 \mathrm{~mm}$.

(B) Immunohistochemistry staining with the anti-MBP antibody in the cerebral cortex (left panel). Antibody-stained areas and DAPI staining regions are marked with red and yellow dashed lines, respectively. Scale bar $=200 \mu \mathrm{m}$. Quantification of the percentage of the myelinated cortex is shown in the right panel. $\mathrm{n}=4$ pairs of $\operatorname{Stag} 2^{f / y}$ and $\operatorname{Stag} 2^{f / y} ; C r e$ littermates were used (P18 or P21) for the comparison. $* * p<0.01$; Mean \pm SD.

(C) Immunohistochemistry staining with the anti-PLP1 antibody in the cerebellum (left panel). Antibody-stained areas and DAPI staining regions are marked with red and yellow dashed lines, respectively. Scale bar $=200 \mu \mathrm{m}$. Quantification of the percentage of the myelinated cerebellum granular layer is shown in the right panel. $\mathrm{n}=3$ pairs of $\operatorname{Stag} 2^{f / y}$ and $\operatorname{Stag} 2^{f / y}$; Cre littermates were used (P20 or P25) for the comparison. * ${ }^{*}<0.05$; Mean \pm SD.

(D) Higher magnification images (left panel) of the immunohistochemistry staining with the antiMBP antibody in (B). Images processed through axial thinning are shown in the right panel. Scale bar $=50 \mu \mathrm{m}$ 
(E,F) Total fiber length (E) and fiber coherency (F) measured using the processed images in (D). $\mathrm{n}=4$ pairs of $\operatorname{Stag} 2^{f / y}$ and $\operatorname{Stag} 2^{f / y} ;$ Cre littermates were used $\left(\mathrm{P} 18\right.$ or P21). ${ }^{*} \mathrm{p}<0.05, * * \mathrm{p}<0.01$; Mean \pm SD.

(G) Transmission electron microscopy images of the optic nerves (left panel). Scale bar $=2 \mu \mathrm{m}$. Quantification of myelinated axon distributions is shown in the right panel. $\mathrm{n}=4$ pairs of P18 Stag $2^{f / y}$ and $S \operatorname{tag} 2^{f / y} ;$ Cre littermates were used. $\mathrm{n} \geq 10$ fields of each mouse were taken, and the average distribution of myelinated axons were calculated for each mouse and plotted. $* * p<0.01$; Mean \pm SD

\section{Figure 4. Deletion of Stag2 in mouse brains causes differentiation delay and transcriptional changes in oligodendrocytes.}

(A) $t$-SNE plot of cell clusters in $S t a g 2^{f / y}$ and $\operatorname{Stag} 2^{f / y}$;Cre forebrains analyzed by single-cell RNAseq (scRNA-seq). $\quad \mathrm{n}=2$ mice of each genotype were used in the scRNA-seq analysis. aNSCs/NPCs, active neural stem cells or neural progenitor cells; Astrocytes/qNSCs, astrocytes or quiescent neural stem cells; OPCcycs, cycling oligodendrocyte (OL) progenitor cells; OPCs, OL progenitor cells; NFOLs, newly formed OLs; mFOLs, myelin-forming OLs; MOLs, matured OLs; VLMCs, vascular and leptomeningeal cells; vSMCs, vascular smooth muscle cells.

(B) $t$-SNE clustering as in (A) but colored by genotype.

(C) Left panel: cell type composition and percentage as colored in (A). Right panel: percentage of cell clusters of the oligodendrocyte lineage.

(D) FeaturePlot of a representative gene (Mal) specifically suppressed in MOLs of Stag ${ }^{f / y}$; Cre forebrains. A maximum cutoff of 3 was used.

(E) Experimental scheme of the magnetic-activated cell sorting (MACS) of primary OLs. 
(F) Volcano plot of bulk RNA-seq results of Stag2 ${ }^{f / y}$ and $\operatorname{Stag} 2^{f / y}$;Cre primary OLs.

(G) Top canonical pathways identified by IPA of the DEGs in (F).

(H) Commons DEGs shared between bulk RNA-seq analyses of the whole brains (WB) and primary OLs.

\section{Figure 5. Loss of Stag2 does not alter compartments and TADs in oligodendrocytes.}

(A) Representative snapshots of balanced Hi-C contact matrices of chromosome 2. Tracks of eigenvector-1 fixed with housekeeping genes are shown below, with A and B compartments shown in red and blue, respectively.

(B) Hexbin plot of eigenvector-1 for genomic bins $(100 \mathrm{~kb})$ in Stag $2^{f / y}$ and Stag ${ }^{f / y}$; Cre oligodendrocytes (OLs).

(C) Chromatin bins were classified into four categories based on the eigenvector sign and whether it has switched with a delta bigger than 1.5. AB, changing from compartment A in Stag $2^{f / y}$ to compartment B in $S \operatorname{Stag} 2^{f / y} ; C r e ;$ BA, from B in $S \operatorname{stag} 2^{f / y}$ to A in $S t a g 2^{f / y} ; C r e ; A A, A$ in both $\operatorname{Stag} 2^{f / y}$ and $\operatorname{Stag} 2^{f / y} ; C r e ; B B, B$ in both $\operatorname{Stag} 2^{f / y}$ and $\operatorname{Stag} 2^{f / y} ; C r e$.

(D) Boxplot of averaged gene expression change of DEGs (RNA logFC cutoff of \pm 0.58 ) inside each genomic bin. Bins counted: AA, 1646; AB, 56; BA, 69; BB, 910. Red dots represent the mean value. An unpaired Wilcoxon test was used for the statistical analysis. ${ }^{*} \mathrm{p}<0.05 ; * * \mathrm{p}<$ $0.01 ; * *$ p $<0.001 ;$ ns, not significant.

(E) Principal component analysis (PCA) plot of the insulation score.

(F) Overlaps of TAD boundaries between genotypes and biological replicates.

(G) Pile-up analysis of TAD boundary-centered local structure flanked by $400 \mathrm{~kb}$ chromatin regions. 
(H) Pile-up analysis of TAD local structure rescaled to an equal size.

Figure 6. Stag2 deletion impairs the formation of total and promoter-anchored loops in oligodendrocytes.

(A) Loop counts (left panel) and length (right panel) in the indicated categories of Stag $2^{f / y}$ and Stag $2^{f / y}$; Cre oligodendrocytes (OLs).

(B) Loop counts plotted against loop length (from 0 to $5 \mathrm{Mb}$ ) of $\operatorname{Stag} 2^{f / y}$ and $\operatorname{Stag} 2^{f / y}$;Cre OLs.

(C) Normalized contact counts for loops across different genomic distances in Stag2 f/y and Stag $2^{f / y} ;$ Cre OLs.

(D) Representative snapshots of contact maps at the $P l s 1$ gene locus. Tracks and narrow peaks from STAG2 and H3K27ac ChIP-seq as well as the loops are plotted below. Transcription direction is indicated by the black arrow.

(E) Pile-up analysis of loop "dots"-centered local maps for the promoter-anchored loops of genes in the indicated categories. The maps are balanced, normalized by distance, and plotted at $5 \mathrm{~kb}$ resolution. The numbers indicate the enrichment of the central pixel over the upper left and bottom right corners.

(F) Pile-up analysis of the local contact maps centered around the transcription start site (TSS) of genes in the indicated categories. Transcription directions are indicated below. 1,000 stable genes are chosen randomly and used for the analysis. The maps are balanced, normalized by distance, and plotted at $5 \mathrm{~kb}$ resolution. Diagonal pixels are omitted.

Figure 7. Proposed roles of STAG2-cohesin-mediated loop extrusion during transcription in oligodendrocytes. 
(A) STAG2-cohesin-mediated chromosome looping connects the enhancer and the promoter, thus facilitating interactions among oligodendrocyte-specific transcription factors, the mediator complex, and the general transcription machinery including RNA polymerase II.

(B) STAG2-cohesin travels along the gene body via transcription-coupled loop extrusion to facilitate pre-mRNA processing.

(C) STAG2-cohesin mediates the formation of gene loops that bring the terminator close to the promoter and facilitate Pol II recycling for multiple rounds of transcription. 

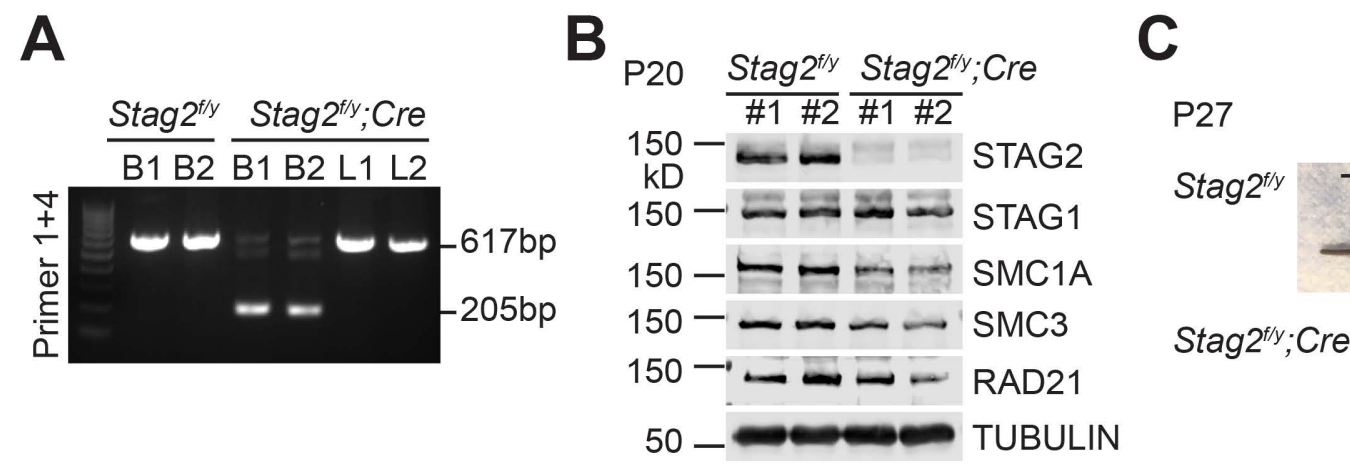

C

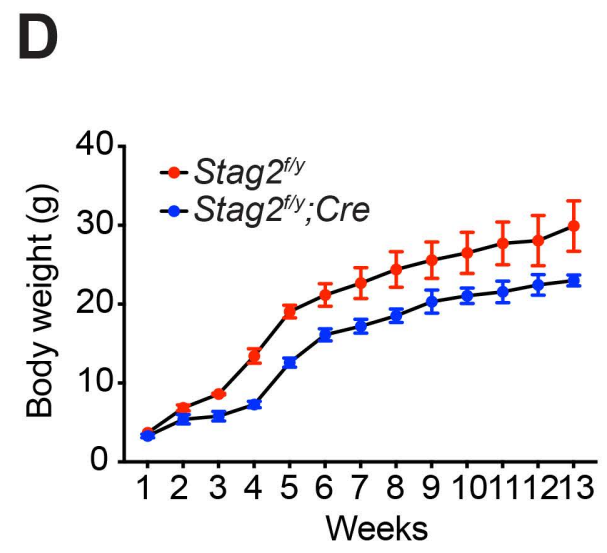

E
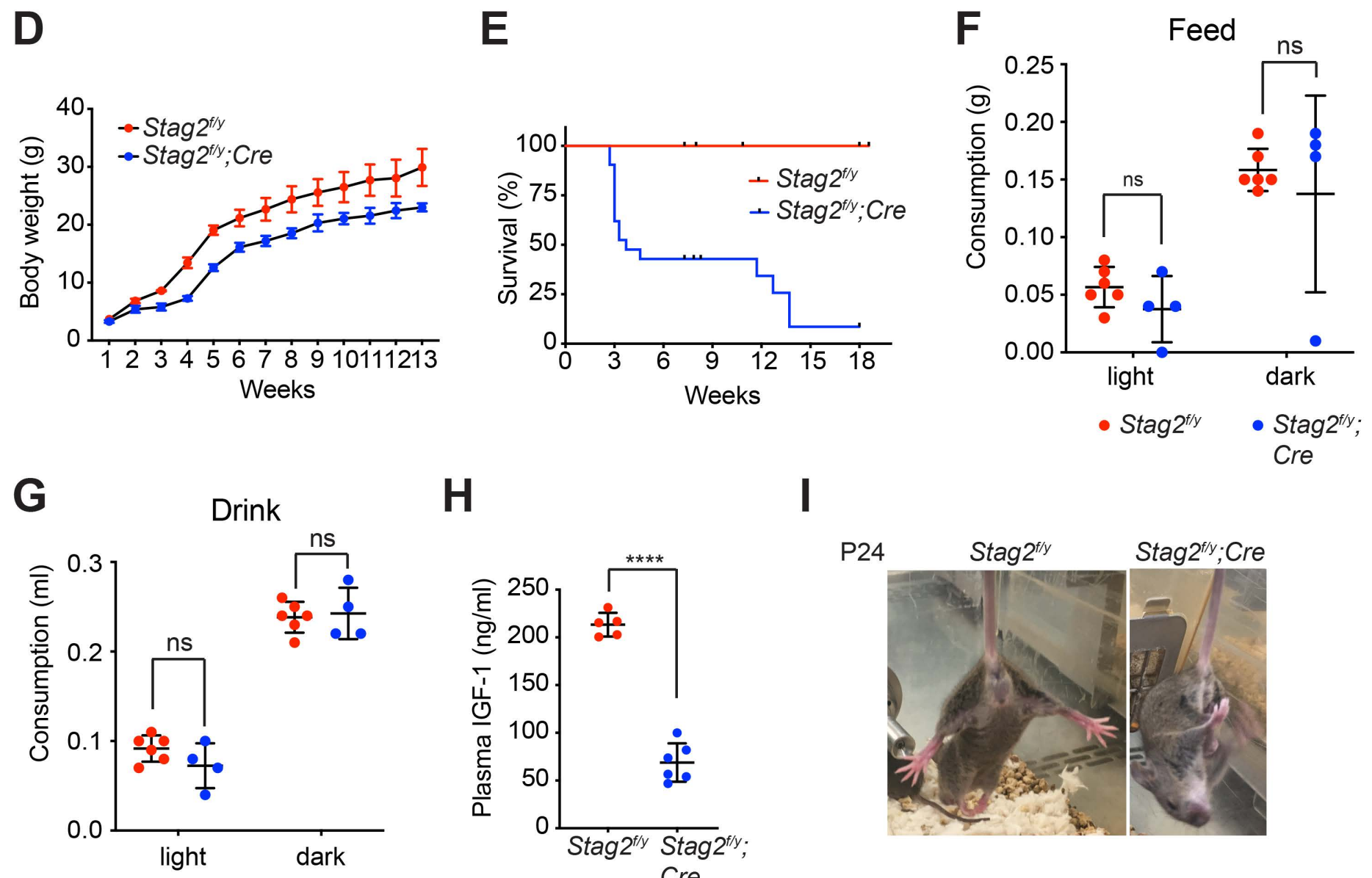

\section{H}
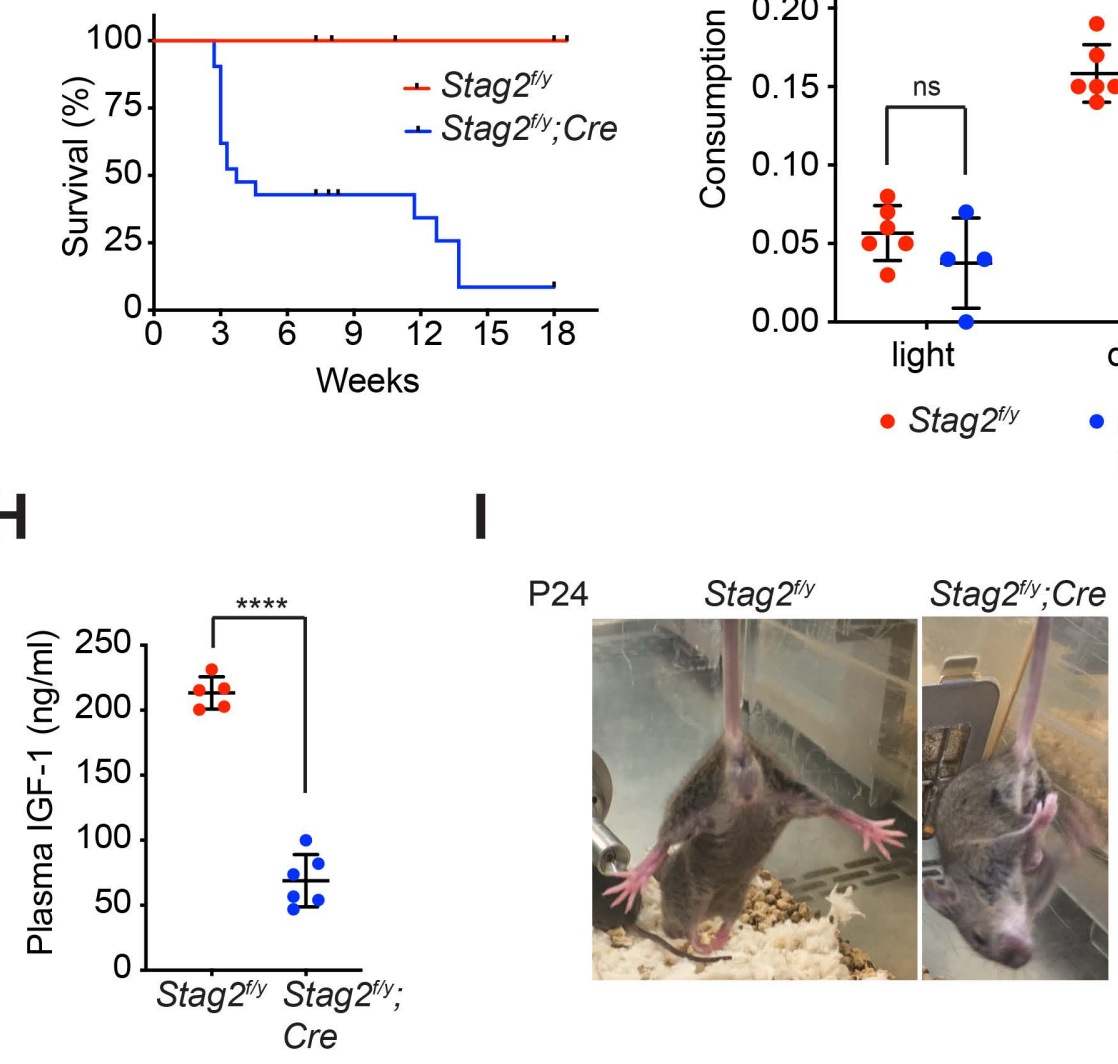

$\begin{aligned} \text { - Stag2 } & \text { - Stag2 ffy } \\ & \text { Cre }\end{aligned}$ 
A

\section{P21}

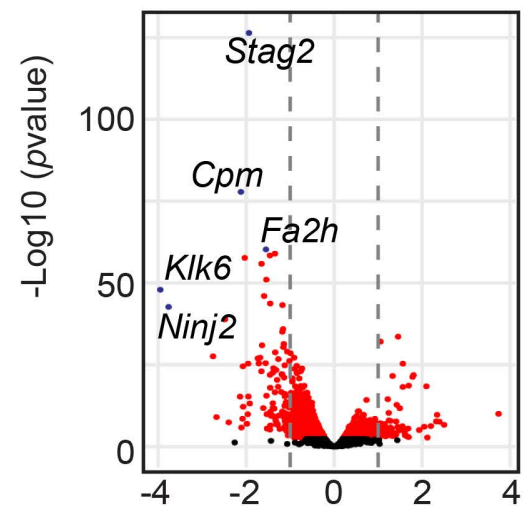

$\operatorname{LogFC}\left(\right.$ Stag $2^{f y} ;$ Cre / Stag $\left.2^{f y}\right)$

B

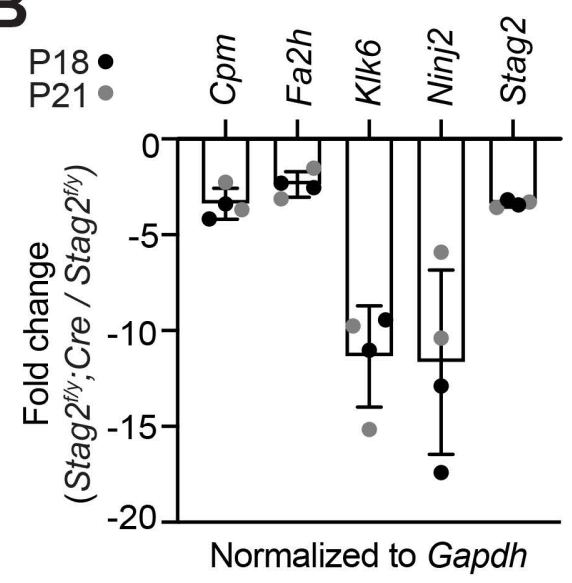

C

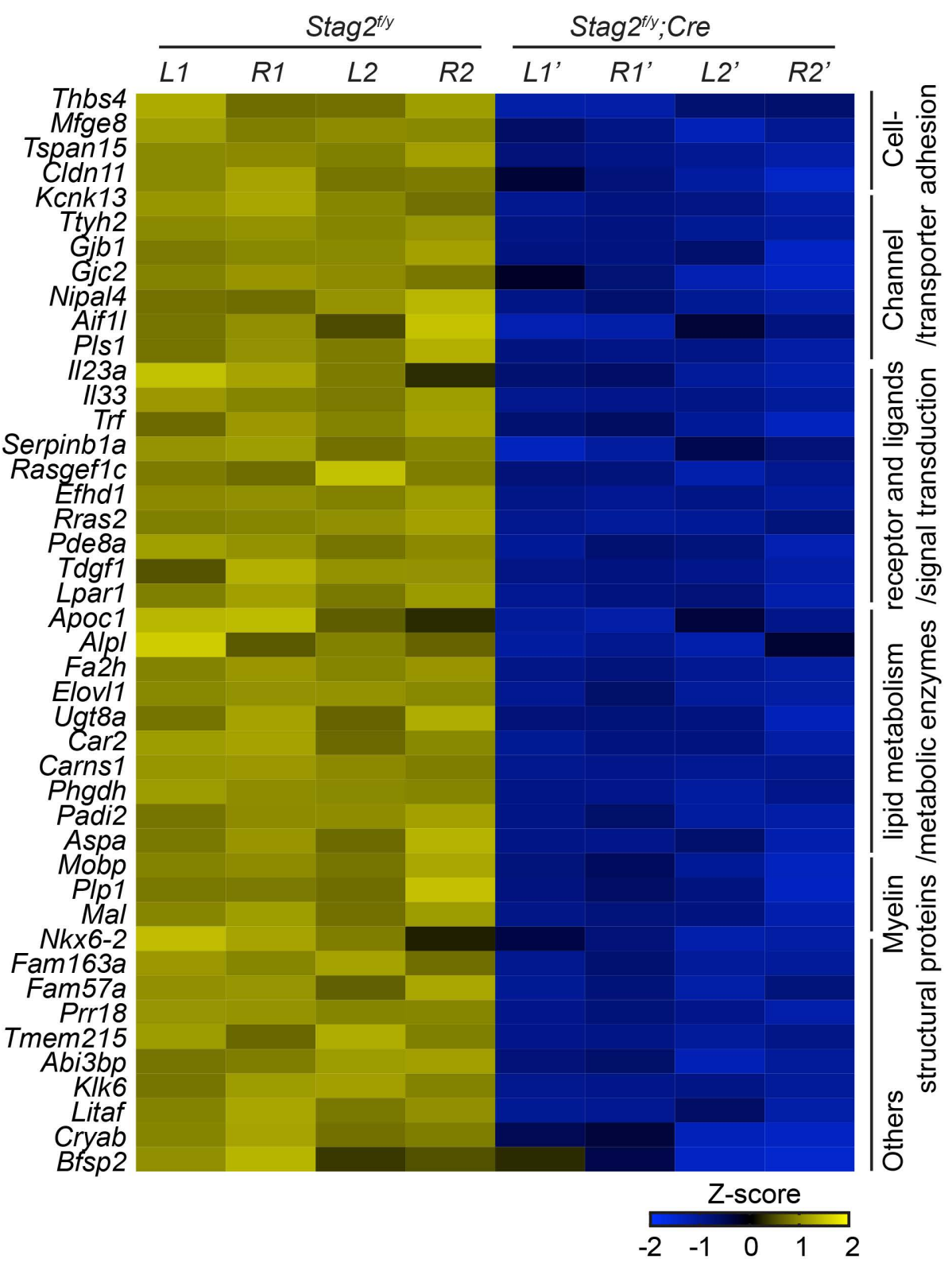

D

Top canonical pathways

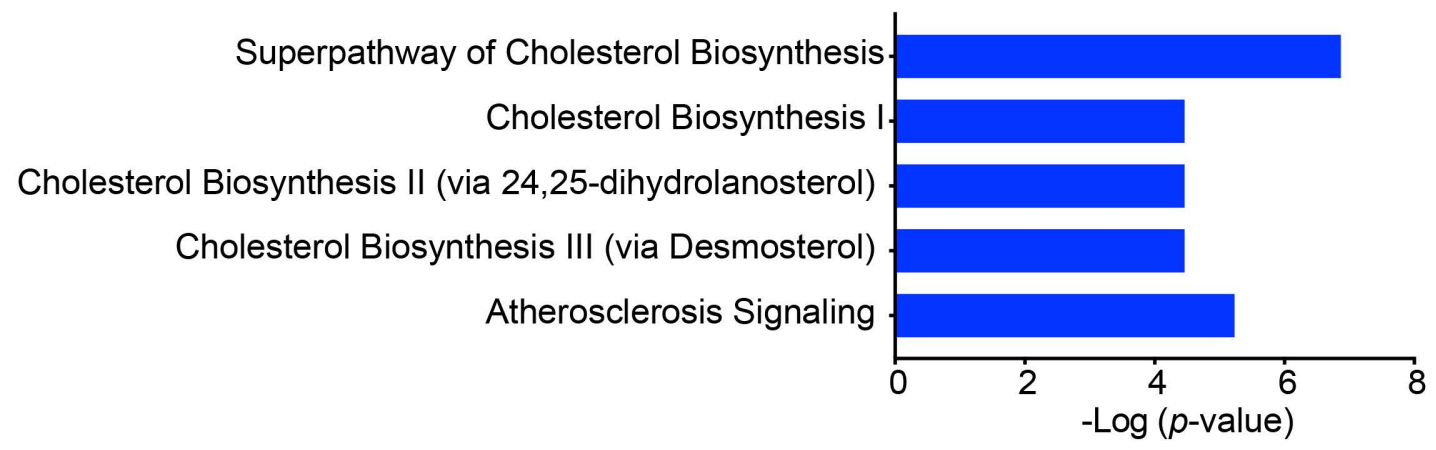


bioRxiv preprint doi: https://doi.org/10.1101/2021.10.10.463866; this version posted November 4, 2021. The copyright holder for this preprint (which was not certified by peer review) is the author/funder, who has granted bioRxiv a license to display the preprint in perpetuity. It is made A P20 Stag $2^{f / y} \quad$ available under aCC-BY-NC-ND 4.0 International license.
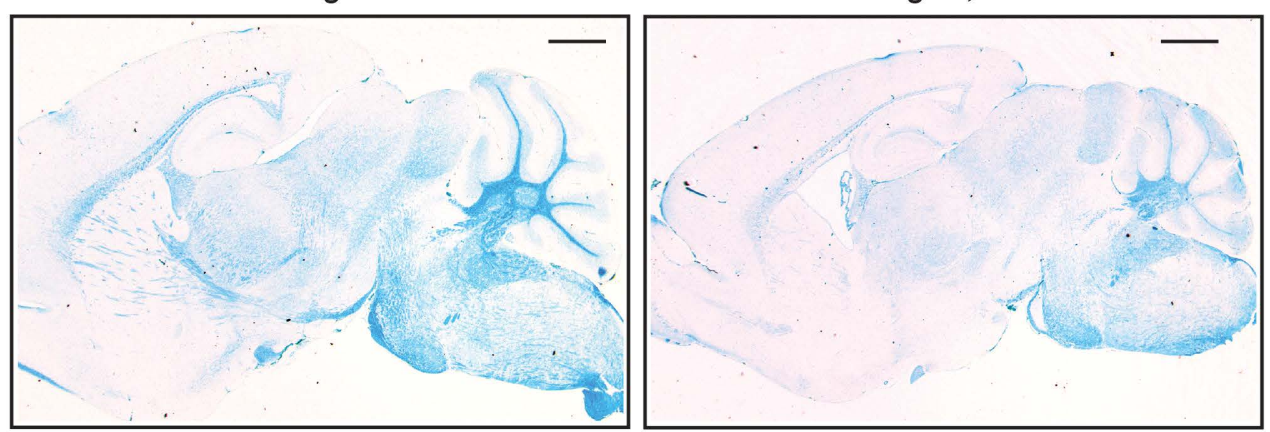

Luxol fast blue

B $\quad \mathrm{P} 18$

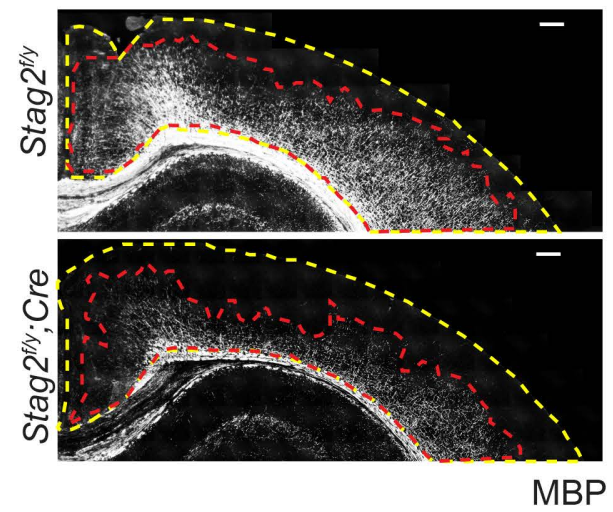

D

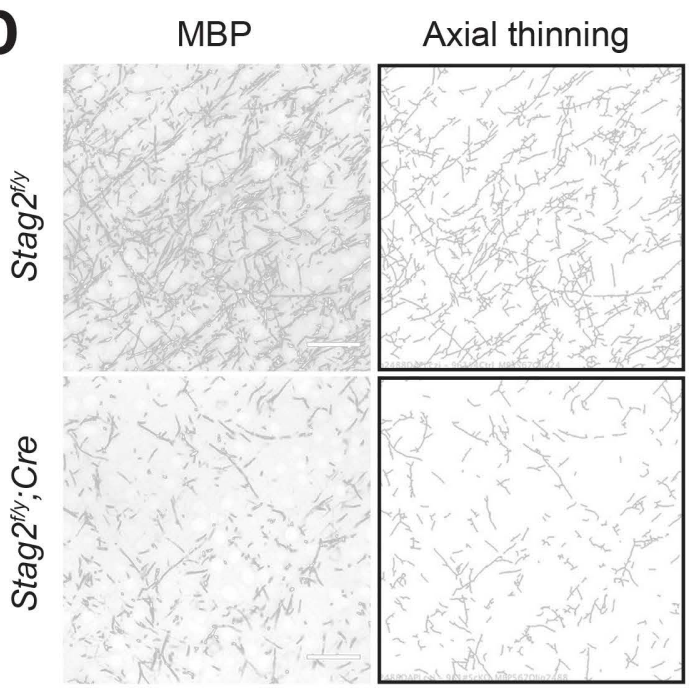

C

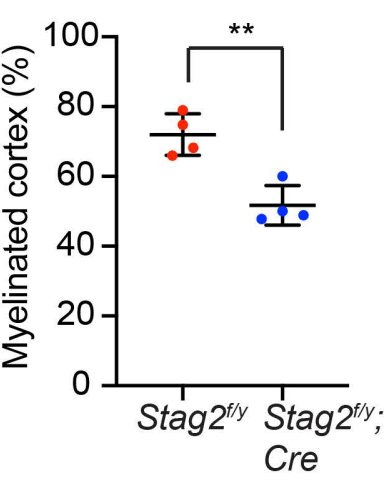

P20 Stag2f/y

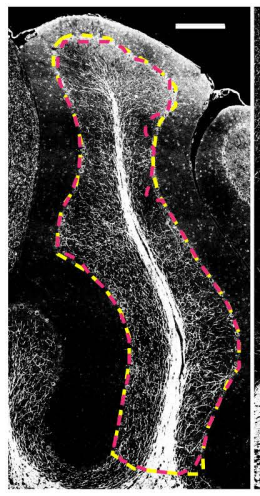

Stag $2^{f / y} ;$ Cre
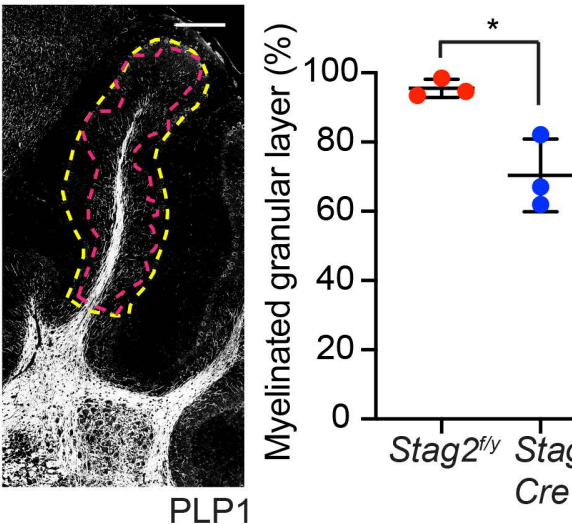

E

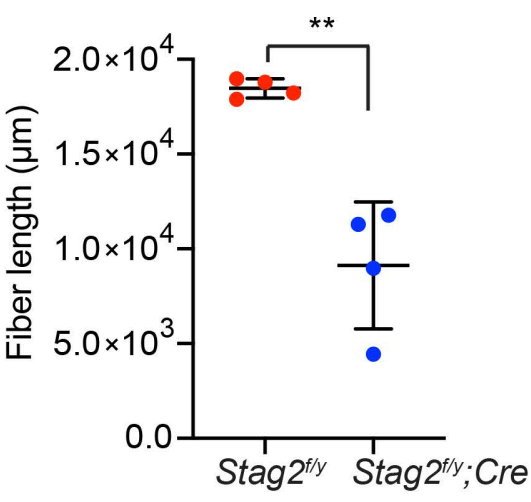

F

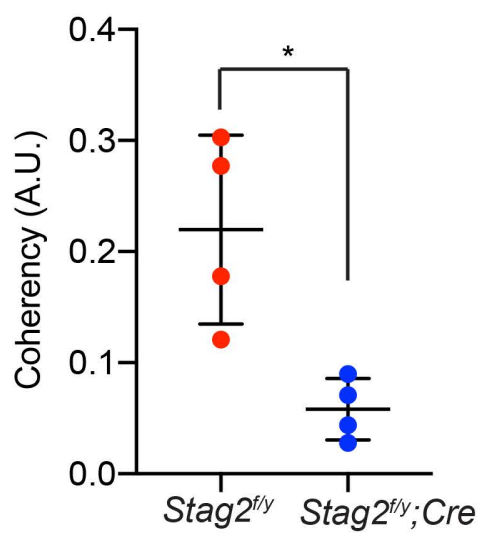

G

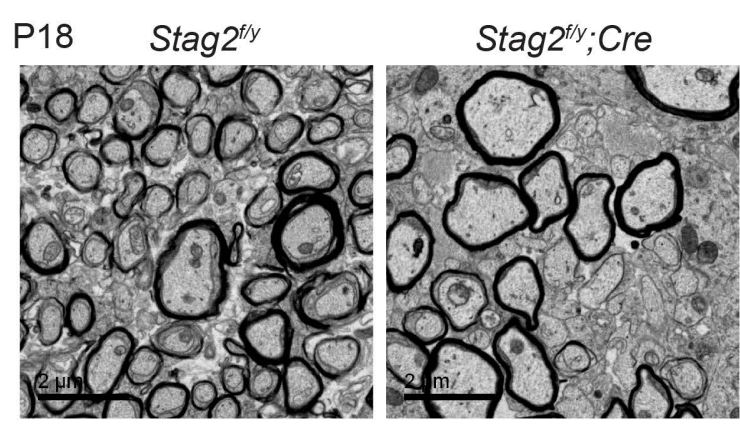

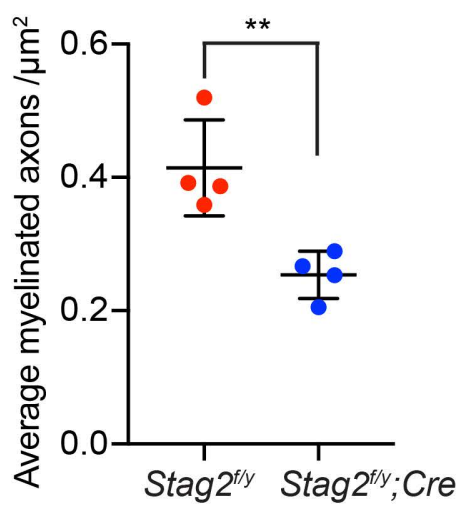




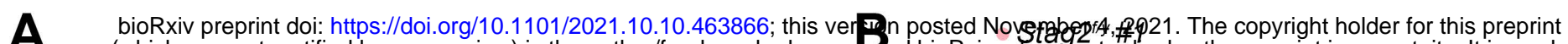
(which was not certified by peer review) is the author/funder, who has gramed bioRxiv a scestoftiofmplay the preprint in perpetuity. It is made P13 available under aCC-BY-NC-ND 4.0 Internatio stag 2 ; $;$;Cre \#1
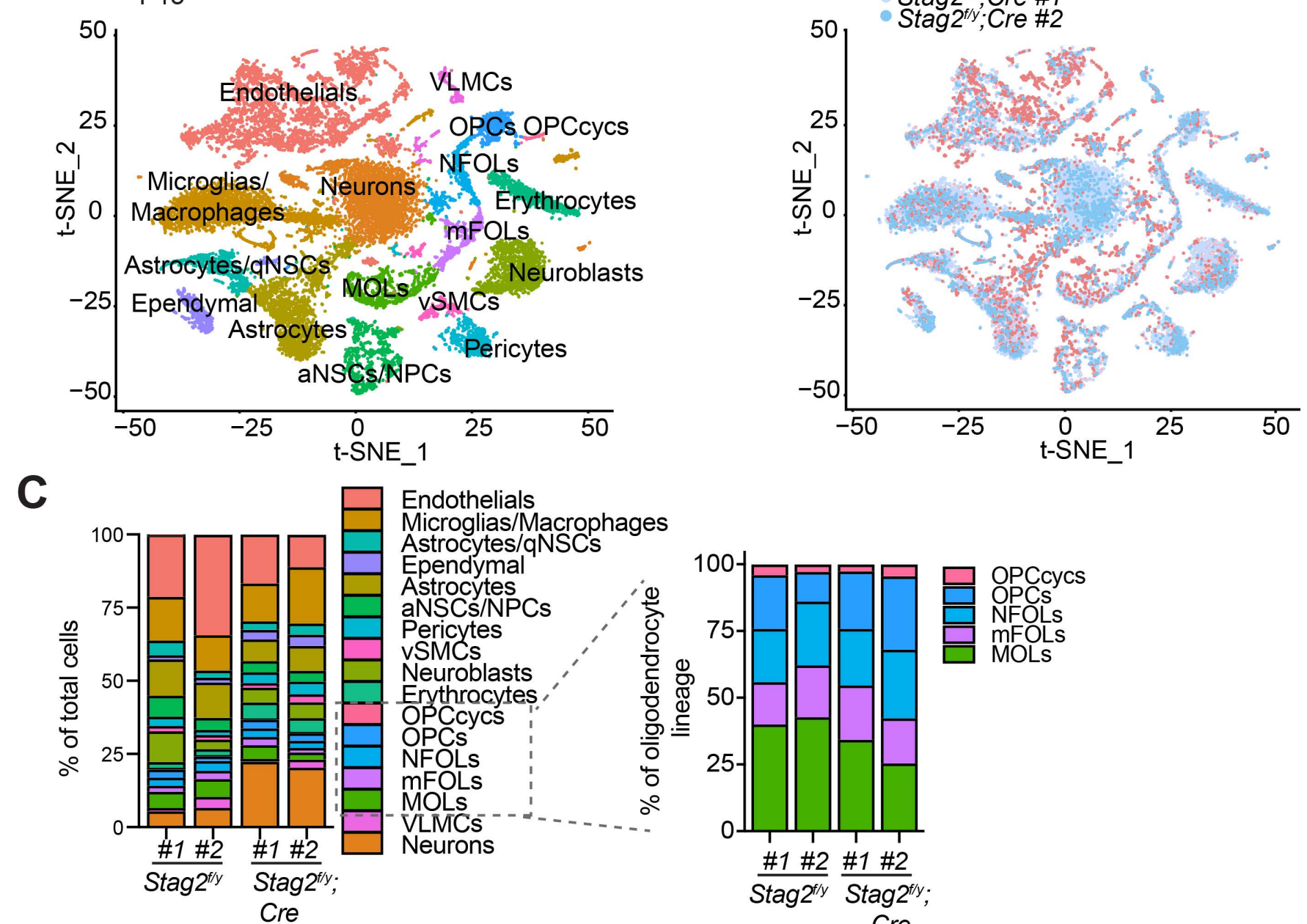

Endothelials

Astrocytes/qNSCs

Ependyma

aNSCS/NPCs

Pericytes

VSMCs

rythrocy

PCcycs

MFOLs

MOLS - . '

D
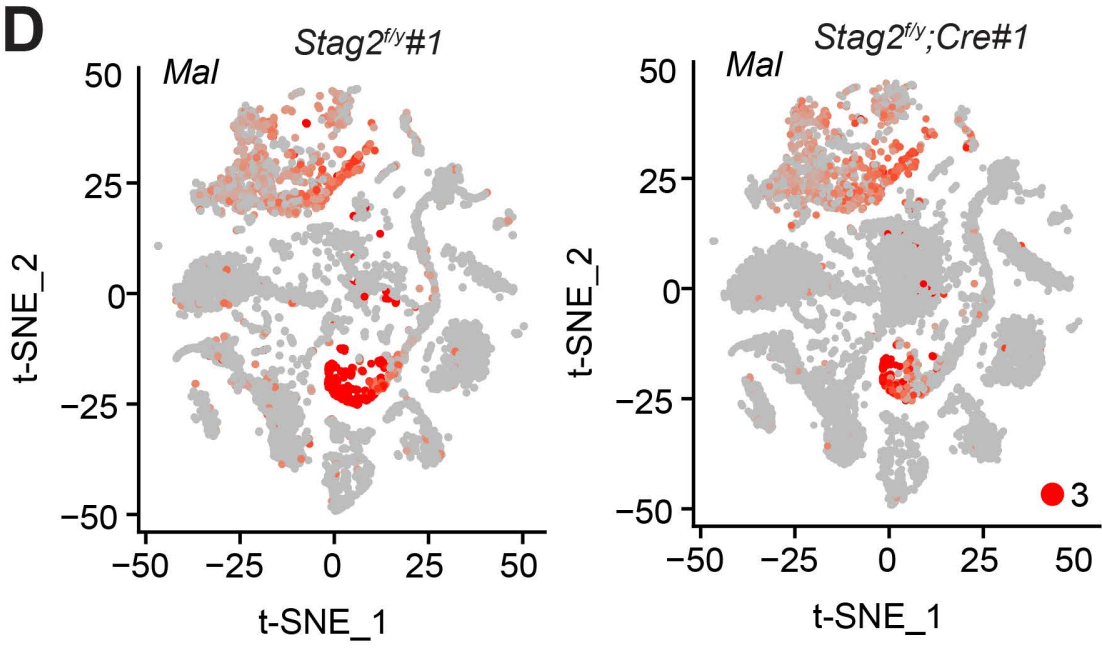

E

\#1 \#2 \#1 \#2

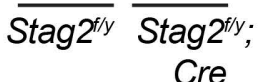

$\mathbf{F}$

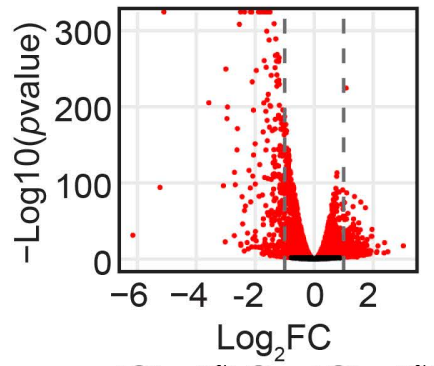

(Stag 2fy; Cre / Stag 2fy)
G

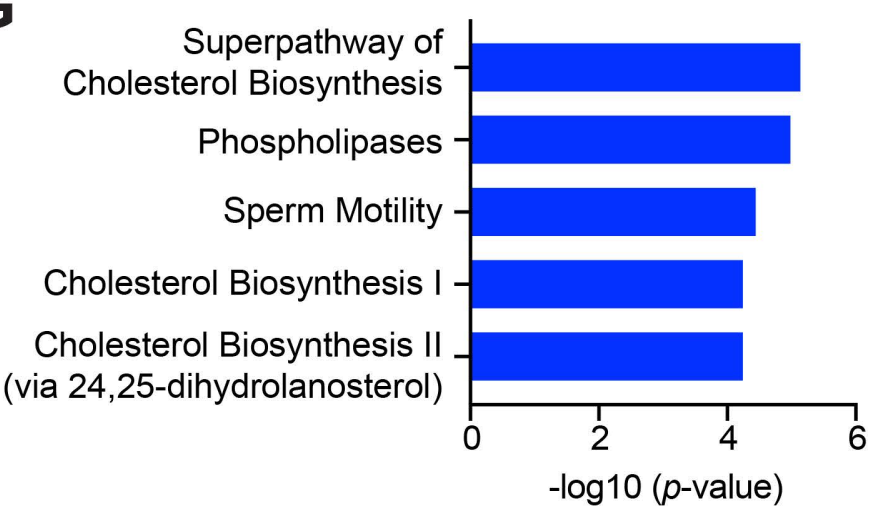

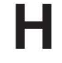

$>2$-fold down in Stag2 ${ }^{f y} ;$ Cre

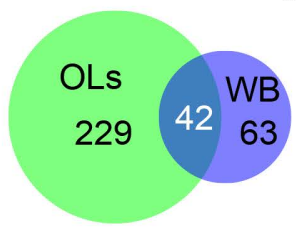

\section{Figure 4}


bioRxiv preprint doi: https://doi.org/10.1101/2021.10.10.463866; this version posted November 4,2021 . The copyright holder for this preprint (which was not certified by peer review) is the author/funder, who has granted bioRxiv a license to display the preprint in perpetuity. It is made

A available under aCC-BY-NC-ND 4.0 International license.

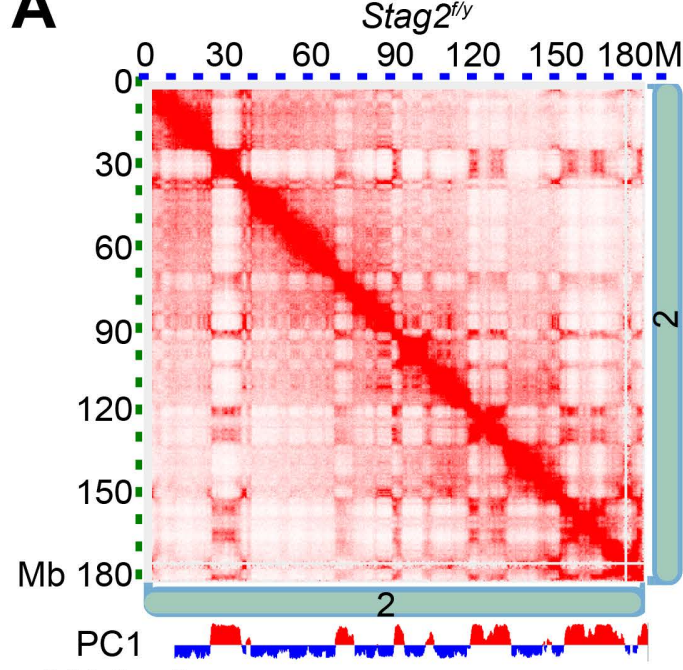

(HK-fixed)

C

Stag2 $2^{f y}$ vs Stag $2^{f y} ;$ Cre

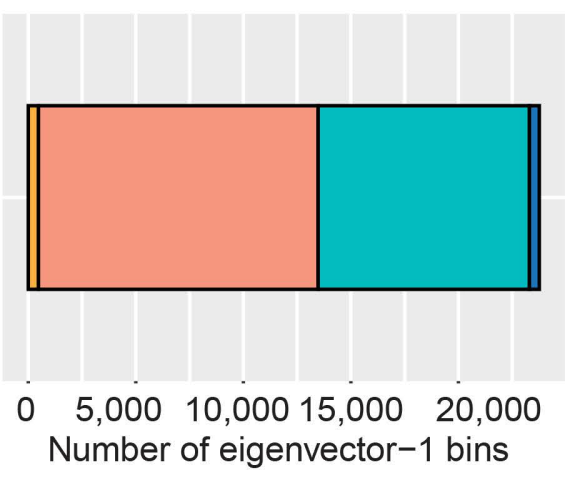

$\square$ AB
AA
BB
BA

$\mathbf{F}$

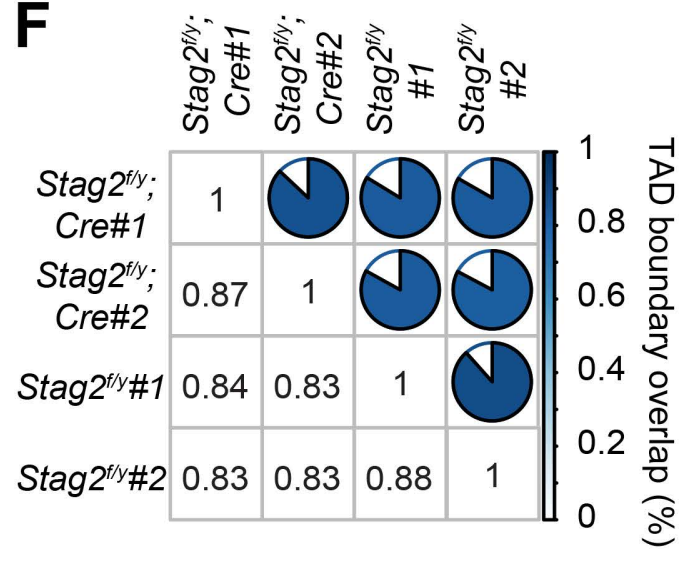

Stag $2^{\text {fyy}} ; \mathrm{Cre}$

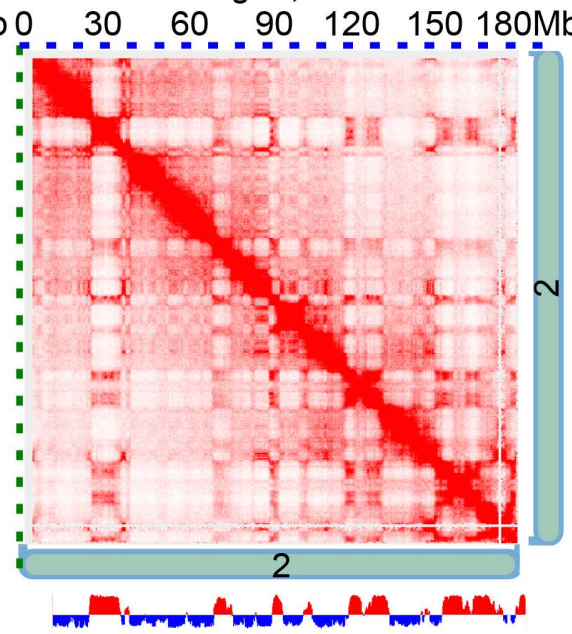

D

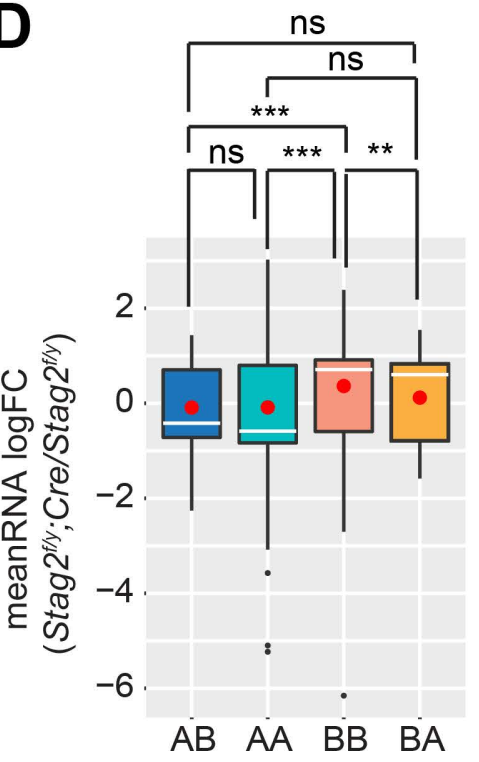

G

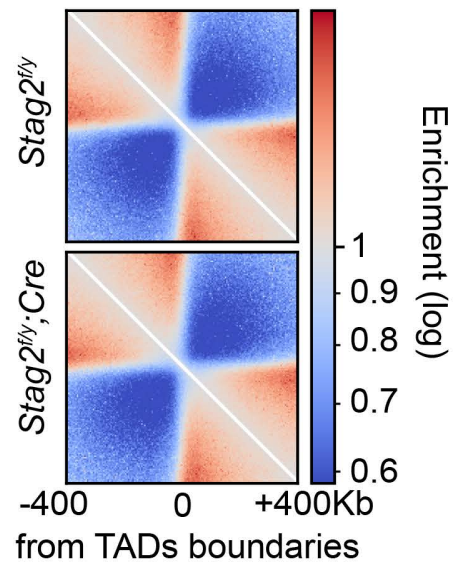

B

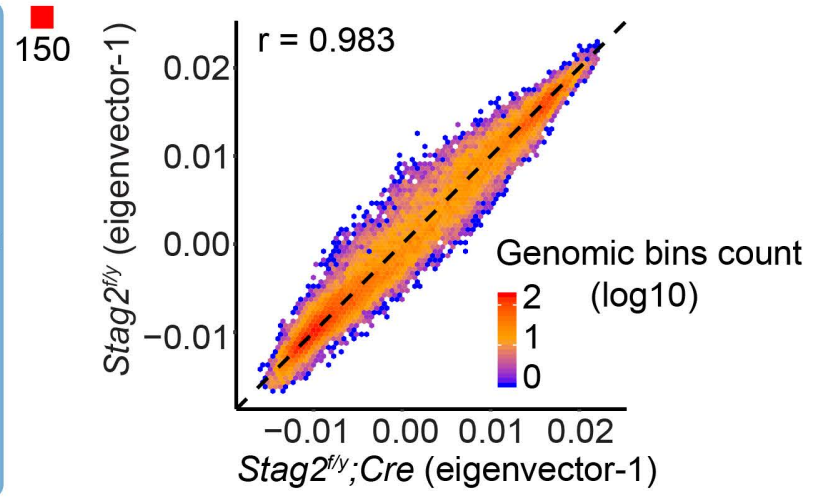

E

PCA by insulation score

Switch

当 $A B$

它 $A A$

BB

BA

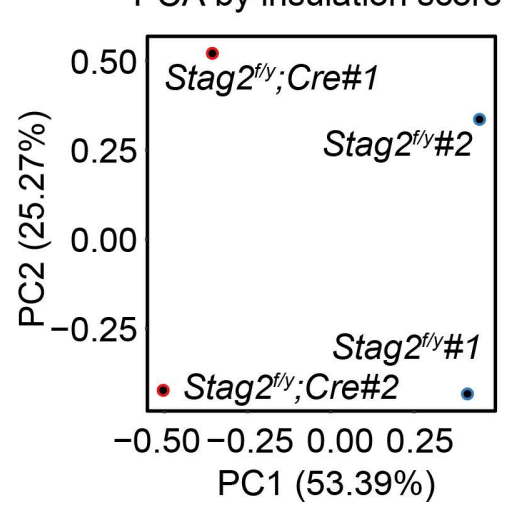

H

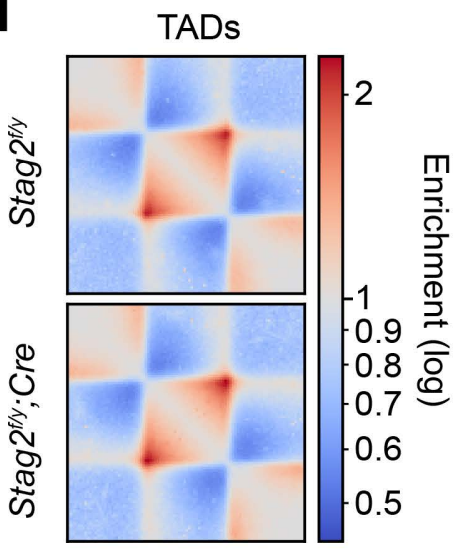


A

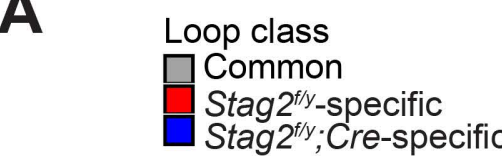

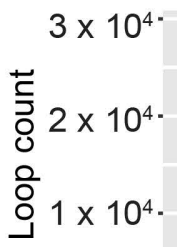

0

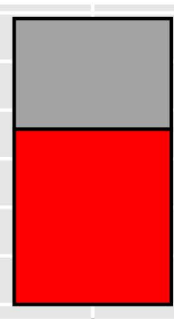

Stag $^{\text {fy }}$ Stag2 $2^{\text {fy }} ;$ Cre Median $320 \quad 410 \quad 560$

(kb)

D
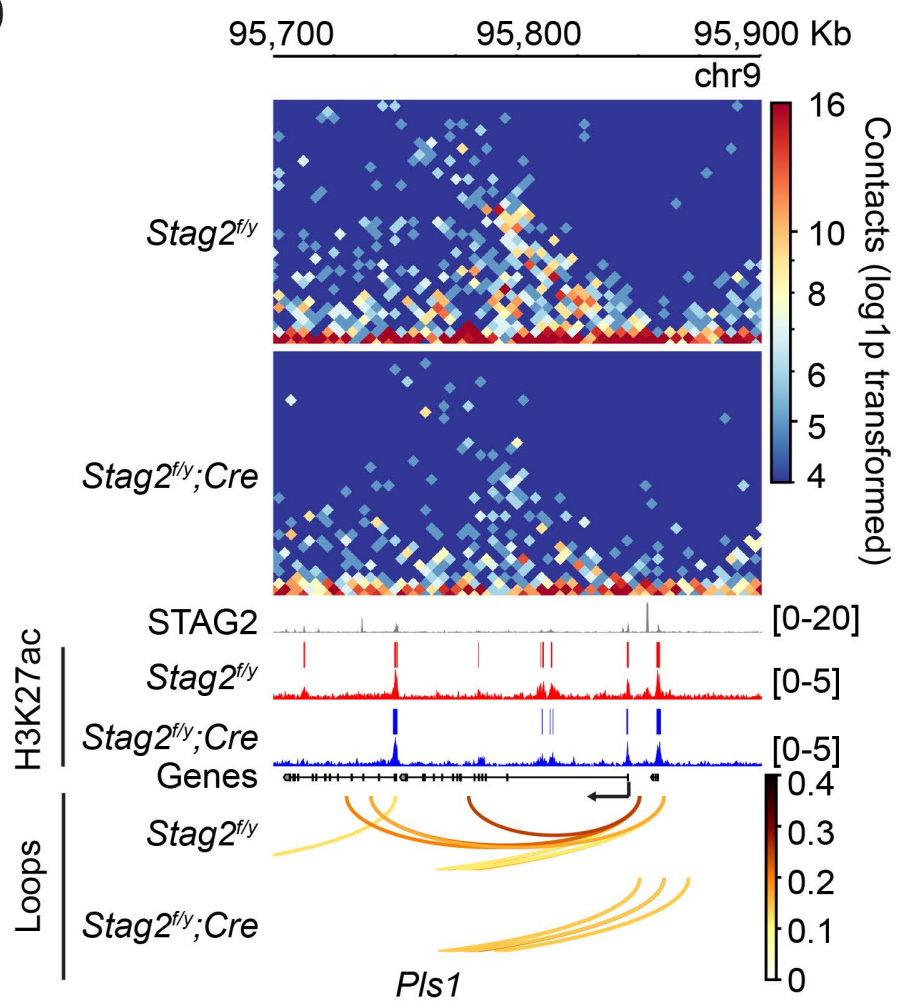

B
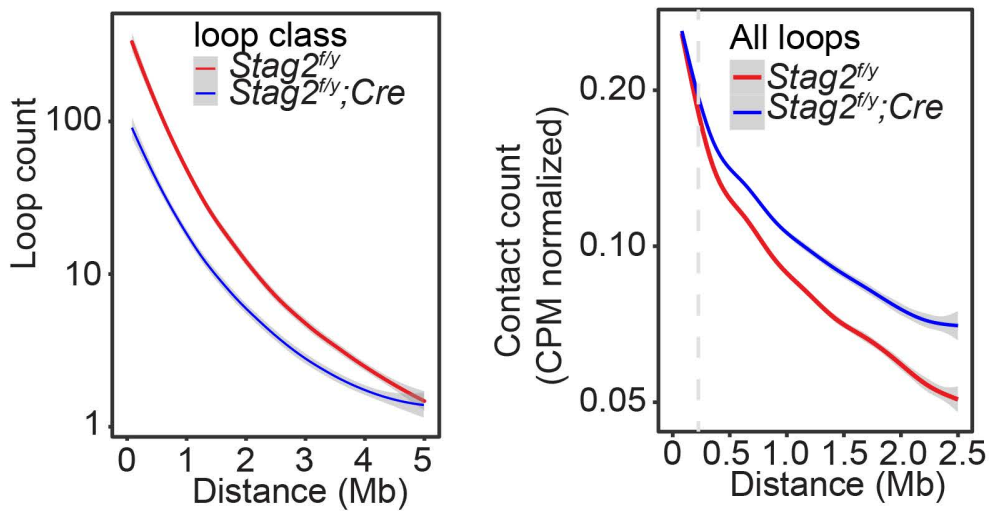

E
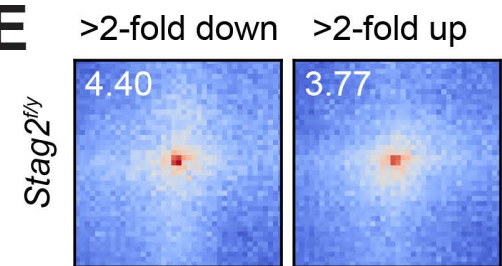

Less than $30 \%$ change
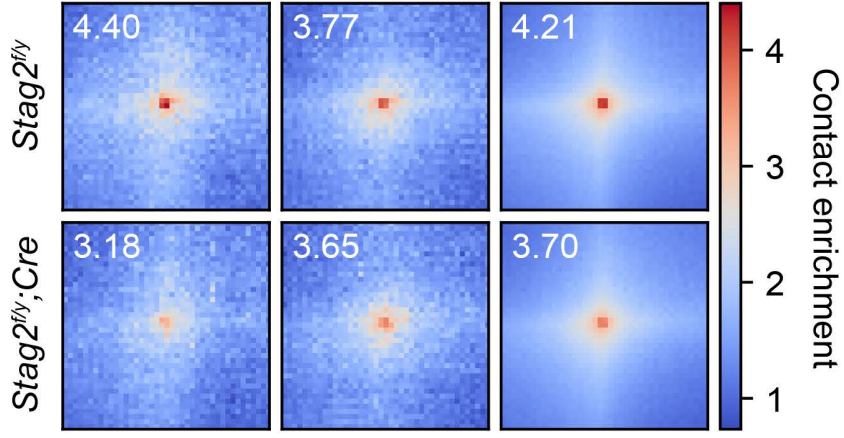

$-100 \quad 0+100 \mathrm{~Kb}$

F $>1.5$-fold down $>1.5$-fold up Less than $30 \%$ change

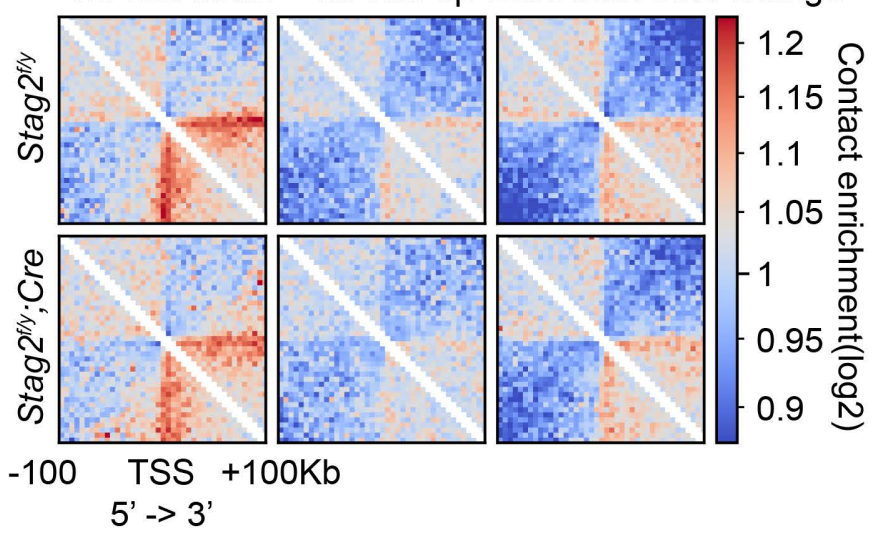


A

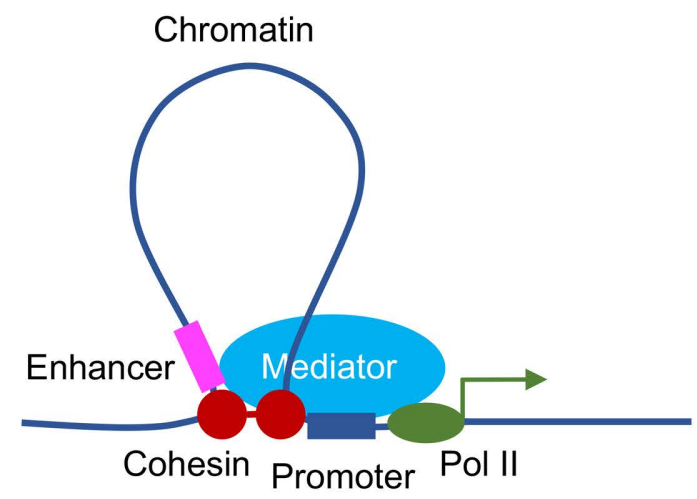

Promoter-enhancer loop
B

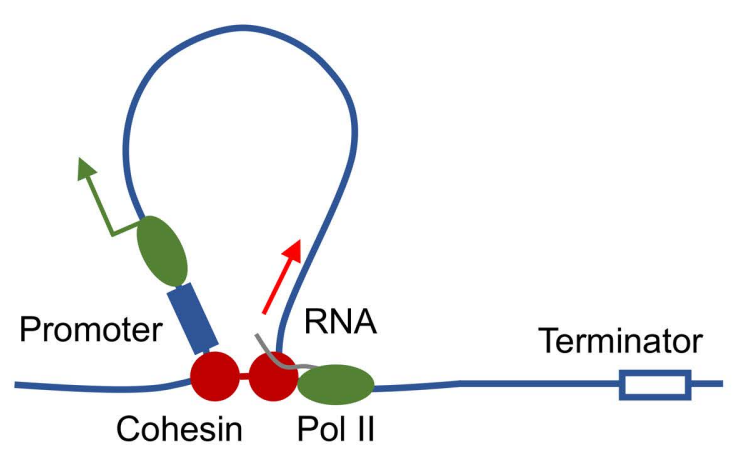

Promoter-gene loop
C

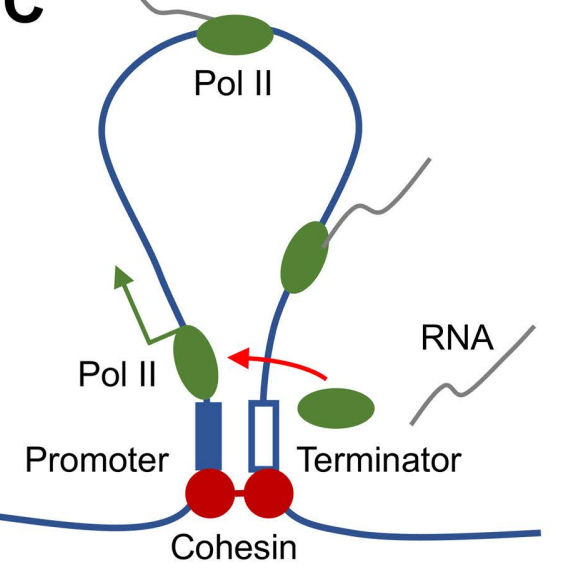

Gene loop

Figure 7 
KEY RESOURCES TABLE

\begin{tabular}{|c|c|c|}
\hline REAGENT or RESOURCE & SOURCE & IDENTIFIER \\
\hline \multicolumn{3}{|l|}{ Antibodies } \\
\hline Rabbit anti-STAG2 & In-house & $\mathrm{N} / \mathrm{A}$ \\
\hline Mouse anti- $\alpha-T U B U L I N$ & Sigma-Aldrich & $\begin{array}{l}\text { T9026, } \\
\text { RRID:AB_477593 }\end{array}$ \\
\hline Rabbit anti-STAG1 & Bethyl Laboratories & $\begin{array}{l}\text { A302-579A, } \\
\text { RRID:AB } 2034857\end{array}$ \\
\hline Rabbit anti-SMC1A & Bethyl Laboratories & $\begin{array}{l}\text { A300-055A, } \\
\text { RRID:AB } 2192467\end{array}$ \\
\hline Rabbit anti-SMC3 & Bethyl Laboratories & $\begin{array}{l}\text { A300-060A, } \\
\text { RRID:AB } 67579\end{array}$ \\
\hline Rabbit anti-RAD21 & Bethyl Laboratories & $\begin{array}{l}\text { A300-080a, } \\
\text { RRID:AB } 2176615\end{array}$ \\
\hline Rat anti-MBP & Abcam & $\begin{array}{l}\text { ab7349, } \\
\text { RRID:AB_305869 }\end{array}$ \\
\hline Rabbit anti-PLP1 & Abcam & $\begin{array}{l}\text { ab28486, } \\
\text { RRID:AB } 776593\end{array}$ \\
\hline Rabbit anti-H3K27ac & Abcam & $\begin{array}{l}\text { ab4729, } \\
\text { RRID:AB } 2118291\end{array}$ \\
\hline Mouse anti-O4 MicroBeads & Miltenyi Biotec & $\begin{array}{l}\text { 130-094-543, } \\
\text { RRID:AB } 2847907\end{array}$ \\
\hline Goat anti-rabbit IgG $(\mathrm{H}+\mathrm{L})$ (DyLight 800 Conjugate) & $\begin{array}{l}\text { Cell Signaling } \\
\text { Technology }\end{array}$ & $\begin{array}{l}\text { 5151S, } \\
\text { RRID:AB } 10697505\end{array}$ \\
\hline Goat anti-mouse lgG $(\mathrm{H}+\mathrm{L})$ (DyLight 680 Conjugate) & $\begin{array}{l}\text { Cell Signaling } \\
\text { Technology }\end{array}$ & $\begin{array}{l}\text { 5470S, } \\
\text { AB_10696895 }\end{array}$ \\
\hline Goat anti-rat lgG $(\mathrm{H}+\mathrm{L})$ Alexa Fluor 568 & $\begin{array}{l}\text { Thermo Fisher } \\
\text { Scientific }\end{array}$ & $\begin{array}{l}\text { A-11077, } \\
\text { RRID:AB } 2534121\end{array}$ \\
\hline Goat anti-rabbit IgG $(\mathrm{H}+\mathrm{L})$ Alexa Fluor 488 & $\begin{array}{l}\text { Thermo Fisher } \\
\text { Scientific }\end{array}$ & $\begin{array}{l}\text { A-11008, } \\
\text { RRID:AB_143165 }\end{array}$ \\
\hline \multicolumn{3}{|l|}{ Chemicals, peptides, and recombinant proteins } \\
\hline Papain & $\begin{array}{l}\text { Worthington } \\
\text { Biochemical }\end{array}$ & LS003119 \\
\hline Deoxyribonuclease I & $\begin{array}{l}\text { Worthington } \\
\text { Biochemical }\end{array}$ & LS002007 \\
\hline Insulin & Sigma-Aldrich & 16634 \\
\hline Biotin & Sigma-Aldrich & B4639 \\
\hline L-Glutamine & Gibco & $25030-164$ \\
\hline N-Acetyl-L-cysteine & Sigma-Aldrich & A8199 \\
\hline Forskolin & Sigma-Aldrich & F6886 \\
\hline CNTF & PeproTECH & $450-13$ \\
\hline PDGF-AA & PeproTECH & $100-13 A$ \\
\hline NT-3 & PeproTECH & $450-03$ \\
\hline Sarkosyl & Sigma-Aldrich & L7414 \\
\hline Apo-transferrin & Sigma-Aldrich & T1147 \\
\hline Putrescine & Sigma-Aldrich & P5780 \\
\hline Progesterone & Sigma-Aldrich & P8783 \\
\hline Sodium selenite & Sigma-Aldrich & S5261 \\
\hline DAPI & Sigma-Aldrich & D9564 \\
\hline Xylenes & Fisher Scientific & X3S-4 \\
\hline Paraformaldehyde & Sigma-Aldrich & 158127 \\
\hline
\end{tabular}




\begin{tabular}{|c|c|c|}
\hline Tamoxifen & Sigma-Aldrich & T5648 \\
\hline (Z)-4-Hydroxytamoxifen & Sigma-Aldrich & $\mathrm{H} 7904$ \\
\hline UTPaS, [35S] & Perkin Elmer & NEG039H \\
\hline \multicolumn{3}{|l|}{ Critical commercial assays } \\
\hline DNeasy Blood \& Tissue Kit & Qiagen & 69506 \\
\hline Precellys lysing kit (Soft tissue homogenizing) & Bertin Instruments & P000912-LYSK0-A.0 \\
\hline Mouse/rat IGF1 Quantikine ELISA kit & R\&D systems & MG100 \\
\hline Rat/Mouse Growth Hormone ELISA kit & EMD Millipore & EZRMGH-45K \\
\hline PCR Purification Kit & Qiagen & 28106 \\
\hline Papain Dissociation System & $\begin{array}{l}\text { Worthington } \\
\text { Biochemical }\end{array}$ & LK003150 \\
\hline TruSeq Stranded mRNA Library Prep kit & IIllumina & 20020594 \\
\hline High-Capacity cDNA Reverse Transcription kit & Applied Biosystems & 4368814 \\
\hline TaqMan Gene Expression Master Mix & Applied Biosystems & 4369016 \\
\hline Chromium Single Cell 3' GEM, Library \& Gel Bead Kit v3 & 10x Genomics & 1000092 \\
\hline KAPA HyperPrep Kits & Kapa Biosystems & KK8503 \\
\hline Next Gen DNA Library Kit & Active Motif & 53216 \\
\hline Next Gen Indexing Kit & Active Motif & 53264 \\
\hline Arima-HiC Kit & Arima Genomics & 510008 \\
\hline \multicolumn{3}{|l|}{ Deposited data } \\
\hline RNA-seq, scRNA-seq, ChIP-seq and Hi-C data & This study & GEOXXX \\
\hline \multicolumn{3}{|l|}{ Experimental models: Organisms/strains } \\
\hline Mouse: Stag2 -/+ & This study & N/A \\
\hline Mouse: Stag2 flox/flox & This study & $\mathrm{N} / \mathrm{A}$ \\
\hline Mouse: FVB/NJ & $\begin{array}{l}\text { The Jackson } \\
\text { Laboratory }\end{array}$ & $\begin{array}{l}\text { 001800, } \\
\text { RRID:IMSR_JAX:00 } \\
1800\end{array}$ \\
\hline Mouse: C57BL/6J & $\begin{array}{l}\text { The Jackson } \\
\text { Laboratory }\end{array}$ & $\begin{array}{l}\text { 000664, } \\
\text { RRID:IMSR_JAX:00 } \\
0664\end{array}$ \\
\hline Mouse: B6.129-Gt(ROSA)26Sortm1(cre/ERT2)Tyj/J & $\begin{array}{l}\text { The Jackson } \\
\text { Laboratory }\end{array}$ & $\begin{array}{l}\text { 008463, } \\
\text { RRID:IMSR_JAX:00 } \\
8463\end{array}$ \\
\hline Mouse: B6.Cg-Tg(Nes-cre) $1 \mathrm{KIn} / \mathrm{J}$ & $\begin{array}{l}\text { The Jackson } \\
\text { Laboratory }\end{array}$ & $\begin{array}{l}003771, \\
\text { RRID:IMSR_JAX:00 } \\
3771\end{array}$ \\
\hline \multicolumn{3}{|l|}{ Oligonucleotides } \\
\hline TaqMan Gene Expression Assay: Stag2 & $\begin{array}{l}\text { Thermo Fisher } \\
\text { Scientific }\end{array}$ & Mm01311611_m1 \\
\hline TaqMan Gene Expression Assay: Klk6 & $\begin{array}{l}\text { Thermo Fisher } \\
\text { Scientific }\end{array}$ & Mm00478322_m1 \\
\hline TaqMan Gene Expression Assay: Ninj2 & $\begin{array}{l}\text { Thermo Fisher } \\
\text { Scientific }\end{array}$ & Mm00450216_m1 \\
\hline TaqMan Gene Expression Assay: Cpm & $\begin{array}{l}\text { Thermo Fisher } \\
\text { Scientific }\end{array}$ & Mm01250802_m1 \\
\hline TaqMan Gene Expression Assay: Fa2h & $\begin{array}{l}\text { Thermo Fisher } \\
\text { Scientific }\end{array}$ & Mm00626259_m1 \\
\hline TaqMan Gene Expression Assay: Gapdh & $\begin{array}{l}\text { Thermo Fisher } \\
\text { Scientific }\end{array}$ & Mm99999915_g1 \\
\hline $\begin{array}{l}\text { Primers containing sgRNAs target sequences on Stag2 } \\
\text { (Table 1) }\end{array}$ & $\begin{array}{l}\text { Integrated DNA } \\
\text { Technologies }\end{array}$ & $\mathrm{N} / \mathrm{A}$ \\
\hline
\end{tabular}


bioRxiv preprint doi: https://doi.org/10.1101/2021.10.10.463866: this version posted November 4. 2021. The copvriaht holder for this preprint (which was not certified by peer review) is the author/funder, who has granted bioRxiv a license to display the preprint in perpetuity. It is made available under aCC-BY-NC-ND 4.0 International license.

\begin{tabular}{|c|c|c|}
\hline Primers for the Stag2 flox/flox mice genotyping (Table 1) & $\begin{array}{l}\text { Integrated DNA } \\
\text { Technologies }\end{array}$ & $\mathrm{N} / \mathrm{A}$ \\
\hline $\begin{array}{l}\text { Primers for the constructs for the riboprobe synthesis } \\
\text { (Table 1) }\end{array}$ & $\begin{array}{l}\text { Integrated DNA } \\
\text { Technologies }\end{array}$ & $\mathrm{N} / \mathrm{A}$ \\
\hline \multicolumn{3}{|l|}{ Software and algorithms } \\
\hline GraphPad Prism & GraphPad Software & $\begin{array}{l}\text { RRID:SCR_002798, } \\
\text { https://www.graphpa } \\
\text { d.com/scientific- } \\
\text { software/prism/ }\end{array}$ \\
\hline ImageJ (Fiji) & ImageJ & $\begin{array}{l}\text { RRID:SCR_002285, } \\
\text { https://imagej.net/sof } \\
\text { tware/fiji/ }\end{array}$ \\
\hline RStudio & The R Foundation & $\begin{array}{l}\text { RRID:SCR_000432, } \\
\text { https://www.rstudio.c } \\
\text { om// }\end{array}$ \\
\hline Bcl2fastq & Illumina & $\begin{array}{l}\text { v2.17, } \\
\text { RRID:SCR_015058 }\end{array}$ \\
\hline Fastqc & (Andrews, 2010) & $\begin{array}{l}\text { V0.11.2, } \\
\text { RRID:SCR_014583 }\end{array}$ \\
\hline Fastq_screen & (Wingett, 2011) & $\begin{array}{l}\text { v0.4.4, } \\
\text { RRID:SCR } 000141\end{array}$ \\
\hline STAR & (Dobin et al., 2013) & $\begin{array}{l}\text { RRID:SCR_004463, } \\
\text { https://github.com/al } \\
\text { exdobin/STAR }\end{array}$ \\
\hline FeatureCounts & (Liao et al., 2014) & $\begin{array}{l}\text { RRID:SCR_012919, } \\
\text { https://bioconductor. } \\
\text { org/packages/releas } \\
\text { e/bioc/html/Rsubrea } \\
\text { d.html }\end{array}$ \\
\hline edgeR & (Robinson et al., 2010) & $\begin{array}{l}\text { RRID:SCR_012802, } \\
\text { https://bioconductor. } \\
\text { org/packages/releas } \\
\text { e/bioc/html/edgeR.ht } \\
\mathrm{ml}\end{array}$ \\
\hline Ingenuity Pathway Analysis & $\begin{array}{l}\text { QIAGEN, (Kramer et } \\
\text { al., 2014) }\end{array}$ & $\begin{array}{l}\text { RRID:SCR_008653, } \\
\text { https://www.qiagenbi } \\
\text { oinformatics.com/pro } \\
\text { ducts/ingenuity- } \\
\text { pathway-analysis }\end{array}$ \\
\hline Bowtie2 & $\begin{array}{l}\text { (Langmead and } \\
\text { Salzberg, 2012) }\end{array}$ & $\begin{array}{l}\text { v2.2.3, } \\
\text { RRID:SCR_016368 }\end{array}$ \\
\hline Picard MarkDuplicates & $\begin{array}{l}\text { Broad Institute, GitHub } \\
\text { Repository, } \\
\text { http://broadinstitute.git } \\
\text { hub.io/picard/ }\end{array}$ & $\begin{array}{l}\text { V1.127 } \\
\text { RRID:SCR_006525 }\end{array}$ \\
\hline MACS2 & (Zhang et al., 2008) & $\begin{array}{l}\text { v2.0.10, } \\
\text { RRID:SCR_013291 }\end{array}$ \\
\hline HOMER & $\begin{array}{l}\text { (Heinz et al., 2010; } \\
\text { Ross-Innes et al., } \\
\text { 2012) }\end{array}$ & $\begin{array}{l}\text { RRID:SCR_010881, } \\
\text { http://homer.ucsd.ed } \\
\text { u/homer/ }\end{array}$ \\
\hline Deeptools & (Ramirez et al., 2016) & $\begin{array}{l}\text { RRID:SCR_016366, } \\
\text { https://deeptools.rea } \\
\text { dthedocs.io/en/devel } \\
\text { op/ }\end{array}$ \\
\hline
\end{tabular}




\begin{tabular}{|c|c|c|}
\hline Galaxy & (Afgan et al., 2018) & $\begin{array}{l}\text { RRID:SCR_006281, } \\
\text { https://usegalaxy.org }\end{array}$ \\
\hline Cell Ranger & 10x Genomics & $\begin{array}{l}\text { RRID:SCR_017344, } \\
\text { https://support.10xge } \\
\text { nomics.com/single- } \\
\text { cell-gene- } \\
\text { expression/software/ } \\
\text { pipelines/latest/using } \\
\text { /mkfastq }\end{array}$ \\
\hline Seurat & $\begin{array}{l}\text { Satija Lab, New York } \\
\text { Genome Center, } \\
\text { (Stuart et al., 2019) }\end{array}$ & $\begin{array}{l}\text { RRID:SCR_016341, } \\
\text { https://satijalab.org/s } \\
\text { eurat }\end{array}$ \\
\hline Monocle3 & $\begin{array}{l}\text { Cole Trapnell's Lab, } \\
\text { UW Genome } \\
\text { Sciences, (Cao et al., } \\
\text { 2019) }\end{array}$ & $\begin{array}{l}\text { RRID:SCR_018685, } \\
\text { https://cole-trapnell- } \\
\text { lab.github.io/monocl } \\
\text { e3/ }\end{array}$ \\
\hline HiC-Bench pipeline & $\begin{array}{l}\text { (Lazaris et al., 2017; } \\
\text { Tsirigos et al., 2012) }\end{array}$ & $\begin{array}{l}\text { https://github.com/N } \\
\text { YU-BFX/hic-bench }\end{array}$ \\
\hline Juicer "pre" tool & $\begin{array}{l}\text { Aiden Lab, (Durand et } \\
\text { al., 2016) }\end{array}$ & $\begin{array}{l}\text { RRID:SCR_017226, } \\
\text { https://github.com/ai } \\
\text { denlab/juicer }\end{array}$ \\
\hline Juicebox & Aiden Lab, BCM & $\begin{array}{l}\text { RRID:SCR_021172, } \\
\text { https://github.com/ai } \\
\text { denlab/Juicebox }\end{array}$ \\
\hline Hic2cool & $\begin{array}{l}\text { (Abdennur and Mirny, } \\
2020 \text { ) }\end{array}$ & $\begin{array}{l}\text { https://github.com/4d } \\
\text { n-dcic/hic2cool }\end{array}$ \\
\hline pyGenomeTracks & $\begin{array}{l}\text { (Lopez-Delisle et al., } \\
\text { 2020) }\end{array}$ & $\begin{array}{l}\text { https://github.com/de } \\
\text { eptools/pyGenomeTr } \\
\text { acks }\end{array}$ \\
\hline Fit-HiC & (Ay et al., 2014) & $\begin{array}{l}\text { https://github.com/ay } \\
\text {-lab/fithic }\end{array}$ \\
\hline Coolpup.py & (Flyamer et al., 2020) & $\begin{array}{l}\text { https://github.com/op } \\
\text { en2c/coolpuppy }\end{array}$ \\
\hline \multicolumn{3}{|l|}{ Other } \\
\hline Precellys Minilys Tissue homogenizer & Bertin Instruments & $\begin{array}{l}\text { EQ06404.200.RD00 } \\
0.0\end{array}$ \\
\hline Odyssey Infrared Imaging System & LI-COR & 9140 \\
\hline LS Columns & Miltenyi Biotec & $130-042-401$ \\
\hline MidiMACS separator & Miltenyi Biotec & $130-042-302$ \\
\hline MACS MultiStand & Miltenyi Biotec & $130-042-303$ \\
\hline Dynabeads Protein A & Invitrogen & 10002D \\
\hline Phenol:chloroform:isoamyl Alcohol 25:24:1 & Sigma-Aldrich & P3803 \\
\hline Chloroform:Isoamyl alcohol 24:1 & Sigma-Aldrich & C0549 \\
\hline ProLong Gold Antifade Mountant & Fisher Scientific & P36934 \\
\hline Proteinase $\mathrm{K}$ & New England Biolabs & P8107S \\
\hline RNase A & Qiagen & 19101 \\
\hline Neurobasal Medium & $\begin{array}{l}\text { Thermo Fisher } \\
\text { Scientific }\end{array}$ & 21103049 \\
\hline DMEM & $\begin{array}{l}\text { Thermo Fisher } \\
\text { Scientific }\end{array}$ & $11965-118$ \\
\hline Penicillin-Streptomycin & $\begin{array}{l}\text { Thermo Fisher } \\
\text { Scientific }\end{array}$ & $15140-163$ \\
\hline Ambion TRIzol Reagent & Invitrogen & $15-596-018$ \\
\hline
\end{tabular}




\begin{tabular}{|l|l|l|}
\hline Complete, EDTA-free Protease Inhibitor Cocktail & Sigma-Aldrich & 5056489001 \\
\hline Formaldehyde solution & Sigma-Aldrich & F8775 \\
\hline B-27 Serum-Free Supplement & $\begin{array}{l}\text { Thermo Fisher } \\
\text { Scientific }\end{array}$ & 17504044 \\
\hline Trace Elements B & Corning & $25-022-\mathrm{Cl}$ \\
\hline Sodium Pyruvate & $\begin{array}{l}\text { Thermo Fisher } \\
\text { Scientific }\end{array}$ & $11360-070$ \\
\hline DPBS, calcium, magnesium & $\begin{array}{l}\text { Thermo Fisher } \\
\text { Scientific }\end{array}$ & 14040182 \\
\hline DPBS, no calcium, no magnesium & $\begin{array}{l}\text { Thermo Fisher } \\
\text { Scientific }\end{array}$ & 14190144 \\
\hline Bovine Serum Albumin & Sigma-Aldrich & A4161 \\
\hline
\end{tabular}

\section{References}

Abdennur, N., and Mirny, L.A. (2020). Cooler: scalable storage for Hi-C data and other genomically labeled arrays. Bioinformatics 36, 311-316.

Afgan, E., Baker, D., Batut, B., van den Beek, M., Bouvier, D., Cech, M., Chilton, J., Clements, D., Coraor, N., Gruning, B.A., et al. (2018). The Galaxy platform for accessible, reproducible and collaborative biomedical analyses: 2018 update. Nucleic Acids Res 46, W537-W544. Andrews, S. (2010). FastQC: a quality control tool for high throughput sequence data. Ay, F., Bailey, T.L., and Noble, W.S. (2014). Statistical confidence estimation for Hi-C data reveals regulatory chromatin contacts. Genome Res 24, 999-1011.

Cao, J., Spielmann, M., Qiu, X., Huang, X., Ibrahim, D.M., Hill, A.J., Zhang, F., Mundlos, S., Christiansen, L., Steemers, F.J., et al. (2019). The single-cell transcriptional landscape of mammalian organogenesis. Nature 566, 496-502.

Dobin, A., Davis, C.A., Schlesinger, F., Drenkow, J., Zaleski, C., Jha, S., Batut, P., Chaisson, M., and Gingeras, T.R. (2013). STAR: ultrafast universal RNA-seq aligner. Bioinformatics 29, $15-21$.

Durand, N.C., Shamim, M.S., Machol, I., Rao, S.S., Huntley, M.H., Lander, E.S., and Aiden, E.L. (2016). Juicer Provides a One-Click System for Analyzing Loop-Resolution Hi-C Experiments. Cell Syst 3, 95-98.

Flyamer, I.M., Illingworth, R.S., and Bickmore, W.A. (2020). Coolpup.py: versatile pile-up analysis of Hi-C data. Bioinformatics 36, 2980-2985.

Heinz, S., Benner, C., Spann, N., Bertolino, E., Lin, Y.C., Laslo, P., Cheng, J.X., Murre, C., Singh, H., and Glass, C.K. (2010). Simple combinations of lineage-determining transcription factors prime cis-regulatory elements required for macrophage and B cell identities. Mol Cell 38, 576-589.

Kramer, A., Green, J., Pollard, J., Jr., and Tugendreich, S. (2014). Causal analysis approaches in Ingenuity Pathway Analysis. Bioinformatics 30, 523-530.

Langmead, B., and Salzberg, S.L. (2012). Fast gapped-read alignment with Bowtie 2. Nat Methods 9, 357-359.

Lazaris, C., Kelly, S., Ntziachristos, P., Aifantis, I., and Tsirigos, A. (2017). HiC-bench: comprehensive and reproducible $\mathrm{Hi}-\mathrm{C}$ data analysis designed for parameter exploration and benchmarking. BMC Genomics 18, 22.

Liao, Y., Smyth, G.K., and Shi, W. (2014). featureCounts: an efficient general purpose program for assigning sequence reads to genomic features. Bioinformatics 30, 923-930. 
Lopez-Delisle, L., Rabbani, L., Wolff, J., Bhardwaj, V., Backofen, R., Gruning, B., Ramirez, F., and Manke, T. (2020). pyGenomeTracks: reproducible plots for multivariate genomic data sets. Bioinformatics.

Ramirez, F., Ryan, D.P., Gruning, B., Bhardwaj, V., Kilpert, F., Richter, A.S., Heyne, S., Dundar, F., and Manke, T. (2016). deepTools2: a next generation web server for deepsequencing data analysis. Nucleic Acids Res 44, W160-165.

Robinson, M.D., McCarthy, D.J., and Smyth, G.K. (2010). edgeR: a Bioconductor package for differential expression analysis of digital gene expression data. Bioinformatics 26, 139-140. Ross-Innes, C.S., Stark, R., Teschendorff, A.E., Holmes, K.A., Ali, H.R., Dunning, M.J., Brown, G.D., Gojis, O., Ellis, I.O., Green, A.R., et al. (2012). Differential oestrogen receptor binding is associated with clinical outcome in breast cancer. Nature 481, 389-393.

Stuart, T., Butler, A., Hoffman, P., Hafemeister, C., Papalexi, E., Mauck, W.M., 3rd, Hao, Y., Stoeckius, M., Smibert, P., and Satija, R. (2019). Comprehensive Integration of Single-Cell Data. Cell 177, 1888-1902 e1821.

Tsirigos, A., Haiminen, N., Bilal, E., and Utro, F. (2012). GenomicTools: a computational platform for developing high-throughput analytics in genomics. Bioinformatics 28, 282-283. Wingett, S. (2011). FastQ Screen: quality control tool to screen a library of sequences in FastQ format against a set of sequence databases. .

Zhang, Y., Liu, T., Meyer, C.A., Eeckhoute, J., Johnson, D.S., Bernstein, B.E., Nusbaum, C., Myers, R.M., Brown, M., Li, W., et al. (2008). Model-based analysis of ChIP-Seq (MACS). Genome Biol 9, R137. 


\section{Supplemental Information}

A

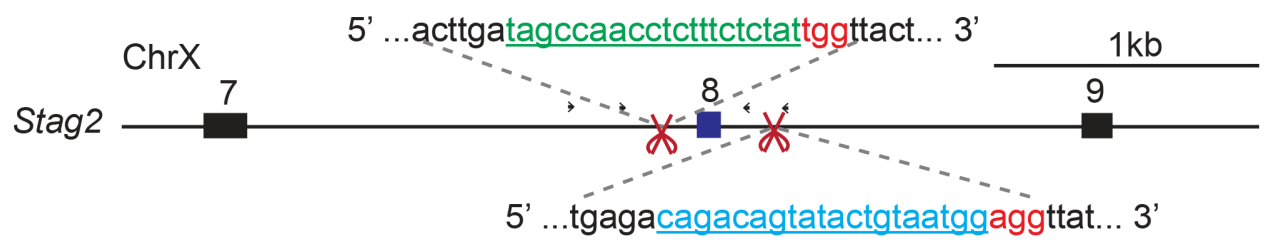

WT allele 5 ' ...tagccaacctcttctctattggttact...Exon8 ...tgagacagacagtatactgtaatggagg... 3'

Del \#1

Del \#2

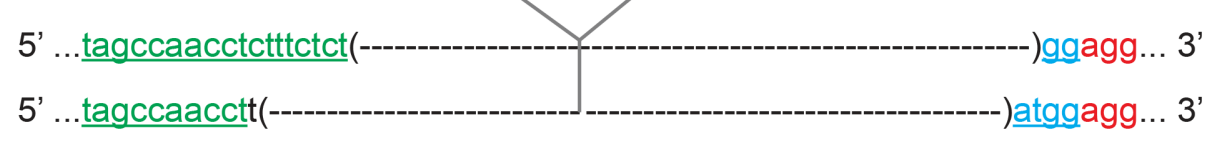

B
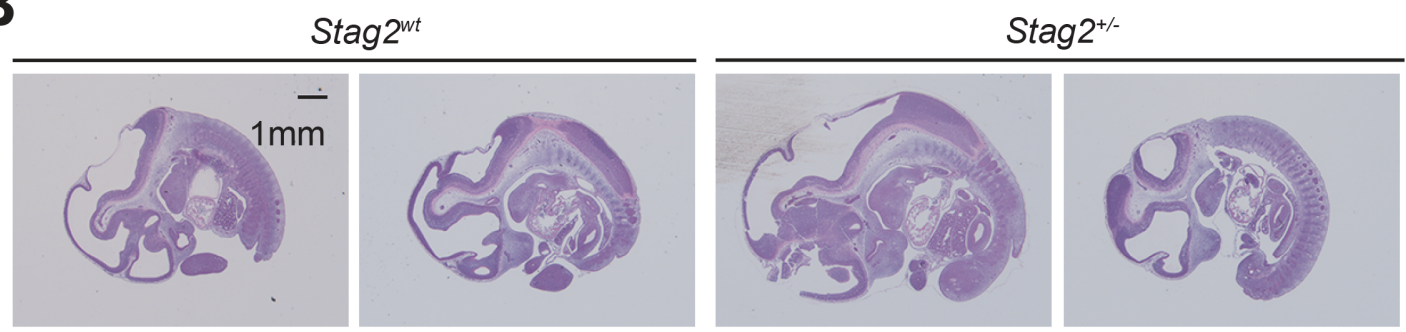

Stag $2^{\text {null }}$
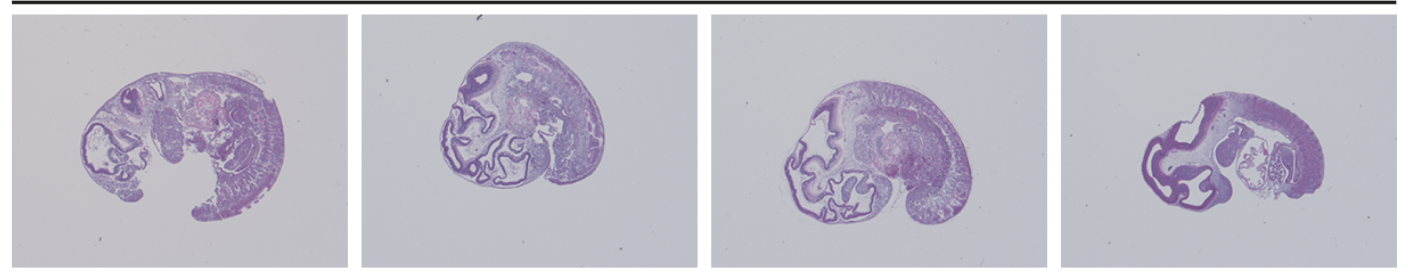

Figure S1. Generation of Stag2 knockout mice using the CRISPR/Cas9 method.

(A) Scheme for disrupting Stag2 in the mouse genome using CRISPR/Cas9 with guide RNAs flanking exon 8. Sequencing analysis of the genomic DNA extracted from two Stag2-disrupted founder mice is shown below.

(B) Hematoxylin and eosin (H\&E) staining of sagittal sections of F2 embryos derived from F1 in (A) at E11.5. 
A

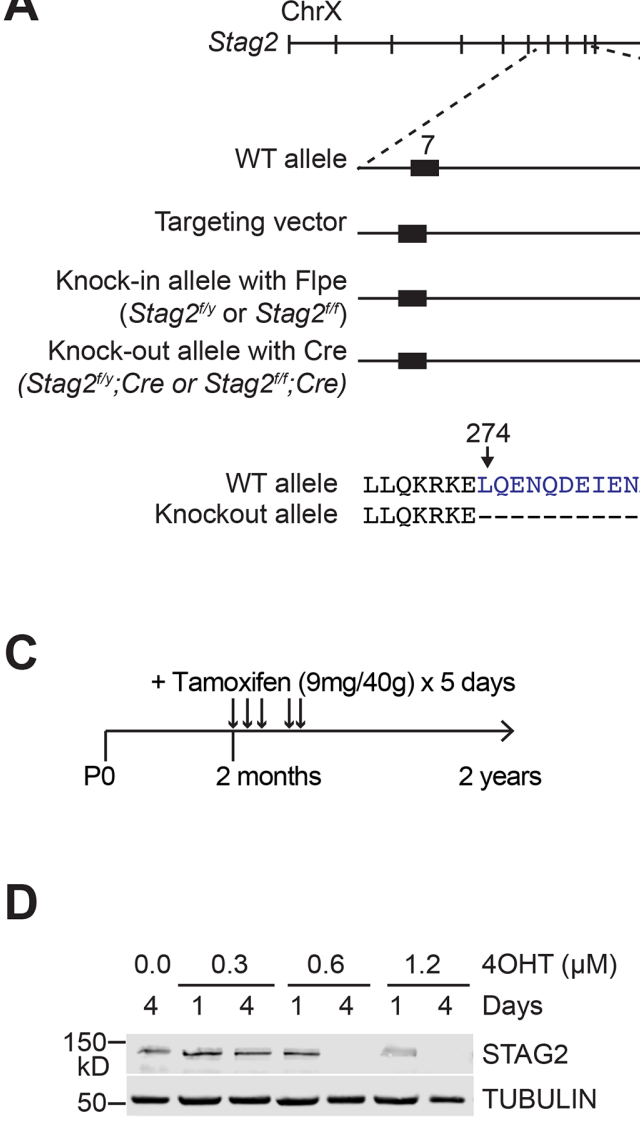

E

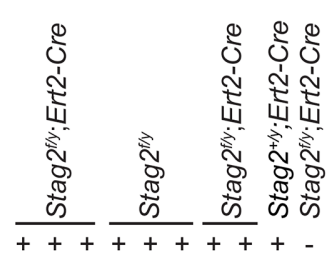

B

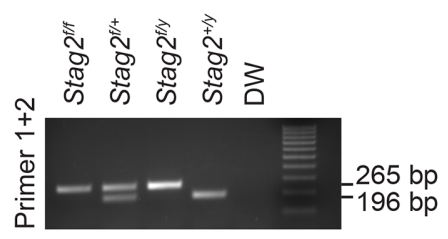

$\mathbf{F}$

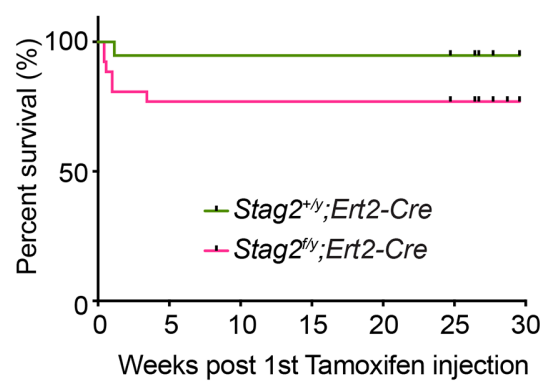

\section{G}

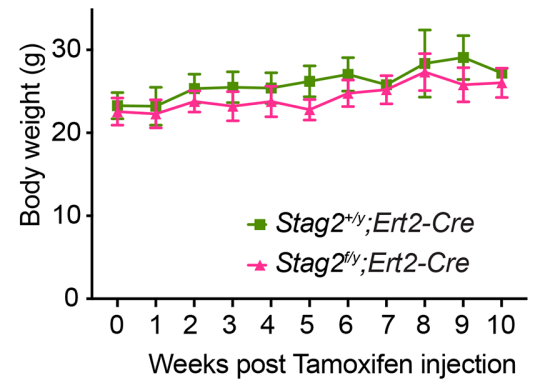

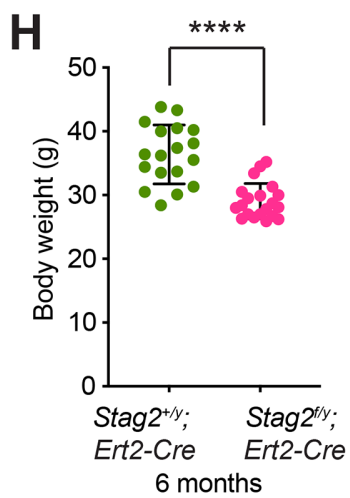

Figure S2. Generation of Stag2 conditional knockout mice by gene targeting.

(A) Scheme for creating the "floxed" Stag2 allele by gene targeting. The genomic structure of the wild-type (WT) Stag2 locus, the targeting vector, the knock-in allele, the disrupted allele after Cremediated recombination, and the positions of the genotyping primers are shown. The amino acid sequence of the knockout allele in the targeted region is shown and aligned with that of the WT allele.

(B) PCR analysis of the genomic DNA extracted from the tails of indicated mice with the primers in $(A)$. 
(C) Experimental scheme of tamoxifen injection into adult $\operatorname{Stag}_{2}^{f / y} ;$ Ert2-Cre and Stag $^{+/ y}$;Ert2-Cre mice.

(D) Western blotting of cell extracts from Stag2 ${ }^{f / y}$;Ert2-Cre mouse embryonic fibroblasts (MEF) treated with or without 4-hydroxytamoxifen (4OHT).

(E) PCR analysis of the genomic DNA extracted from the blood of indicated mice with the primers in (A).

(F) Survival curves of Stag2 $2^{f / y}$;Ert2-Cre $(\mathrm{n}=26)$ and $\operatorname{Stag}^{+/ y}$;Ert2-Cre $(\mathrm{n}=19)$ mice after tamoxifen injection.

(G) Body weight of mice in (F).

(H) Body weight of Stag $2^{f / y} ; \operatorname{Ert} 2-C r e(n=20)$ and $\operatorname{Stag}^{+/ y} ; \operatorname{Ert} 2-C r e(n=18)$ mice at 6 months post tamoxifen injection. $* * * *-\mathrm{p}<0.0001$. 

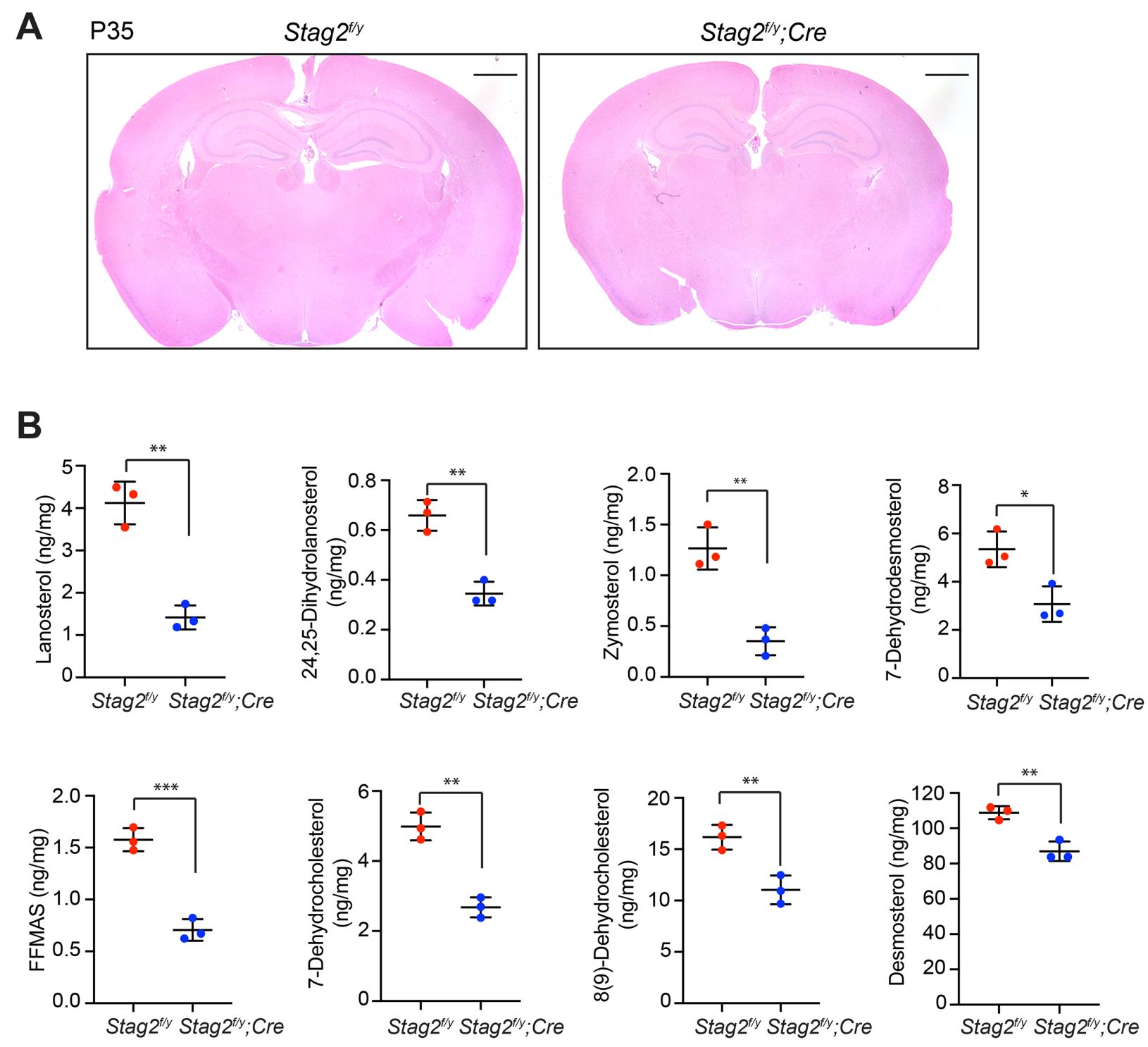

Figure S3. STAG2 deficiency in mouse brains attenuates cholesterol biosynthesis.

(A) H\&E staining of the coronal sections of Stag $2^{f / y}$ and $\operatorname{Stag} 2^{f / y}$;Cre mouse brains. Scale bar, 1 $\mathrm{mm}$.

(B) Mass spectrometry analysis of cholesterol precursors in Stag $2^{f / y}$ and Stag $2^{f / y}$;Cre brains. $\mathrm{n}=3$ mice per genotype. ${ }^{*} \mathrm{p}<0.05, * * \mathrm{p}<0.01, * * * \mathrm{p}<0.001$; Mean \pm SD. 

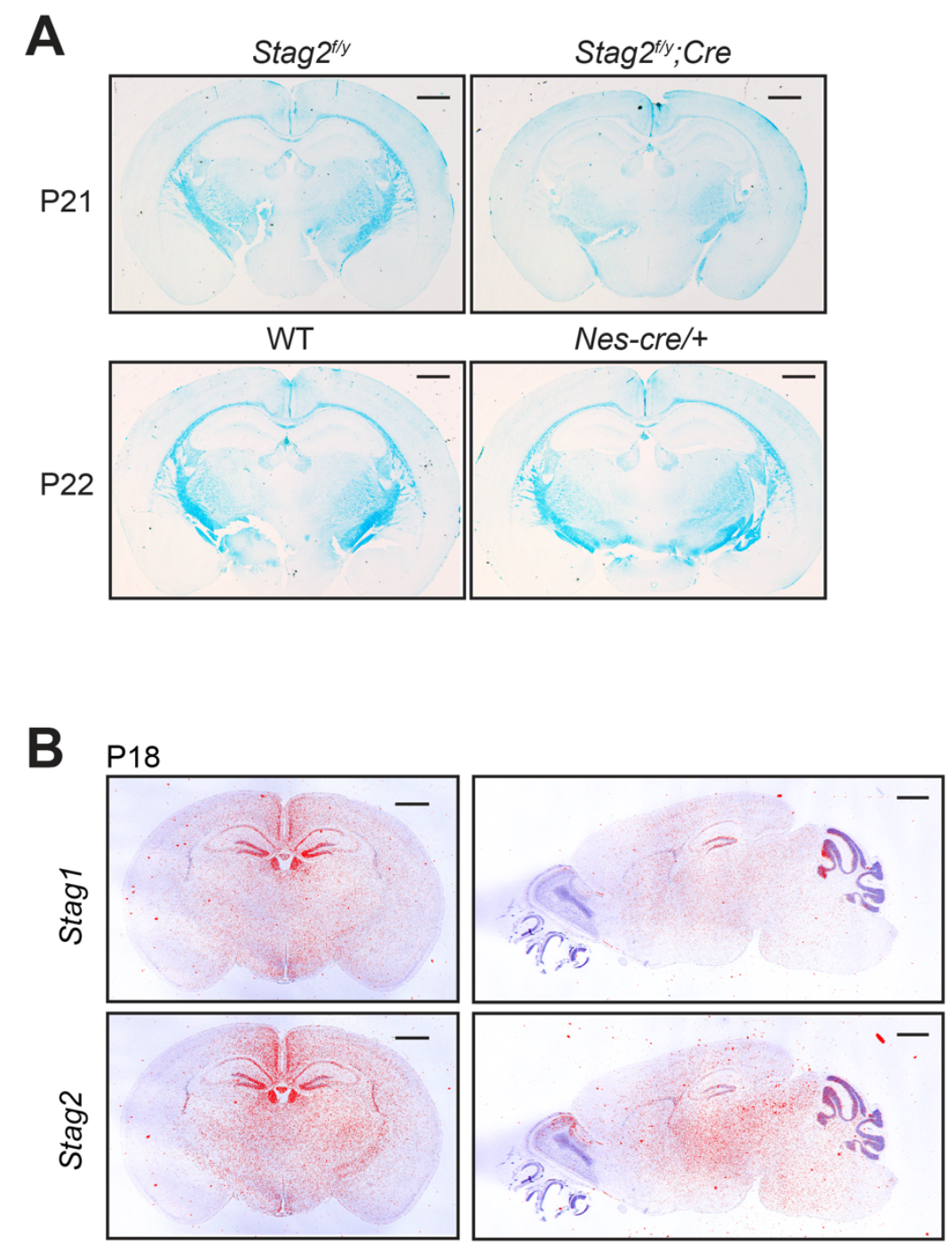

Figure S4. Brain-specific Stag2 deletion impairs CNS myelination.

(A) Luxol fast blue staining of the coronal brain sections of mice with the indicated genotypes. $n$ $=3$ mice each for Stag $2^{f / y}$ and Stag $2^{f / y}$;Cre genotypes. $\mathrm{n}=2$ mice each for WT and Nes-Cre/+ groups. animals per genotype. Scale bar $=1 \mathrm{~mm}$.

(B) In situ hybridization of ${ }^{35} \mathrm{~S}$-labeled RNA probes of the coronal (left) and sagittal (right) sections of WT mouse brains. Bright field images (purple) were overlaid with autoradiography images (red). Scale bar $=1 \mathrm{~mm}$. 

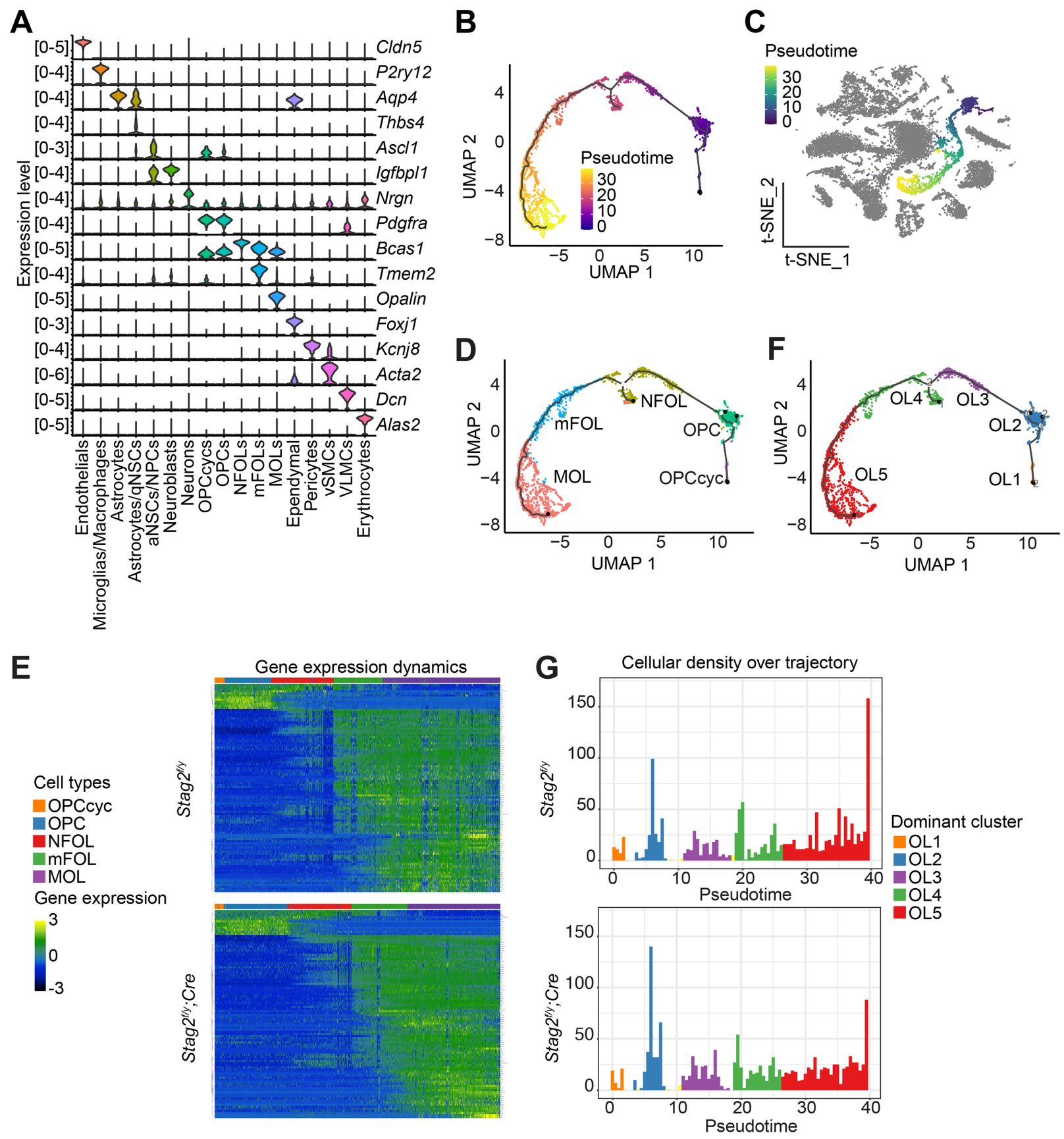

Figure S5. Stag2 deletion causes differentiation delay in the oligodendrocyte lineage.

(A) Violin plot of the expression levels of feature genes of the indicated brain cell types.

(B) Trajectory inference analysis of oligodendrocyte (OL) lineage cells extracted from the singlecell RNA-seq dataset using Monocle3. Cells are colored from purple to yellow by pseudotime variables.

(C) OL differentiation trajectory in the $t-S N E$ plot. The OL lineage is colored from navy blue to yellow by pseudotime variables. Cells of other lineages are colored grey.

(D) Distribution of the assigned OL cell types along the trajectory. 
(E) Heatmap of gene expression dynamics over pseudotime along the OL differentiation trajectory. Each row represents one of the top 100 most variable genes along pseudotime. Each column represents a single cell.

(F) Re-clustered OL subgroups in the trajectory inference analysis.

(G) Cell density across pseudotime for the OL differentiation trajectory. Dominant clusters for each pseudotime bin are color labeled as in (F). 


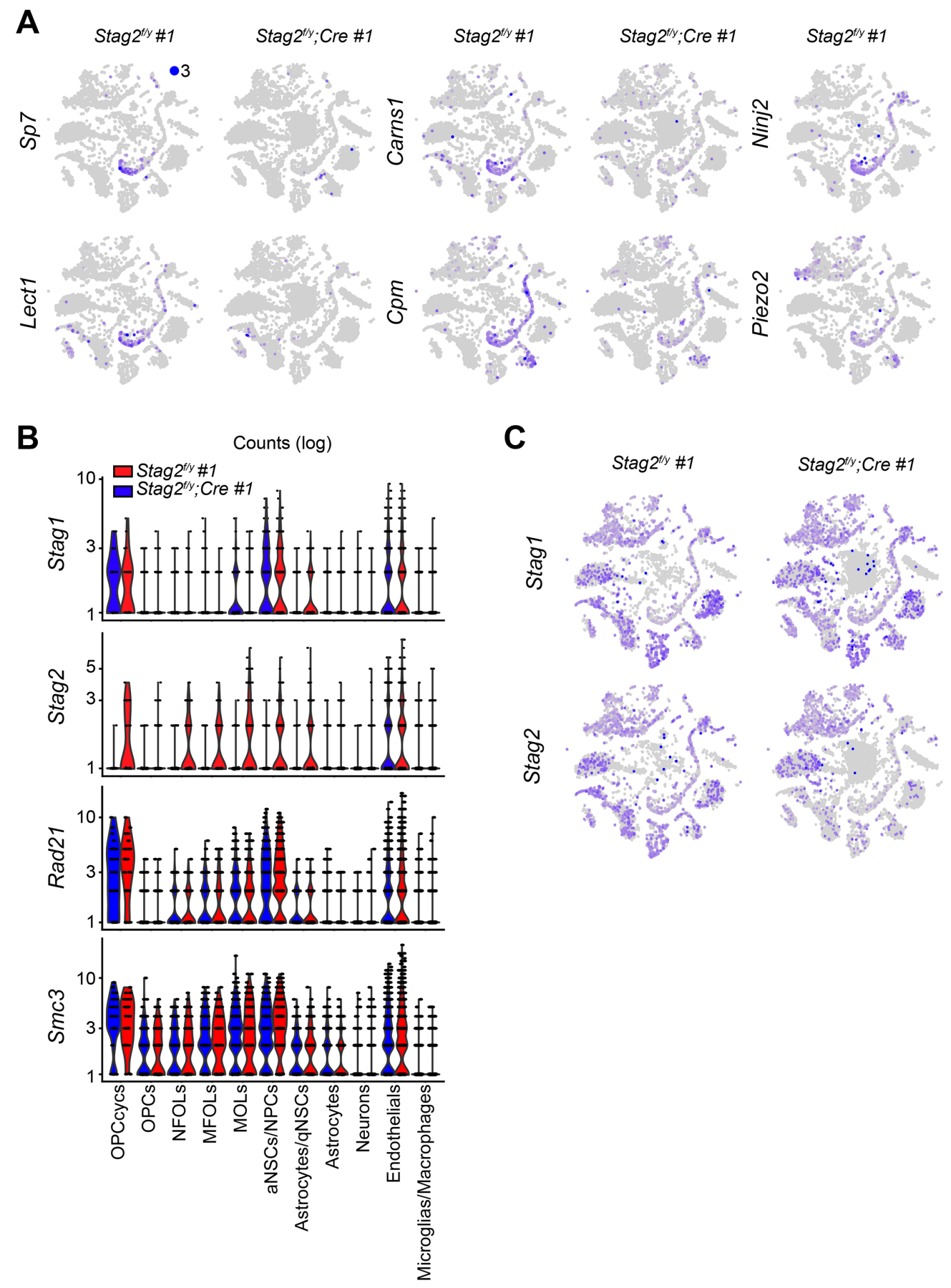

Figure S6. STAG2 regulates the transcription of oligodendrocyte genes.

(A) FeaturePlot of the expression levels of representative down-regulated genes in the $\mathrm{Stag} 2^{f / y}$; $\mathrm{Cre}$ whole brains. Maximum cutoff of 3 was used.

(B) Violin plot of the expression of cohesin subunit genes in the indicated brain cell types from the scRNA-seq transcriptome analysis.

(C) FeaturePlot of the expression of Stag1 and Stag2 in Stag $2^{f / y}$ and Stag $2^{f / y}$;Cre forebrains. Maximum cutoff of 3 was used. 
A

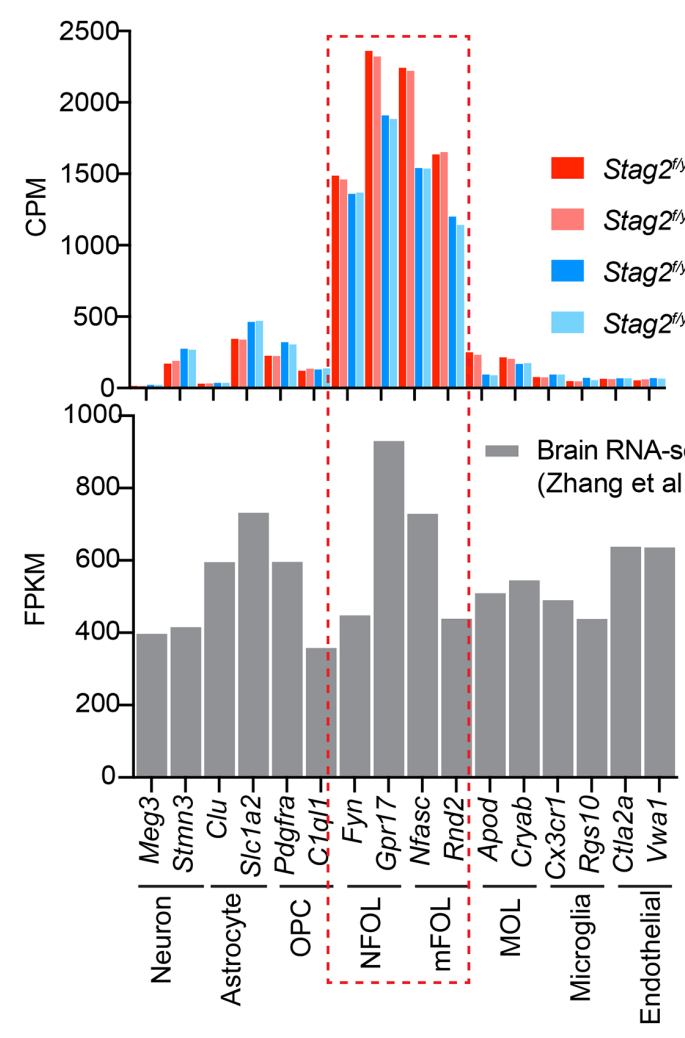

B
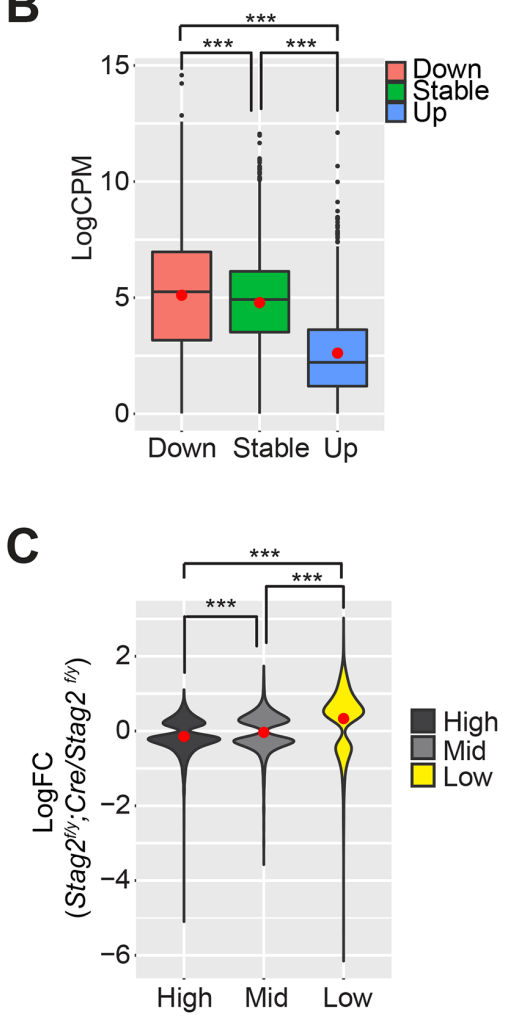

D

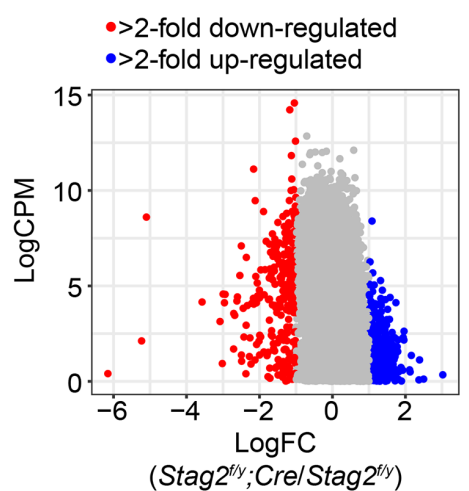

E

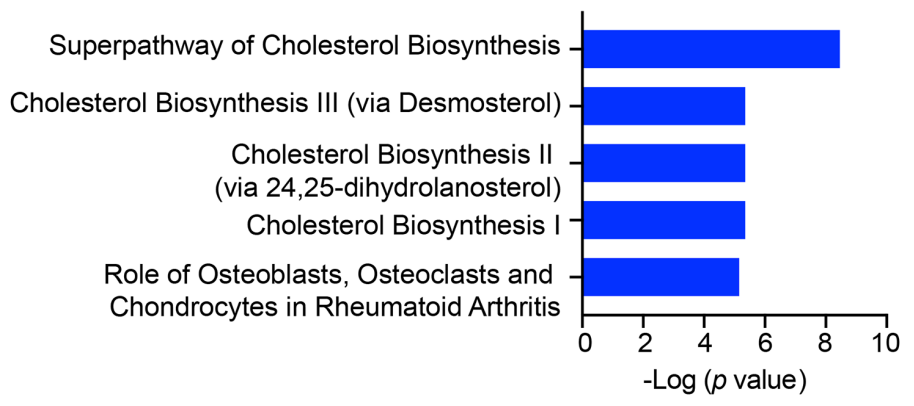

Figure S7. STAG2 regulates transcription in primary oligodendrocytes.

(A) The expression levels of signature genes of indicated brain cell types in the isolated primary oligodendrocytes (OLs) in this study. The expression levels of the same set of signature genes in the individually isolated cell types from previous studies are shown below. NFOL and mFOL signature genes are highly enriched in the isolated primary OLs in this study.

(B) Boxplot of the expression levels for genes in the indicated categories. Red dots represent the mean values. $* * * p<0.001$.

(C) Violin plot of the expression changes for the active genes with different expression levels. Red dots represent the mean value. $* * * p<0.001$.

(D) Scatter plot of the gene expression level against transcriptional changes.

(E) IPA analysis of the down-regulated gene sets. 
A

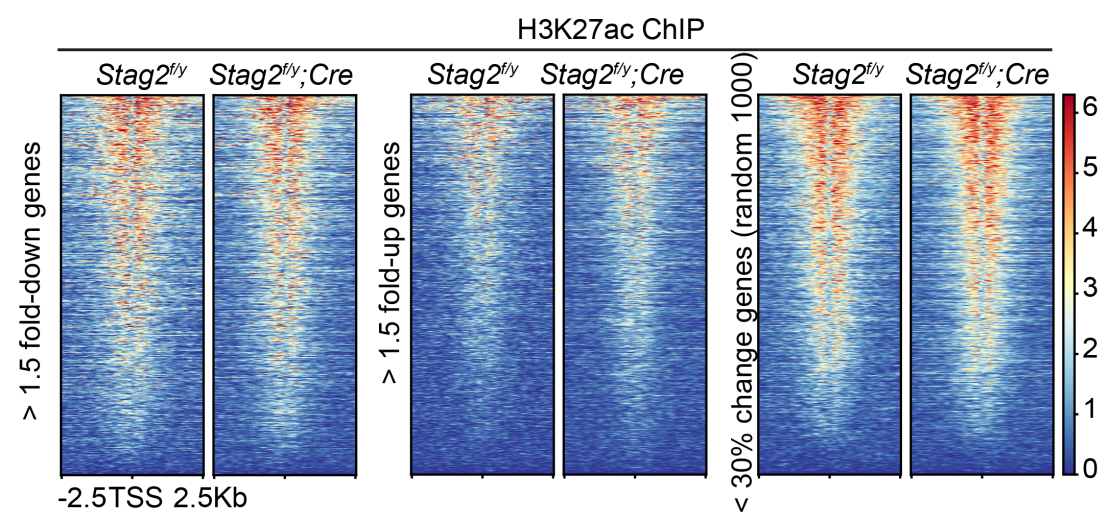

B

distance from TSS (bp)

C $=$ stable genes

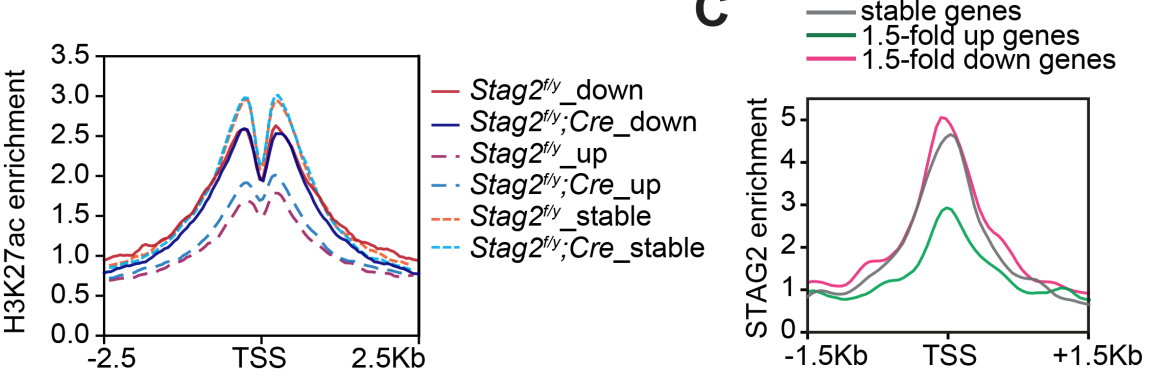

D

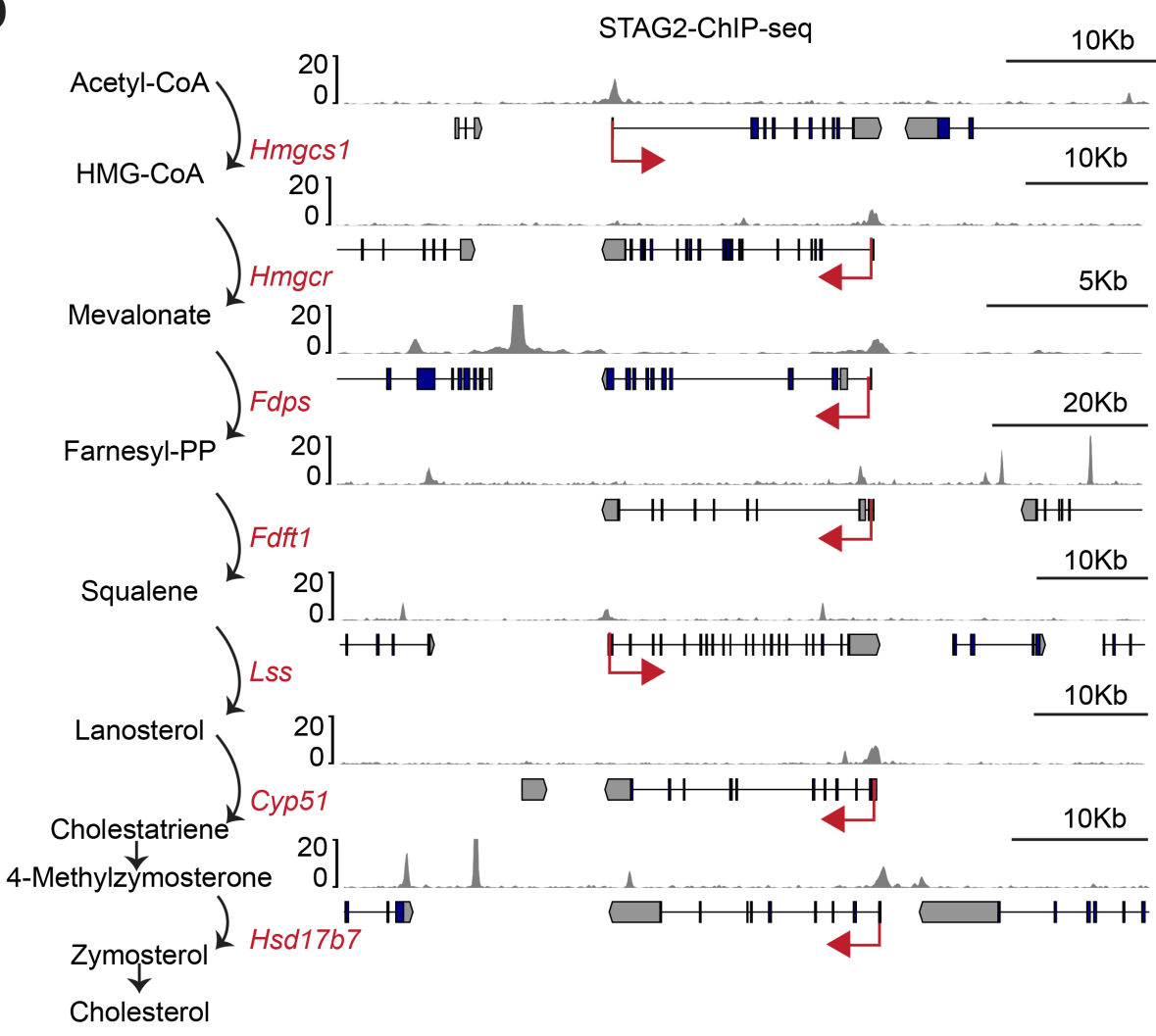

Figure S8. Enrichment of STAG2 and histone modifications at gene promoters. 
(A) Heatmap of H3K27ac ChIP-seq signal enrichment in the promoter regions of genes in the indicated categories.

(B) Density profile of H3K27ac ChIP-seq signal enrichment in the promoter regions of genes in the indicated categories.

(C) Density profile of STAG2 ChIP-seq signal enrichment in the promoter regions of genes in the indicated categories.

(D) Binding of STAG2 at the genomic loci of down-regulated genes that encode cholesterol biosynthetic enzymes as revealed by ChIP-seq. 


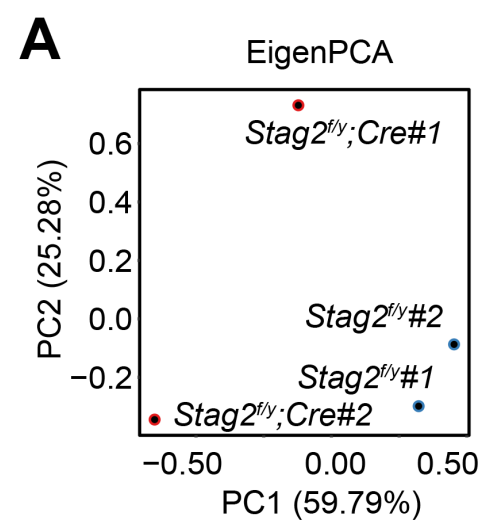

C

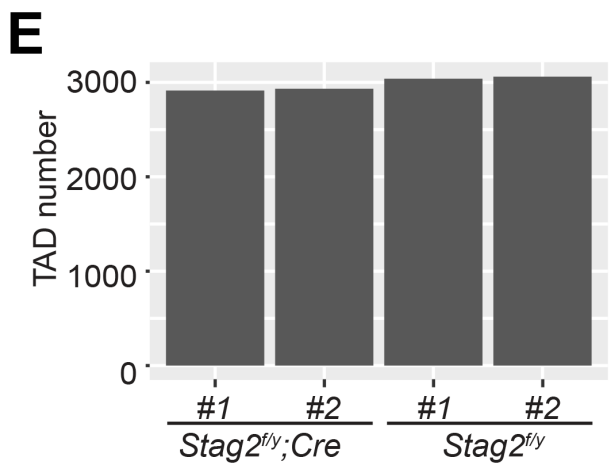

B

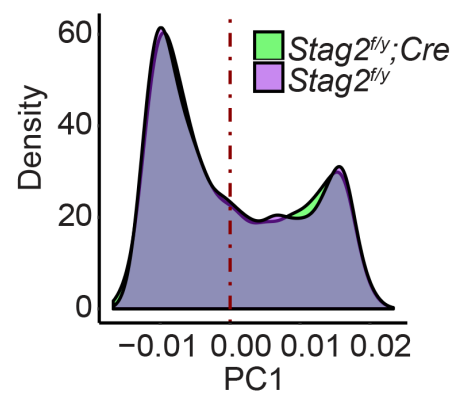

D

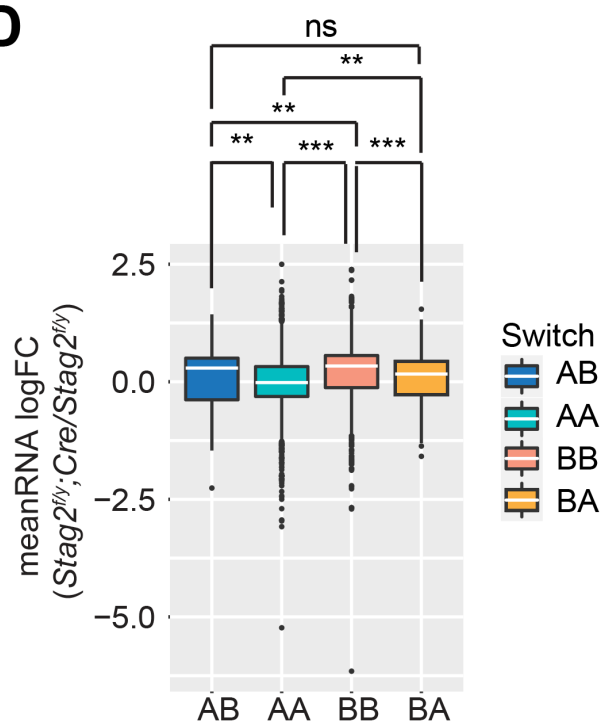

Figure S9. Stag2 deletion does not alter chromatin compartmentalization or TAD formation in oligodendrocytes.

(A) Principal component analysis (PCA) plot of the eigenvectors of the indicated samples.

(B) Density plot of principal component 1 (PC1) of Stag2 $2^{f / y}$ and Stag2 ${ }^{f / y}$;Cre oligodendrocytes.

(C) Compartment compositions of the indicated samples. 
(D) Boxplot of the average gene expression change for all the differentially expressed genes (FDR $<0.05)$ inside each genomic bin. Bins counted: AA, 5806; AB, 155; BA, 251; BB, 2659. The unpaired Wilcoxon-test was used for the statistical analysis. ${ }^{*} \mathrm{p}<0.05 ; * *_{\mathrm{p}}<0.01 ; * * \mathrm{p}<0.001$; ns, not significant.

(E) TAD numbers of the indicated samples.

(F) TAD size distributions of the indicated samples. 
A
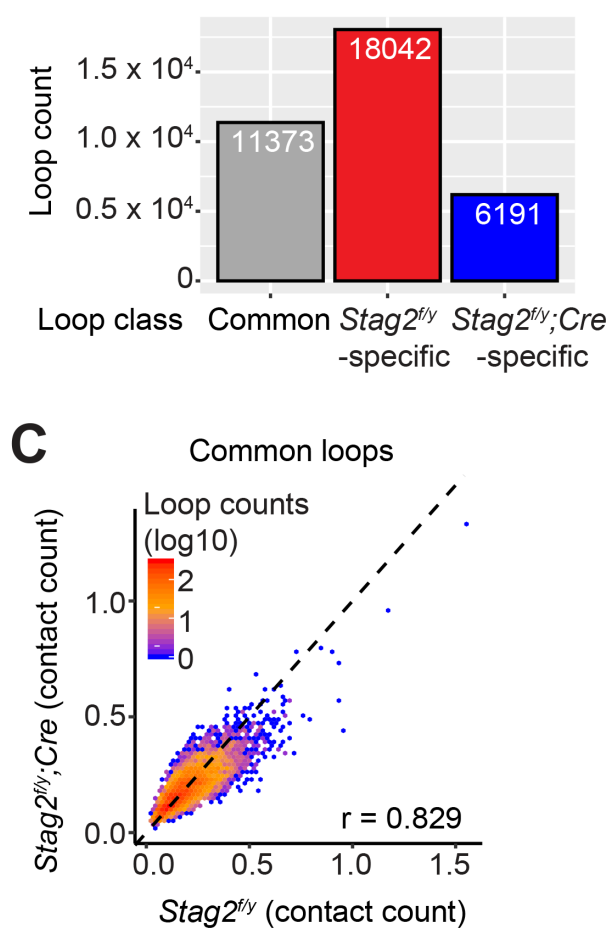

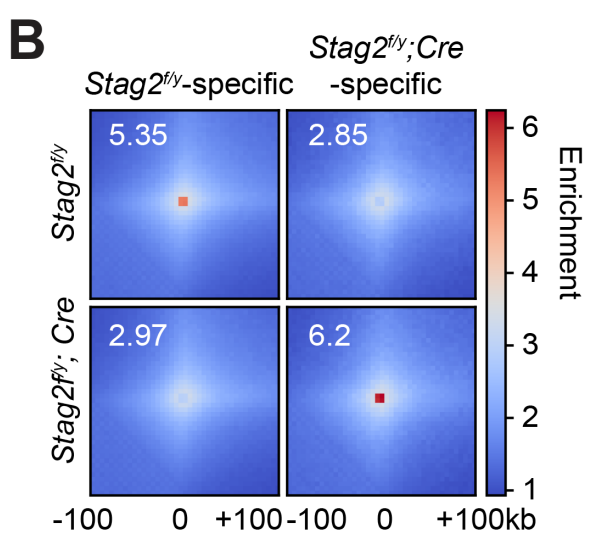

D Loop strength (common loops)

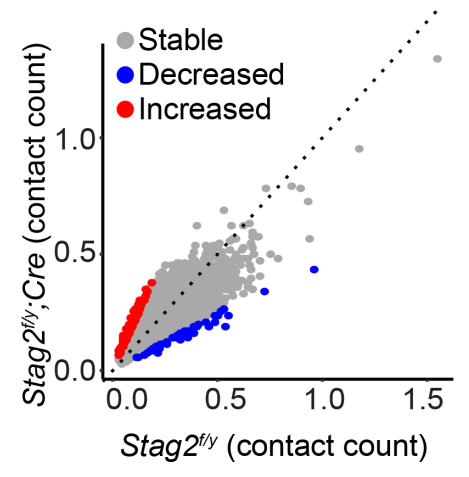

E Common \& group-specific loops

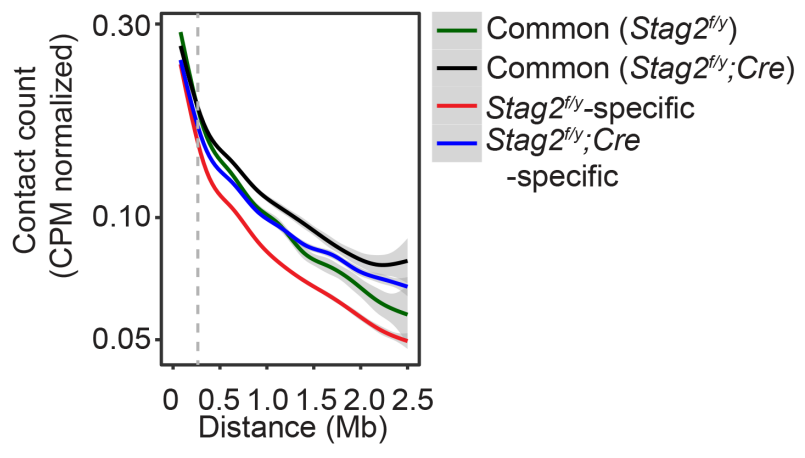

Figure S10. Stag2 deletion reduces chromatin loops in oligodendrocytes.

(A) Loop numbers of the indicated categories.

(B) Pile-up analysis of loop "dots"-centered local contact maps for loops specific to Stag $2^{f / y}$ or Stag ${ }^{2 f y} ;$ Cre oligodendrocytes (OLs).

(C) Hexbin plot of contact counts of common loops in Stag2 $2^{f / y}$ and Stage ${ }^{f y} ; \mathrm{Cre}$ OLs.

(D) Scatter plot of contact counts of common loops in Stag $2^{f / y}$ and Stag $2^{f / y}$; Cre OLs. Loops with significantly changed strength in Stag $2^{f / y}$; Cre OLs are highlighted in red (increased) and blue (decreased). $\log _{2} \mathrm{FC}$ threshold of 1 was used.

(E) Normalized contact counts for loops in the indicated categories across different genomic distances. 

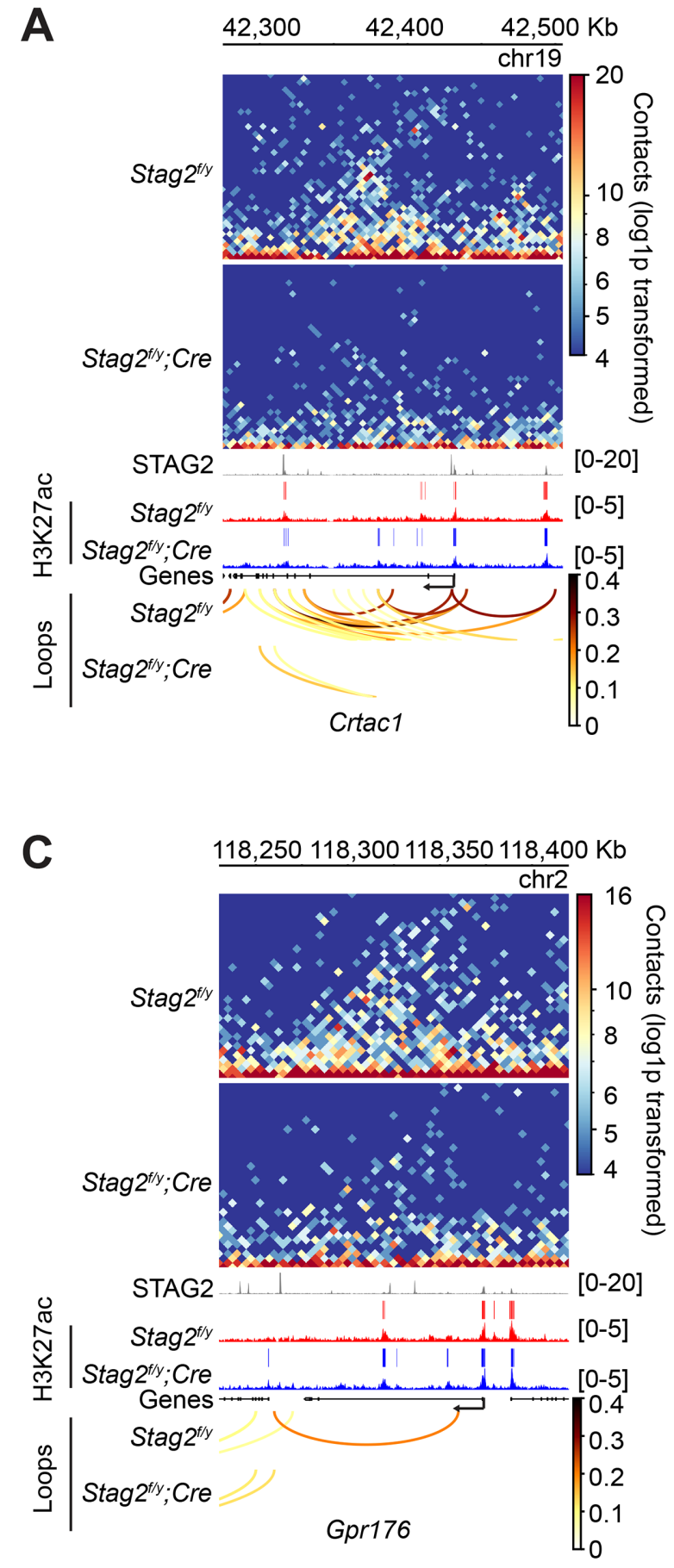

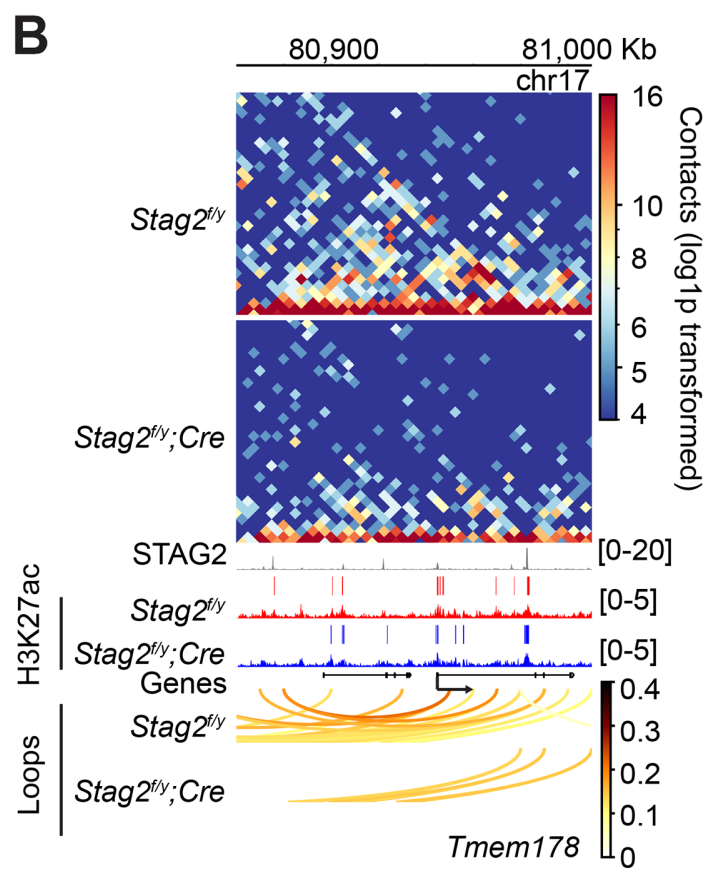

D
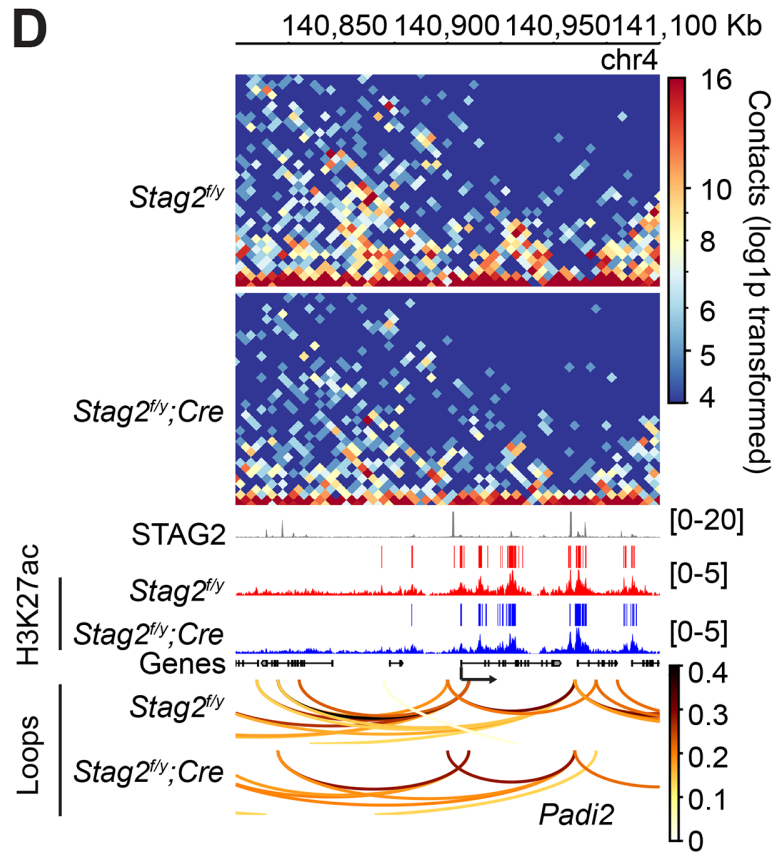

Figure S11. STAG2 controls local chromatin looping at differentially regulated genes.

(A-D) Snapshots of the contact maps at the indicated differentially regulated genes. Tracks and peaks from STAG2 and H3K27ac ChIP-seq as well as loops are shown below. Transcription directions are indicated by arrows. 

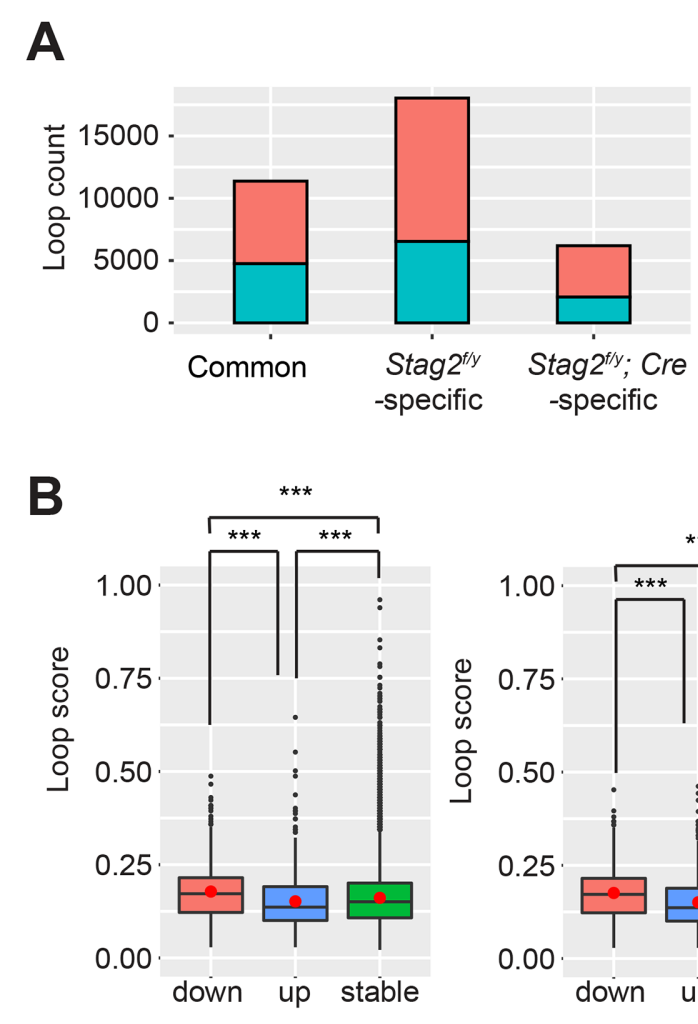
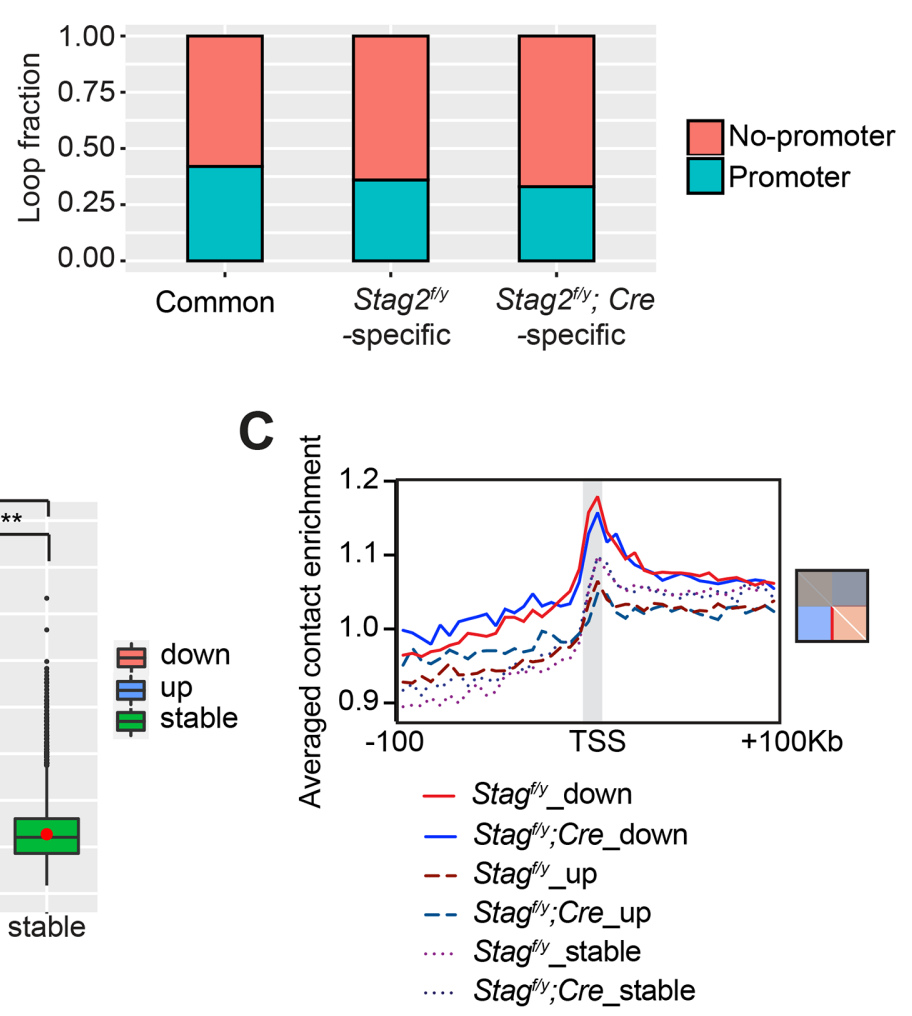

Figure S12. STAG2 regulates the formation of promoter-anchored loops in oligodendrocytes. (A) Loop counts (left panel) and fractions (right panel) of loops anchored at promoter or nonpromoter regions in the indicated categories.

(B) Loop score of the loops in Figure 6E. Loop score from Stag $2^{f / y}$ oligodendrocytes (OLs) was used for common loops on the left, and loop score from Stag $2^{f y}$; Cre OLs was used for common loops on the right. The unpaired Wilcoxon test was used for the statistical analysis. ${ }^{* * *} \mathrm{p}<0.001$. (C) Profile plot of the average enrichment score for the bottom half of each graph panel in Figure 6F. Diagonal pixels were omitted. 